\title{
HYDROGEN FROM RENEWABLE RESOURCES RESEARCH
}

\author{
Annual Report. \\ to the
}

Solar Energy Research Institute

1617 Cole Boulevard

Golden, Colorado 80401

SERI Subcontract No. XX-9-19016-1

July 1990

by

Patrick K. Takahashi

Principal Investigator

Kelton R. McKinley

Program Manager

Publication No. 90-1026

Hawaii Natural Energy Institute

University of Hawaii at Manoa

Honolulu, Hawaii 96822 


\section{DISCLAIMER}

This report was prepared as an account of work sponsored by the Solar Energy Research Institute, a Division of Midwest Research Institute, in support of its contract with the United States Department of Energy. Neither the Solar Energy Research Institute, the Midwest Research Institute, the United States Government, nor the Untied States Department of Energy, nor any of their employees, nor any of their contractors, subcontractors, or their employees, makes any warranty, express or implied, or assumes any legal liability or responsibility for the accuracy, completeness or usefulness of any information, apparatus, product or process disclosed, or represents that its use would not infringe privately owned rights. 


\section{Table of Contents}

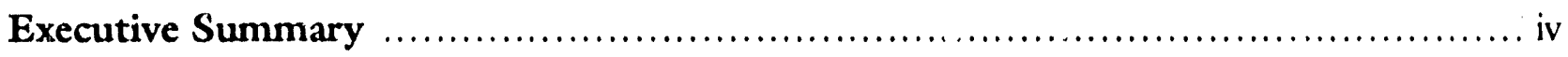

\section{Task 1}

Hydrogen Production by Gasification of Glucose

and Wet Biomass in Supercritical Water

\section{Task 2}

Photoelectrochemical Production of Hydrogen

\section{Subtask 2.1}

Photoemission and Photoluminescence

Studies of Catalyzed Photoelectrode Surfaces

for Hydrogen Production

\section{Subtasks 2.2 and 2.4}

Solar Energy Chemical Conversion

by Means of PEC Methods Using

Coated Si Electrodes.

\section{Subtask 2.3}

Assessment of Impedance Spectroscopy

Methods for Evaluation of Semiconductor-

Electrolyte Interfaces

Task 3

Solar Energy Conversion with Cyanobacteria

Task 4

Nonclassical Polyhydride Metal Complexes

as Hydrogen Storage Materials

Appendix

Statement of Work Appendix A 


\section{SERI Annual Technical Report \\ Executive Summary \\ August 1990}

\section{Historical Perspective}

In 1986 the Hawaii Natural Energy Institute (HNEI) and the Florida Solar Energy Center (FSEC) were contracted by the Solar Energy Research Institute (SERI) to conduct an assessment of hydrogen production technologies and economic feasibilities of the production and use of hydrogen from renewable resources. During the 1987/88 time frame follow-on work was completed with the most promising technologies reexamined. Modest research and development efforts were also initiated at that time. The 1988/89 time frame presented a significant milestone in HNEI hydrogen efforts in that nearly all contract dollars were for the first time expended in support of expanded research and development efforts within the Hawaii Natural Energy Institute itself and the University of Hawaii community. In the $1989 / 90$ period all monies were directed toward research and development with an emphasis on integration of tasks, focusing on two important issues, production and storage.

\section{Teclinical Personnel}

The current year's efforts consisted of four tasks, one task containing three subtasks.

- Hydrogen Production by Gasification of Glucose and Wet Biomass in Supercritical Water

Task Leader: Michael Antal, Coral Industries Professor, University of Hawaii at Manoa

- Photoelectrochemical Production of Hydrogen

Task Leader: Richard Rocheleau, University of Hawaii at Manoa

Photoemission and Photoluminescence Studies of Catalyzed Photoclectrode Surfaces for Hydrogen Production

Subtask Leader: William Pong, University of Hawaii at Manoa

Solar Energy Chemical Conversion by Means of Photoelectrochemical (PEC) Methods Using Coated Silicon Electrodes

Subtask Co-Leaders: Richard Rocheleau and Shiv K. Sharma, University of Hawaii at Manoa 
Assessment of Impedance Spectroscopy Methods for Evaluation of

Semiconductor-Electrolyte Interfaces

Subtask Leader: Bruce E. Liebert, University of Hawaii at Manoa

- Solar Energy Conversion with Cyanobacteria

Subtask. Co-Leaders: Suresh S. Patil and Edward J. Bylina, University of Hawaii at Manoa

- Nonclassical Polyhydride Metal Complexes as Hydrogen Storage Materials

Subtask Leader: Craig Jensen, University of Hawaii at Manoa

\section{Program Overview}

With hydrogen from biomass representing the best near-term alternative for hydrogen production in Hawaii, the research in that area still holds a prominent position in HNEI's efforts. Steam gasification of biomass has been observed in supercritical water with temperatures equal to or higher than $500^{\circ} \mathrm{C}$ and residence times equal to or longer than 30 seconds. The primary gas products of $\mathrm{H}_{2}$ and $\mathrm{CO}_{2}$ were found at a ratio close to $2: 1$. The products exiting the reactor are ideal for hydrogen production and the synthesis of methanol.

Improved photoelectrochemical production of hydrogen depends upon a better understanding of the materials involved and the various materials interfaces. In the photoluminescence subtask discontinuous metal layers in the form of microislands deposited on semiconductor photoelectrode surfaces were examined using

photoemission and photoluminescence techniques. Investigations of the size effect of the metal islands on the generation of the open-circuit photovoltage at the surface and the surface recombination loss of the photoexcited electrons were conducted. The photoemission results indicate that the optimal photovoltage could be produced for a discontinuous metal layer on a suitable semiconductor surface. The photoluminescence study showed the emission due to surface recombination was affected by the metal microislands. Further study using these techniq̨ues with new methods of depositing metal clusters on surfaces is highly desirable.

Semiconductor photoelectrochemical cells are being studied as a low-cost method for the production of hydrogen from water using sunlight as the energy source in the Solar Energy Chemical Conversion subtask. A major advantage of these systems is the direct conversion of solar energy into chemical energy in the form of $\mathrm{H}_{2}$. Initial experiments have been carried out using p-type Si photocathodes. This subtask represents an applied program directed toward the optimization of stable, high efficiency photoelectrodes using semiconductor materials at a projected low cost.

The Assessment of Impedance Spectroscopy subtask continued the experimental work on the impedance, modeling the results to appropriate equivalent circuits and determining the flatband potential in different electrolytes. 
Photoelectrochemical characterizations will be compared to impedance measurements during the coming year.

Hydrogen production in cyanobacteria is attractive for the longer term because these organisms are able to generate hydrogen using light energy with water as the source of the reductant. Genetic manipulation of the hydrogenase systems in these organisms holds the key to increased production rates. Overall protein scquence homology between the hydrogenases that have been characterized is rathe: low; however, conserved regions are observed in the small and large subunits of these hydrogenases. Work continues with the hybridized probe containing the Bradyrbizobium japonicum uptake-hydrogenase structural genes to Anabaena chromosomal DNA.

Nonclassical Polyhydride Metal Complexes, the fourth task area, continues work on this promising method for improved storage of molecular hydrogen, $\mathrm{H}_{2}$. Newly synthesized novel cobalt group nonclassical polyhydride complexes have shown promising hydriding/dehydriding behavior. This past year studies focused on reversible elimination of $\mathrm{H}_{2}$ from the iridium polyhydride complexes. NMR spectroscopy methods were used for observation. Understanding of metal hydride interactions has been advanced by this work.

Details concerning each of these efforts follow in specific technical reports for each of the tasks and subtasks mentioned. The $1990 / 91$ period will see continuation and expansion of efforts in each of these areas with the exception of the supercritical water work, which will move to a companion program at HNEI, the Hawaii Integrated Biofuels Program. The renewed interest in reducing our national dependency on imported petroleum could give impetus to research and development efforts represented by the Hydrogen from Renewable Resources Research Program. 
HYDROGEN FROM RENEWABLE RESOURCES RESEARCH

Task Summaries 
Task 1

\title{
HYDROGEN PRODUCTION BY GASIFICATION OF GLUCOSE AND WET BIOMASS IN SUPERCRITICAL WATER
}

\author{
Task Leader: Michael J. Antal, Jr., Coral Industries Professor \\ Supaporn Manarungson, Graduate Assistant \\ William S. Mok, Chemical Research Engineer
}

\begin{abstract}
Glucose was used as a model reactant to determine practical conditions for wet biomass gasification in supercritical water. The factors influencing the conversion and gas yields of wet biomass gasification are temperature, residence time, initial concentration, and the feedstock. The primary gas products of both glucose and wet biomass gasification are $\mathrm{H}_{2}$ and $\mathrm{CC}_{2}$. The estimated carbon conversion of glucose (66 to $71 \%$ ) is lower than that of wet biomass (74 to 87\%) at $550^{\circ} \mathrm{C}$ and 28 seconds. The ratio of $\mathrm{H}_{2}$ and $\mathrm{CO}_{2}$ for glucose and wet biomass gasification are $1.6: 1.0$ and $2.2: 1.0$ respectively at the same conditions. For glucose, molar $\mathrm{H}_{2}$ yield in excess of $500 \%$ was achieved. Higher yield can be expected with further increases in temperature and residence time. The result agrees with global reaction for steam gasification of carbohydrate:
\end{abstract}

$$
\mathrm{C}_{6} \mathrm{H}_{10} \mathrm{O}_{5}+7 \mathrm{H}_{2} \mathrm{O} \rightarrow 6 \mathrm{CO}_{2}+12 \mathrm{H}_{2}
$$

\section{INTRODUCTION}

Land biomass has always been used to produce energy and fuels. However, aquatic biomass, which constitutes one of the world's largest available biomass feedstocks, has not been regarded as a potential fuel source because of its high moisture content and the high cost of water removal. Supercritical fluid, such as supercritical water (SCW), plays an inportant role as a solvent media in both chemical reactions and extraction processes. Currently, in the MODAR process, SCW is applied with the gasification process 't' oxidize organic wastes to destroy toxic substances [1]. Pyrolytic gasification is a high temperature thermochemical process which converts biomass to fuels and other useful organic materials. The objective of this project is to use this biomass, in its wet form, to produce hydrogen gas by a pyrolytic gasification process in SCW.

NOTE: The material for this task was presented at the World Hydrogen Energy Conference \#8, Honolulu and Waikoloa, Hawaii, 22 July 1930 and is published in substantially the same form in Hydrogen Energy Progress VIII, T. Veziroglu and P. K. Takahashi, eds., pp. 345-355. 


\section{PREVIOUS RESEARCH}

Pyrolytic gasification has been used to yield either fucl gases or liquid products. Very few investigators have studied the gasification of biomass in SCW. Modell studied the gasification of forest products in SCW to produce liquid and gaseous fuels [2]. In U.S. Patent No. 4,113,446 it was revealed that the products of the reaction of some organic materials iriclude $\mathrm{CO}, \mathrm{H}_{2}, \mathrm{CO}_{2}$, $\mathrm{CH}_{4}$, and light hydrocarbons and liquid organics at $374^{\circ} \mathrm{C}$ and $218 \mathrm{arm}$ [3]. Also, there is no char formation at that condition. The effect of oxygen on the reactant conversion in SCW has been studied by a few investigators. Webley and Tester modeled and presented the independence of methanol conversion on oxygen in global kinetic expressions [4]. Eckert, Leman, and Yang studied the kinetics of the uncatalyzed and homogeneously catalyzed oxidation of pchlorophenol in water near the critical point [5]. They found that the rate of disappearance of $\mathrm{p}$-chlorophenol is unaffected by oxygen concentration. Helling and Tester also found that the rate of global expression for the oxidation of $\mathrm{CO}$ in SCW is zeroth order for oxygen [6].

\section{EXPERIMENTAL APPARATUS AND PROCEDURES}

The supercritical fluid reactor, described in earlier publications $[7,8]$, was modified to accommodate a slurry feed reservoir for this study (Figure 1). Initially glucose was used as a reactant model. For the wet biomass gasification experiment algac (Gracilaria sp.), kelp, and sewage sludge were chosen as representative materials.

\section{RESULTS AND DISCUSSION}

\section{GLUCOSE GASIFICATION IN SUPERCRITICAL WATER}

The gasification of glucose in SCW to produce hydrogen was studied over the temperature range $400^{\circ}$ to $550^{\circ} \mathrm{C}$ at 25.0 to $34.5 \mathrm{MPa}$. The influences of temperature, reactant concentration, residence time, and oxygen on the carbon balance and the gaseous product yields were studied.

The effect of temperature is seen in Table 1. Increasing the temperature of the reaction increases the carbon balance and yields of $\mathrm{CO}_{2}$ and $\mathrm{H}_{2}$ while $\mathrm{CO}$ remains constant over the temperature range of $460^{\circ}$ to $550^{\circ} \mathrm{C}$. Tables 2 and 3 display the effect of residence time. Time affects the carbon balance and $\mathrm{CO}_{2}$, $\mathrm{H}_{2}$, and $\mathrm{CO}$ in the same way as temperature.

Tabis 4 displays the effect of reactant concentration, comparing the results of 0.01 to $0.05 \mathrm{M}$ glucose at both $550^{\circ}$ and $500^{\circ} \mathrm{C}$. The carbon balance, $\mathrm{CO}_{2}$, $\mathrm{H}_{2}$, and $\mathrm{CH}_{4}$ decrease when the concentration of reactant increases. The slight increase of $\mathrm{CO}_{2}$ observed when the concentration increases from 0.005 to 0.01 $\mathrm{M}$ at 28 seconds residence time is probably not significant. 
The effect of oxygen was examined with dihydroxyacetone (DHA) and glucose as the reactants and hydrogen peroxide $\left(\mathrm{H}_{2} \mathrm{O}_{2}\right)$ as the oxidizer. Hydrogen peroxide decomposes in the reactor to provide free oxygen. Table 5 contains the data of experiments with $0.005 \mathrm{M}$ and $0.01 \mathrm{M} \mathrm{DHA}$ and $0.005 \mathrm{M}$ glucose, with and without hydrogen peroxide. The presence of oxygen increases the carbon balance and $\mathrm{CO}_{2}$, but decreases the yield of hydrogen. These results suggest that oxygen selectively attacks and oxidizes the gaseous products, lowering the yield of hydrogen gas. Because of this negative effect, no further studies of partial oxidation were conducted.

As the next step toward more complicated feedstock, soluble starch was studied as a reactant. This material was chosen because its solubility permits the preparation of a homogeneous polymeric feed solution. Comparing the gasification of soluble starch and glucose, soluble starch gives higher carbon balance and $\mathrm{CO}$, but lower $\mathrm{CO}_{2}$ and $\mathrm{H}_{2}$ than glucose at the same reaction condition. The results are in Taule 6 . In Table 7 results of a study of residence time effect on starch gasification are displayed. As in the case of glucose, the higher yields of gas and carbon conversion are observed with increasing residence time.

Experiments with model compounds indicate that high yields (up to $500 \%$ molar yield) of hydrogen can be obtained from gasification in SCW. Yields are improved at high temperature $\left(>500^{\circ} \mathrm{C}\right)$, long residence time $(\sim 1$ minute), and low reactant concentration $(0.9 \mathrm{gm} / \mathrm{liter})$. Based on these preliminary results, the following practical condition for wet biomass gasification was determined: $480^{\circ}$ to $550^{\circ} \mathrm{C}, 34.5 \mathrm{MPa}$, and 28 seconds residence time.

\section{WET BIOMASS GASIFICATION}

From the study of gasification of glucose in SCW, a practical condition of $550^{\circ} \mathrm{C}$ and $34.5 \mathrm{MPa}$ was chosen to study the gasification of wet biomass in SCW to produce hydrogen. The influences of the reactant and reactant concentration on carbon balance and gaseous products were determined. The carbon balance and yields of gas from wet biomass are calculated by using the chemical compositions determined by an independent laboratory (Table 8). The primary gas products in every experiment are $\mathrm{H}_{2}$ and $\mathrm{CO}_{2}$, but the ratio of the two gases varies.

The first experiment was gasification of algae in SCW. Carbon balance and the yields of gases from a solution of $1.121 \mathrm{gm}$ algae/liter at a residence time of 28 seconds are displayed in Table 9. The ratio of $\mathrm{H}_{2}$ and $\mathrm{CO}_{2}$ is about 2.2:1.0. The estimated carbon conversion is in the range of 74 to $87 \%$, which is higher than that from the glucose experiment (66 to $71 \%)$ at the same condition.

The second experiment was a control experiment. The purpose of this experiment was to see if there is any reaction between water and the wall of the reactor at the reactant condition. A small amount of gas product (less than $5 \%$ of 
$\mathrm{H}_{2}$ gas yield from the algae experiment) was obtained. This shows that the reaction between $\mathrm{H}_{2} \mathrm{O}$ and the carbon deposits on the inside wall of the reactor does not contribute significantly to the gas yiclds of the algae experiment.

The results of the algae gasification at higher concentration are also displayed in Table 9. The algae concentration is about three times the previously-mentioned experiment ( $3.336 \mathrm{gm}$ algae/liter of solution). The operating condition is $520^{\circ} \mathrm{C}, 31.7 \mathrm{MPa}$, and 25 seconds residence time. The effects of initial reactant concentration and temperature on carbon balance and gas yields of this experiment are the same as the glucose gasification experiment. The carbon balance and gas yields are lower when initial reactant concentration increases but temperature decreases. The ratio of $\mathrm{H}_{2}$ and $\mathrm{CO}_{2}$, which are major products, is about 2.5:1.0.

The third algae experiment was conducted at $550^{\circ} \mathrm{C}, 34.5 \mathrm{MPa}$, and 49 seconds residence time. The results of sample no. M1 are obviously different from the other two. The carbon balance and gas yields of sample no. M1 are very much lower than those of the others. Some of the algae feeding and passing through the reactor settled and accumulated on the bottom of the reactor, resulting in non-homogeneous mixture. The changing concentration with respect to time would account for the large variations in observed gas yields.

For kelp gasification the operating condition was $550^{\circ} \mathrm{C}, 34.5 \mathrm{MPa}$, and 49 seconds residence time. Two initial concentrations, 7.78 and $25.0 \mathrm{gm} \mathrm{kelp} / \mathrm{liter}$ of solution, were studied. The results are in Table 10. In the experiment of 25.0 $\mathrm{gm} /$ liter, the total amount of gas product was collected from the accumulator. The carbon balance and gas yields for kelp, compared to those of algae gasification, are lower.

In the case of sewage sludge gasification, the chemical composition of sewage sludge was assumed to be the same as that of rav sewage sludge reported by Urban and Antal [9] (Table 8). Carbon balance and gas yields of this experiment are generally lower than those of the above (Table 11).

\section{CONCLUSION}

In supercritical water with temperature equal to or higher than $500^{\circ} \mathrm{C}$ and residence time equal to or longer than 30 seconds, steam gasification of biomass is observed. Noting that the hydrogen balance based only on the organic reactant exceeds unity, and that the $\mathrm{H}_{2}$ to $\mathrm{CO}_{2}$ product ratio close to $2: 1$ was observed, the global stoichiometry of the governing reaction appears to be

$$
\mathrm{C}_{6} \mathrm{H}_{10} \mathrm{O}_{5}+7 \mathrm{H}_{2} \mathrm{O} \longrightarrow 6 \mathrm{CO}_{2}+12 \mathrm{H}_{2}
$$

Hydrogen and carbon dioxide products exiting the reactor are available at 5000 psi and high temperature, ideal for the synthesis of methanol. Alternatively, the gas can be quenched at high pressure and separated to generate pure hydrogen without extra cost by a controlled reduction of pressure. 


\section{REFERENCES}

1. Modell, M., G. G. Gaudet, M. Simson, G. T. Hong, and K. Biemann. 1982. Supercritical Water: Testing Reveals New Process Holds Promise. Solid Wastes Management, August.

2. Modell, M. 1982. Gasification and Liquefaction of Forest Products in Supercritical Water. Fundamentals of Thermochemical Biomass Conversion p95 - 119. Elsvier Applied Science Publishers.

3. Modell, M., R. C. Reid, and S. I. Amin. 1978. Gasification Process. U. S. Patent 4,113,446. September 12.

4. Webley, P. A. and J. W. Tester. Report on the Fundamental Kinetics of Oxidation in Supercritical Water.

5. Eckert, C. A., G. W. Leman, and H. Yang. Homogeneous Catalysis for Wet Oxidation Design and Economic Feasibility of a Mobile Detoxification Unit. Final Report.

6. Helling, R. K. and J. W. Tester. 1987. Oxidation Kinetics of Carbon Monoxide in Supercritical Water. J. Energy and Fuels 1(5):417-423.

7. Mok, W. S., M. J. Antal, Ir., and M. Jones, Jr. 1989. Formation of Acrylic Acid from Lactic Acid in Supercritical Water. J. Org. Chem. 54(19):4956.

8. Ramayya, S., A. Brittain, C. DeAlmeida, W. S. Mok, and M. J. Antal, Jr. 1987. Acid-Catalyzed Dehydration of Alcohols in Supercritical Water. Fuel 66:1363 - 1370.

9. Urban, L. D. and M. J. Antal, Jr. 1982. Study of the Kinetics of Sewage Slndge Pyrolysis Using DSC and TGA. Fuel 61:799 - 806. 
Table 1. The Effect of Temperature on Glucose Gasification in SCW $0.01 \mathrm{M}$ glucose reacting at $34.5 \mathrm{MPa}$

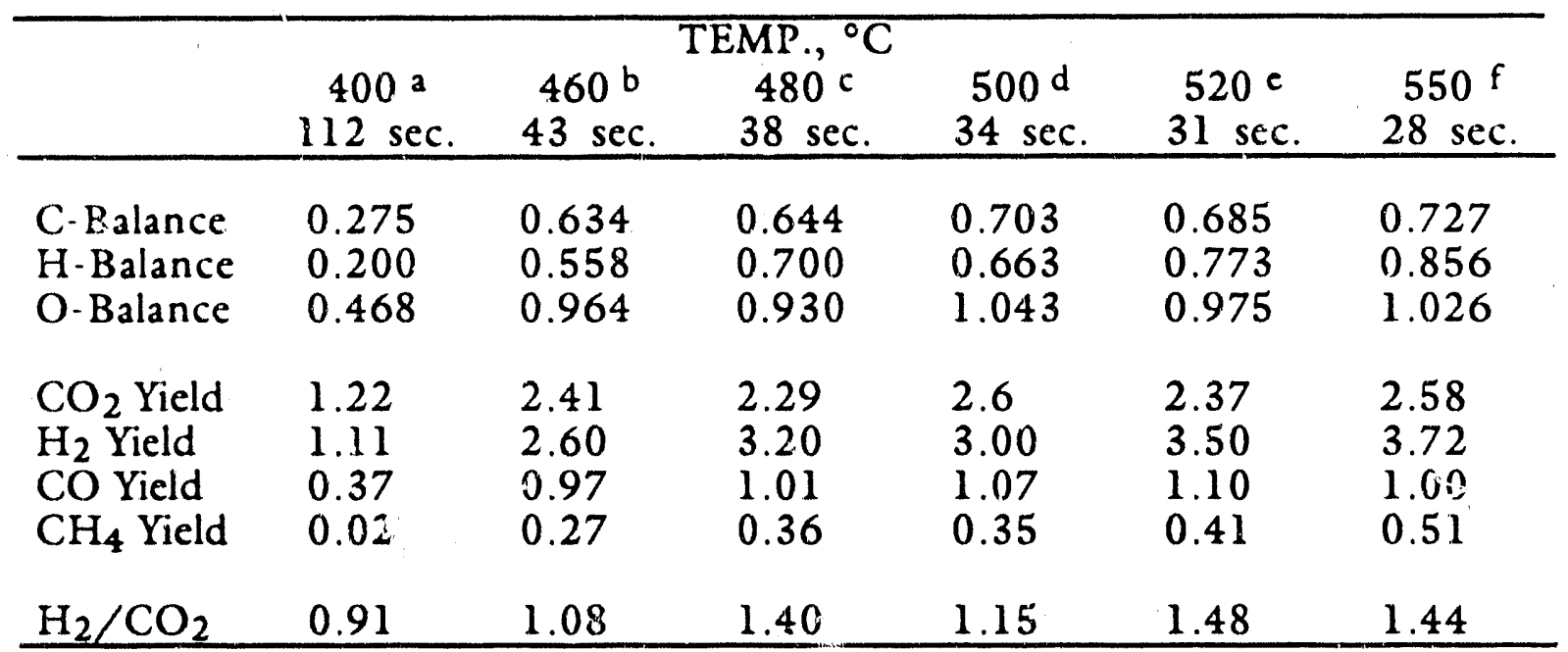

a The dverage of exp. no. 37, 38, and 39

b The average of exp. no. 21 and 22

c The average of exp. no. 23, 24, and 25

d The average of exp. no. 30 and 31

e The average of exp. no. 32 and 33

$f$ The average of exp. no. 34,35 , and 36

I'able 2. The Effect of Residence Time on Glucose Gasification in SCW $0.05 \mathrm{M}$ glucose at $550^{\circ} \mathrm{C}, 27.5 \mathrm{MPa}$

\begin{tabular}{lcc}
\hline & $\begin{array}{c}\text { Residence } \\
28 \text { a }\end{array}$ & $\begin{array}{c}53 \mathrm{~b} \\
53\end{array}$ \\
\hline C-Balance & 0.644 & 0.686 \\
H-Balance & 0.739 & 1.118 \\
O-Balance & 0.922 & 0.887 \\
& & \\
$\mathrm{CO}_{2}$ Yield & $2.4 \varepsilon$ & 2.40 \\
$\mathrm{H}_{2}$ Yield & 2.93 & 4.54 \\
$\mathrm{CO}$ Yieid & 0.57 & 0.51 \\
$\mathrm{CH}_{4}$ Yield & 0.41 & 0.87 \\
$\mathrm{H}_{2} / \mathrm{CO}_{2}$ & 1.18 & 1.89 \\
\hline
\end{tabular}

a The data of exp. no. 13

b The average of exp. no. 18 and 19 
Table 3. The Effect of Residence Time on Glucose Gasification in SCW $0.01 \mathrm{M}$ glucose at $550^{\circ} \mathrm{C}, 34.5 \mathrm{MPa}$

\begin{tabular}{lcc} 
& $\begin{array}{r}\text { Residence } \\
28^{\mathrm{a}}\end{array}$ & $\begin{array}{c}\text { Time, sec. } \\
56^{\mathrm{b}}\end{array}$ \\
\hline C-Balarice & 0.727 & 0.798 \\
$\mathrm{H}$-Balance & 0.856 & 1.064 \\
O-Balance & 1.026 & 1.024 \\
$\mathrm{CO}_{2}$ Yield & 2.58 & 2.51 \\
$\mathrm{H}_{2}$ Yield & 3.72 & 4.27 \\
$\mathrm{CO}$ Yicld & 1.00 & 1.14 \\
$\mathrm{CH}_{4}$ Yield & 0.51 & 0.77 \\
$\mathrm{H}_{2} / \mathrm{CO}_{2}$ & 1.44 & 1.70 \\
\hline
\end{tabular}

Table 4. The Effect of Reactant Concentration on Glucose Gasification in SCW glucose at $500^{\circ}$ and $550^{\circ} \mathrm{C}$ and $34.5 \mathrm{MPa}$

\begin{tabular}{|c|c|c|c|c|c|}
\hline & \multicolumn{3}{|c|}{ at $550^{\circ} \mathrm{C}, 28 \mathrm{sec}$} & \multicolumn{2}{|c|}{ at $500^{\circ} \mathrm{C}, 34 \mathrm{sec}$} \\
\hline & $0.005 \mathrm{M}^{2}$ & $0.01 \mathrm{Mb}^{\mathrm{b}}$ & $0.05 \mathrm{Mc}$ & $0.01 \mathrm{Md}$ & $0.05 \mathrm{Mc}$ \\
\hline C-Balnnce & 0.695 & 0.727 & 0.570 & 0.703 & 0.419 \\
\hline H-Balance & 1.123 & 1.064 & 0.586 & 0.663 & 0.352 \\
\hline O-Balance & 0.982 & 1.024 & 0.699 & 1.043 & 0.568 \\
\hline $\mathrm{CO}_{2}$ Yield & 2.43 & 2.58 & 1.45 & 2.60 & 1.21 \\
\hline $\mathrm{H}_{2}$ Yield & 5.45 & 3.72 & 2.34 & 3.00 & 1.57 \\
\hline CO Yield & 1.04 & 1.00 & 1.30 & 1.07 & 1.00 \\
\hline $\mathrm{CH}_{4}$ Yield & 0.47 & 0.51 & 0.41 & 0.35 & 0.18 \\
\hline $\mathrm{H}_{2} / \mathrm{CO}_{2}$ & 2.24 & 1.44 & 1.61 & 1.15 & 1.30 \\
\hline
\end{tabular}

a The average data of exp. no. 43,44 , and 45

$b$ The average data of exp. no. 34,35 , and 36

c The average data of exp. no. 57 and 58

d The average data of exp. no. 30 and 31

e The average data of exp. no. 55 and 56 
Table 5. The Effect of Pxygen on Glucose Gasification in SCW $0.01 \mathrm{M} \mathrm{DHA}$ and $0.005 \mathrm{M}$ glucose at different conditions

\begin{tabular}{|c|c|c|c|c|c|c|}
\hline & \multicolumn{2}{|c|}{$\begin{array}{c}0.005 \mathrm{M} \mathrm{DHA} \\
\text { at } 480^{\circ} \mathrm{C}, 25 \mathrm{MPa}, \\
6 \mathrm{sec} \text {. } \\
\end{array}$} & \multicolumn{2}{|c|}{$\begin{array}{c}0.01 \mathrm{M} \mathrm{DHA} \\
\text { at } 430^{\circ} \mathrm{C}, 25 \mathrm{MPa}, \\
24 \mathrm{sec} . \\
\end{array}$} & \multicolumn{2}{|c|}{$\begin{array}{r}0.005 \mathrm{M} \text { Glucose } \\
\text { at } 550^{\circ} \mathrm{C}, 34.5 \mathrm{MPa}, \\
28 \mathrm{sec} .\end{array}$} \\
\hline & $\begin{array}{c}\overline{\mathrm{W} / \mathrm{O}} \\
\mathrm{H}_{2} \mathrm{O}_{2}^{\mathrm{a}} \\
\end{array}$ & $\begin{array}{c}\mathrm{W} 0.01 \mathrm{M} \\
\mathrm{H}_{2} \mathrm{O}_{2} \mathrm{~b}\end{array}$ & $\begin{array}{c}\mathrm{W} / \mathrm{O} \\
\mathrm{H}_{2} \mathrm{O}_{2} \mathrm{c}\end{array}$ & $\begin{array}{c}\mathrm{W} 0.01 \mathrm{M} \\
\mathrm{H}_{2} \mathrm{O}_{2}{ }^{\mathrm{d}}\end{array}$ & $\begin{array}{c}\overline{\mathrm{W} / \mathrm{O}} \\
\mathrm{H}_{2} \mathrm{O}_{2} \mathrm{e} \\
\end{array}$ & $\begin{array}{c}\mathrm{W} \mathrm{0.(05} \mathrm{M} \\
\mathrm{H}_{2} \mathrm{O}_{2} \mathrm{f} \\
\end{array}$ \\
\hline $\begin{array}{l}\text { C-Balance } \\
\text { H-Balance } \\
\text { O-Balance }\end{array}$ & $\begin{array}{l}0.602 \\
0.556 \\
0.942\end{array}$ & $\begin{array}{l}0.937 \\
0.487 \\
1.609\end{array}$ & $\begin{array}{l}1.097 \\
1.305 \\
1.459\end{array}$ & $\begin{array}{l}1.217 \\
1.373 \\
1.778\end{array}$ & $\begin{array}{l}0.695 \\
1.123 \\
0.982\end{array}$ & $\begin{array}{l}0.785 \\
1.045 \\
1.120\end{array}$ \\
\hline $\begin{array}{l}\mathrm{CO}_{2} \text { Yield } \\
\mathrm{H}_{2} \text { Yield } \\
\mathrm{CO} \text { Yield } \\
\mathrm{CH}_{4} \text { Yield }\end{array}$ & $\begin{array}{l}1.18 \\
1.34 \\
0.47 \\
0.16\end{array}$ & $\begin{array}{l}2.17 \\
1.14 \\
0.48 \\
0.16\end{array}$ & $\begin{array}{l}1.72 \\
2.86 \\
0.95 \\
0.39\end{array}$ & $\begin{array}{l}2.25 \\
3.02 \\
0.84 \\
0.50\end{array}$ & $\begin{array}{l}2.43 \\
5.45 \\
1.04 \\
0.47\end{array}$ & $\begin{array}{l}2.79 \\
4.83 \\
1.15 \\
0.54\end{array}$ \\
\hline $\mathrm{H}_{2} / \mathrm{CO}_{2}$ & 1.14 & 0.53 & 1.66 & 1.34 & 2.24 & 1.73 \\
\hline
\end{tabular}

a The data of exp. no. 1

b The average data of exp. no. 2 and 3

c The average data of exp. no. 28 and 29

d The average data of exp. no. 26 and 27

e The average data of exp. no. 43,44 , at .45

$f$ The average date of exp. no. 40,41 , and 42

Table 6. The Effect of Reactant on Biomass Gasification in SCW

$0.45 \mathrm{gm} / 1$ glucose and $0.45 \mathrm{gm} / \mathrm{l}$ soluble starch at $550^{\circ} \mathrm{C}, 34.5 \mathrm{MPa}$, and 28 seconds residence time

\begin{tabular}{lcc}
\hline & Glucose $^{a}$ & Soluble Starch $b$ \\
\hline C-Balance & 0.695 & 0.732 \\
H-Balance & 1.123 & 1.041 \\
O-Balance & 0.982 & 1.161 \\
& & \\
$\mathrm{CO}_{2}$ Yield & 2.43 & 2.19 \\
$\mathrm{H}_{2}$ Yield & 5.45 & 3.83 \\
$\mathrm{CO}$ Yield & 1.04 & 1.42 \\
$\mathrm{CH}_{4}$ Yield & 0.47 & 0.50 \\
$\mathrm{H}_{2} / \mathrm{CO}_{2}$ & 2.24 & 1.75 \\
\hline
\end{tabular}

a The average data of exp. no. 43,44 , and 45

b The average data of exp. no. 52, 53, and 54 
Table 7. The Effect of Residence Time on Soluble Starch Gasification in SCW $0.45 \mathrm{gm} / 1$ of soluble starch at $550^{\circ} \mathrm{C}, 34.5 \mathrm{MPa}$

\begin{tabular}{lll}
\hline & $28 \mathrm{sec} .^{\mathrm{a}}$ & $56 \mathrm{sec}^{\mathrm{b}}$ \\
\hline C-Balance & 0.732 & 0.883 \\
$\mathrm{H}$-Balance & 1.041 & 1.266 \\
$\mathrm{O}-$ Balance & 1.161 & 1.394 \\
& & \\
$\mathrm{CO}_{2}$ Yield & 2.19 & 2.94 \\
$\mathrm{H}_{2}$ Yield & 3.83 & 4.31 \\
CO Yield & 1.42 & 1.10 \\
$\mathrm{CH}_{4}$ Yield & 0.50 & 0.67 \\
$\mathrm{H}_{2} / \mathrm{CO}_{2}$ & 1.75 & 1.47 \\
\hline
\end{tabular}

a The average data of exp. 1o. 49,50 , and 51

b The average data of exp. no. 52,53 , and 54

Table 8. Chemical Composition of Wet Biomass Used in This Experiment

\begin{tabular}{llcc}
\hline Biomass & \multicolumn{3}{c}{ Ultimate Analysis } \\
& $\% \mathrm{C}$ & $\% \mathrm{H}$ & $\% \mathrm{O}$ \\
\hline Gracilaria $^{\mathrm{a}}$ & 42.91 & 6.60 & 40.02 \\
Kelp $^{\mathrm{a}}$ & 23.22 & 2.96 & 40.13 \\
& & & \\
Sewage sludge b & 38.9 & 5.8 & 23.4 \\
\hline
\end{tabular}

a Analyzed by independent company

b From ref. [8] 


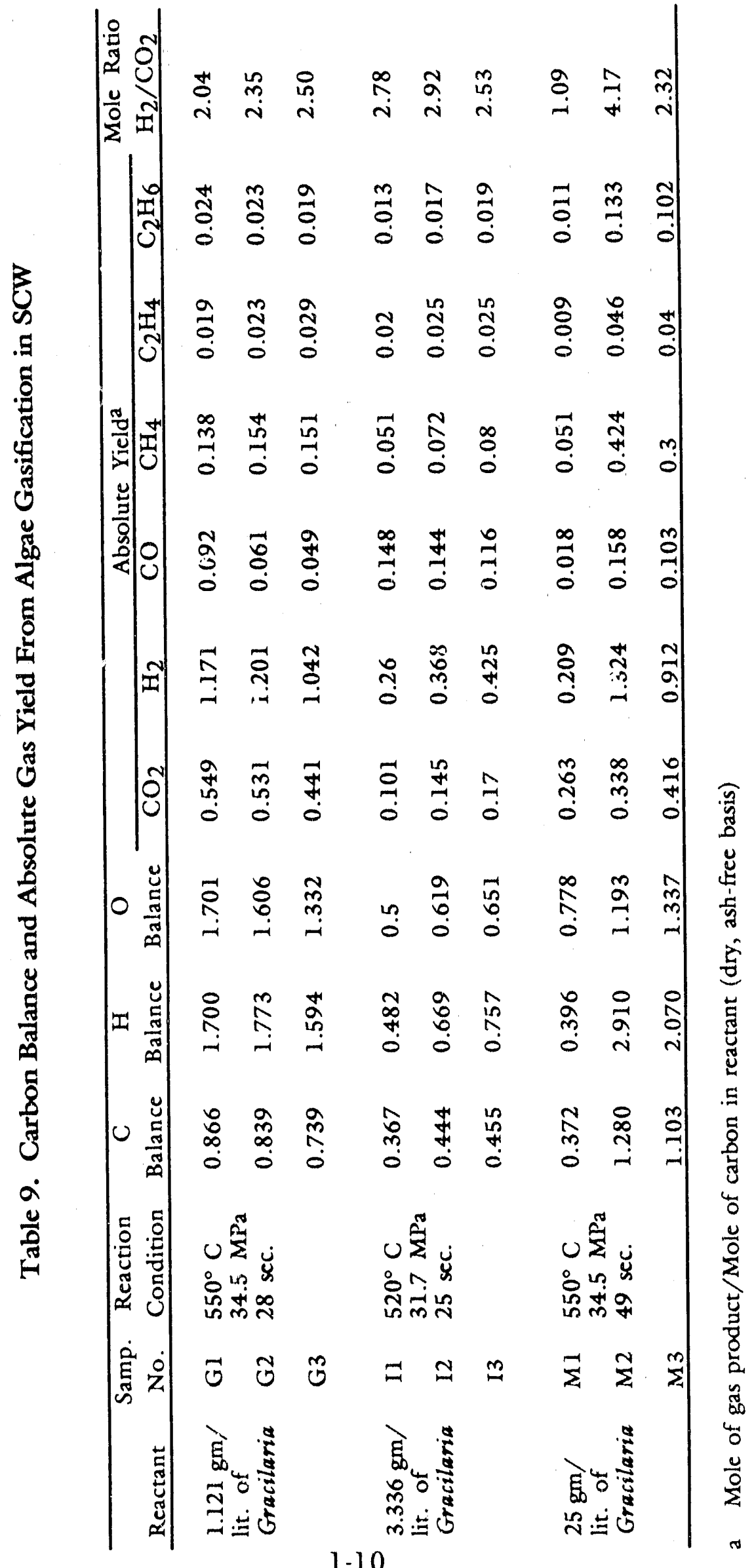




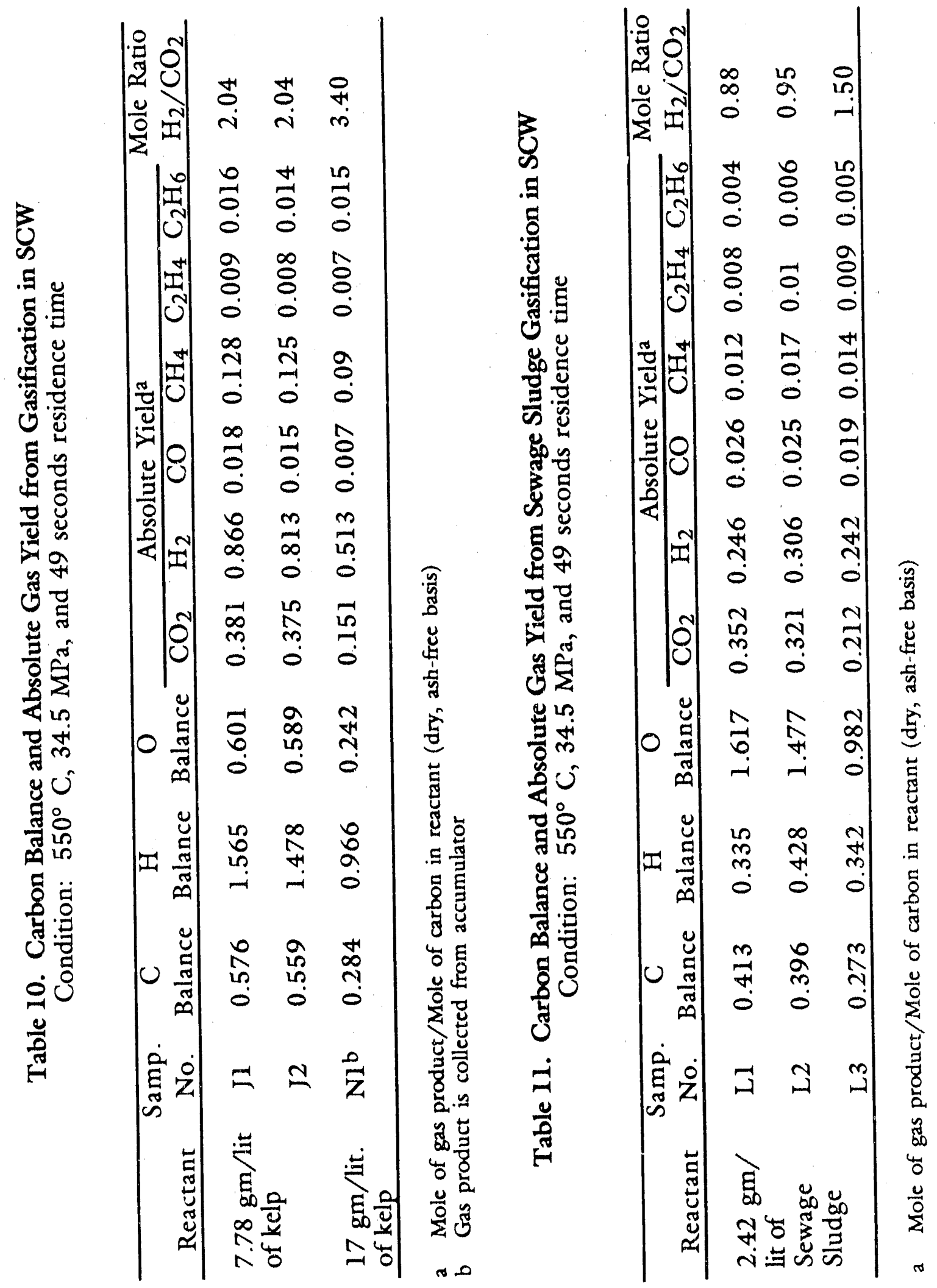




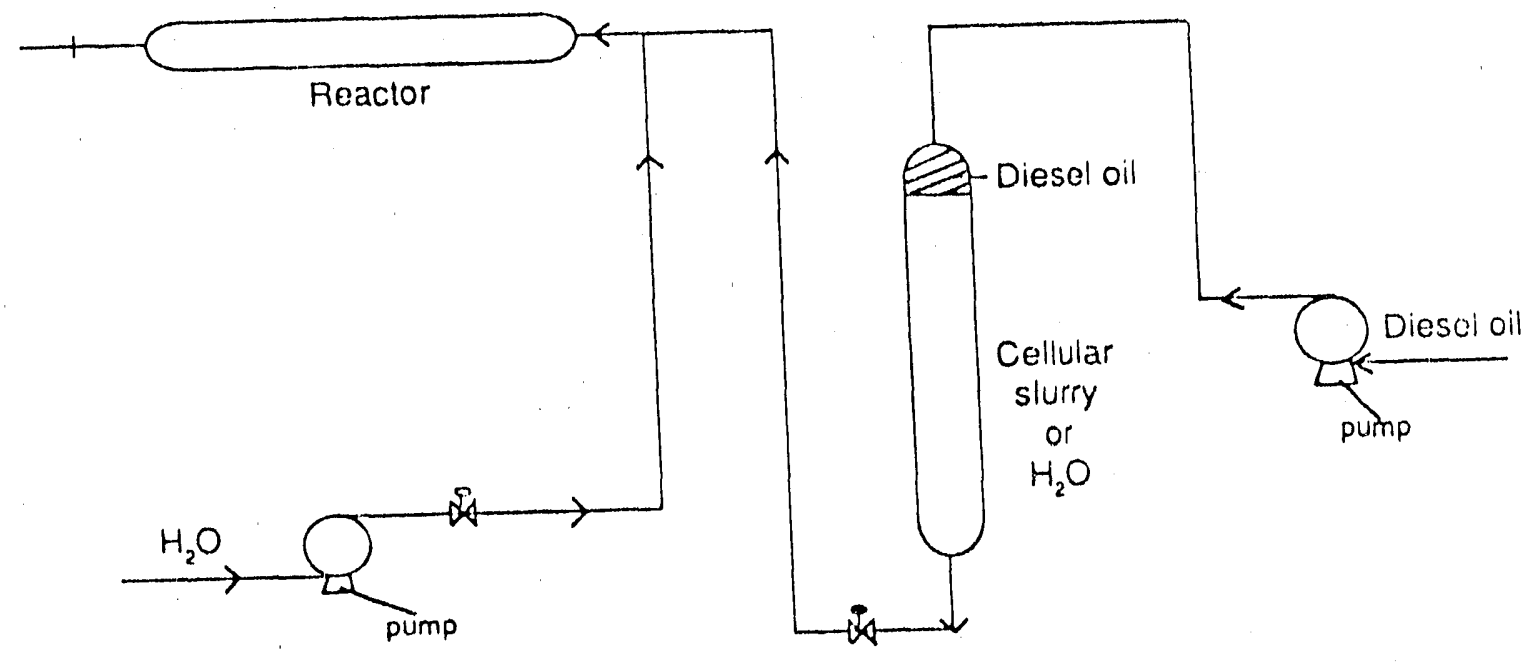

Figure 1. Diesel oil is pumped into the cylinder and displaces the solution, feeding the reactor 
Task 2

PHOTOELECTROCHEMICAL PRODUCTION OF HYDROGEN

\author{
Subtask 2.1 \\ PHOTOEMISSION AND PHOTOLUMINESCENCE STUDIES OF \\ CATALYZED PHOTOELECTRODE SURFACES FOR HYDROGEN \\ PRODUCTION
}

\author{
Subtask Leader: W. Pong \\ J. F. Zheng, Graduate Assistant
}

\begin{abstract}
Discontinuous metal layers in the form of microislands deposited on semiconductor photoelectrode surfaces are known to catalyze reactions for hydrogen production in photoelectrochemical cells. In an effort to determine how the metal islands can be made to improve the photoelectrode efficiency, we have applied photoemission and photoluminesccince techniques to investigate the size effect of the metal islands on: 1) the generation of the open-circuit photovoltage at the surface, and 2) the surface recombination loss of the photoexcited electrons. The photoemission results indicate that the optimal photovoltage could be produced for a discontinuous metal layer on a suitable semiconductor surface. In the photoluminescence study the emission due to surface recombination was found to be affected by the metal microislands.
\end{abstract}

\title{
INTRODUCTION
}

In the study of photoelectrodes for generating hydrogen from water with sunlight, we are interested in problems concerning the enhancement of barrier heights at the semiconductor interface and the reduction of surface recombination loss of photoexcited electrons and holes. These problems are the major requirements that must be satisfied for the photoelectrochemical system to be efficient.

In the hydrogen generating system, the efficiency of the photoelectrode depends on the ratio of the rate of hydrogen evolution to the sum of this rate and the recombination and leakage rates. Thus the efficiency can be increased by reducing the rates of recombination of the photoexcited carriers and leakage of the minority carriers through the interfacial Schottky barrier. In recent years significant progress has been made to reduce these rates by using catalyzed photoelectrodes [1].

NOTE: The material for this task was presented at the World Hydrogen Energy Conference \#8, Honolulu and Waikoloa, Hawaii, 22 July 1990 and is published in substantially the same form in Hydrogen Energy Progress VIII,

T. Veziroglu and P. K. Takahashi, eds., pp. 473-481. 
A metal catalyst such as platinum deposited on a semiconductor surface can enhance the photoproduction of hydrogen [2]. For example, a platinum catalyst in the form of microislands can increase the hydrogen generating current density of the p-type InP photocathode by a factor of $10^{4}[3]$. To be effective, the average diameter of the microisland must be smaller than the wavelength of the exciting light. 'The loss of photons due to the coverage of the surface by the metal could be milimized by making the spacing between the metal islands sufficiently large. On the other hand, the separation has to be sufficiently small to ensure high collection efficiency of the photoexcited electrons.

Discr ntinuous Pt layers on Si photoelectrodes have also been studied. Of particular interest is that a relatively high open-circuit photovoltage has been observed for metal deposits consisting of microislands 2 to $10 \mathrm{~nm}$ wide [4]. The results suggest that metal islands of a certain size can enhance the charge transfer at the interface. However, the structural and electronic properties of small metal islands are not well understood.

In an effort to gain a better understanding of the catalyzed photoelectrode surface, we have performed photocmission and photoluminescence studies of semiconductor surfaces covered with metal islands of various sizes. The objective of the investigation was to determine the optimal size of the metal clusters for generating the photovoltage and reducing the surface recombination loss.

\section{PHOTOEMISSION STUDY}

We have applied an X-ray photoemission technique to investigate the metal microislands on the semiconductor surface. The technique has the advantage in that the open-circuit photovoltage can be monitored without making electrical contact with the discontinuous metal layer in the vacuum after the metal deposition. The photoemission measurements were made with and without light bias. For optical excitation above the bandgap energy, the electron-hole pair separation in the space-charge region of the Schottky barrier could produce a photovoltage to shift the Fermi level of the metal deposit relative to that of the semiconductor substrate. Consequently, the measured binding energy of the photoelectron from the core level of the metal may appear to be different in the presence of light bias.

\section{EXPERIMENTAL}

Thin chromium $(\mathrm{Cr})$ films were deposited on $\mathrm{p} \cdot \mathrm{Si} / \mathrm{SiO}$ surfares in our experiment because $\mathrm{Cr}$ is known to help generate the highest photovoltage [5]. The p-type Si wafer with a polished surface (111) was etched with hydrofluoric acid and thermally oxidized to form a thin $\mathrm{SiO}_{\mathrm{x}}$ coating of thickness approximately $15 \AA$. Ohmic contact was made on the back surface of the $\mathrm{Si}$ substrate with Ga-In eutectic $(75.5 \%: 24.5 \%)$. The $\mathrm{p}-\mathrm{Si} / \mathrm{SiO}_{\mathrm{x}}$ substrate could 
be transferred from the metal deposition chamber to the ESCA (Electron Spectroscopy for Chemical Analysis) system through a gate valve as dis! ayed in Figure 1.

The X-ray photoemission was measured using a Perkin-Elmer ESCA system (Model 5100). The photoslectrons were excited from the metal deposits with X-ray photons from a $\mathrm{Mg}$ target. The X-ray intensity was kept low to minimize the effect of illumination from the X-ray source. As illustrated in Figure 2, the light bias was provided by a 300 -watt xenon source. A water cell and UV filter were used to prevent optical heating and UV excitation of electrons from the metal deposits or the substrate.

\section{RESULTS}

The observed binding energy of the X-ray photoelectrons from the $\mathrm{Cr}$ deposits on the $\mathrm{p}-\mathrm{Si} / \mathrm{SiO}_{\mathbf{x}}$ substrate was found to be shifted to lower encrgy when the metal coating substrate was illuminated by light from the xenon source. For example, the energy shift of the $\mathrm{Cr} 2 \mathrm{P}-3 / 2$ peak of the photoelectron spectrum of $\mathrm{Cr}$ is displayed in Figure 3. The energy shift appeared to be proportional to the photovoltage.

The increase in the photovoltage as seen by the apparent shift in binding energy versus the amount of $\mathrm{Cr}$ deposited on the $\mathrm{p}-\mathrm{Si} / \mathrm{SiO}_{\mathrm{x}}$ surface is displayed in Figure 4.

The effective thickness $t$ of the Cr layer was estimated in terms of the photoelectron escape length $\mathrm{L}$. We assumed the relative photoemission yield of $\mathrm{Cr}$ could be described by $[1-\exp (-t / L)]$. The structure of the Cr layer that provided the nearly optimal photovoltage was also analyzed by scanning tunneling microscopy (STM). The structural features of the Cr layer as scen by STM are displayed in Figure 5. Microislands of width $26 \mathrm{~nm}$ and height $37 \mathrm{~nm}$ were observed. The $\mathrm{Cr}$ layer was clearly discontinuous.

\section{PHOTOLUMINESCENCE STUDY}

Since surface recombination loss could appear as photon emission, the measurements of the emission may provide information on the recombination loss at the semiconductor interface. The experimental arrangement for the measurements we made is displayed in Figure 6.

\section{EXPERIMENTAL}

Photoluminescence of n-type InP photoelectrode was observed at room temperature in an electrochemical cell containing $1 \mathrm{M} \mathrm{KCl}$ electrolyte. The three clectrodes, including the reference and the Pt counter electrode, were mounted in a pyrex tube that was placed in a metal chamber containing the photomultiplier 
tube and filter. The photomultiplier tube was cooled with vapor from boiling liquid nitrogen. The bias voltage on the photoelectrode was controlled by a potentiostat. The optical excitation was provided by a $\mathrm{He}-\mathrm{Ne}$ laser. The exciting light passed through a monochromator and a lens which focused the beam on the InP surface. The InP wafers were $S n$-doped and their exposed surface was polished and etched. The carrier concentration is about $10^{18} \mathrm{~cm}^{-3}$. The InP electrode could be removed from the cell and placed in a vacuum for metal deposition on the InP surface.

\section{RESULTS}

The photcluminescence of InP observed with our filter and photomultiplier tube was in the wavelength range of $900 \mathrm{~mm}$. The intensity of the emission was found to be dependent on the bias voltage. This is in agreement with the results of recent work on InP $[6,7]$. We also found that the photoluminescence was a strong function of the Co deposits on the InP surface. The curves showing the emission intensity are displayed in Figure 7. The decrease in emission due to the Co deposits on InP can be much greater than the reduction reported for Co film on GaAs [8]. It appears that a dramatic reduction of the emission is observed only if a critical amount of $\mathrm{Co}$ is deposited on the $r$ type InP surface.

\section{CONCLUSIONS}

$\mathrm{X}$-ray photoemission measurements with light bias can provide information concerning the dependence of the open-circuit photovoltage on the metal microislands deposited on the semiconductor surface. Thus the technique should be useful for adjusting the metal island size and separation to optimize the photovoltage.

The results of our photoluminescence study of InP suggest that metal islands of certain size and separation on the semiconductor surface can suppress the photoluminescence due to recombination. Higher coverage with more metal deposits appears to be less effective.

Further study using these techniques with new methods of depositing metal clusters on surfaces would be highly desirable.

\section{ACKNOWLEDGEMENTS}

We would like to thank Professor K. Sattler, Dr. Ulrich Mueller, N. Venkateswaran, and $\mathrm{J}$. Xhic for their assistance in using scanning tunneling microscopy to analyze the discontinuous metal layers. The contribution of $\mathrm{Z}$. $X$. He to this study is also acknowledged. 


\section{REFERENCES}

1. Heller, A. 1985. In Catalysis and Surface Science p. 353. H. Heincmann and G. Somorjai (ed). New York:Marcel Dekker, Inc.

2. Heller, f. and R. G. Vadimsky. 1981. Phys. Rep. Lett. 46:1153.

3. Heller, A., E. Aharon-Shalom, W. A. Bonner, and B. Miller. 1982. J. Am. Chem. Soc. 104:6942.

4. Nakato Y., H. Yano, S. Nishiura, T. Ueda, and H. Tsubomura. 1987. J. Electroanal. Chem. 228:97.

5. Matsumura M., H. Iwata, T. Inoue, and H. Tsubomura. 1986. Solar Energy Materials 14:475.

6. Park, K. and H. Neff, 1987. J. Electrochem. Soc, 134:764.

7. Etcheberry A., J. Vigneron, J. L. Sculfort, and J. Gautron. 1989: Appl. Phys. Lett. 55:145.

3. Ahmed S., J. Leduc, and J. Trudel. 1988. In Luminescence and Technology p. 243. C. W. Struck, B. DiBartolo, and W. M. Yen (ed). The Electrochemical Society, Inc., Pennington. 
SAMPLE PREPARATION CHAMB, ESCA SYSTEM

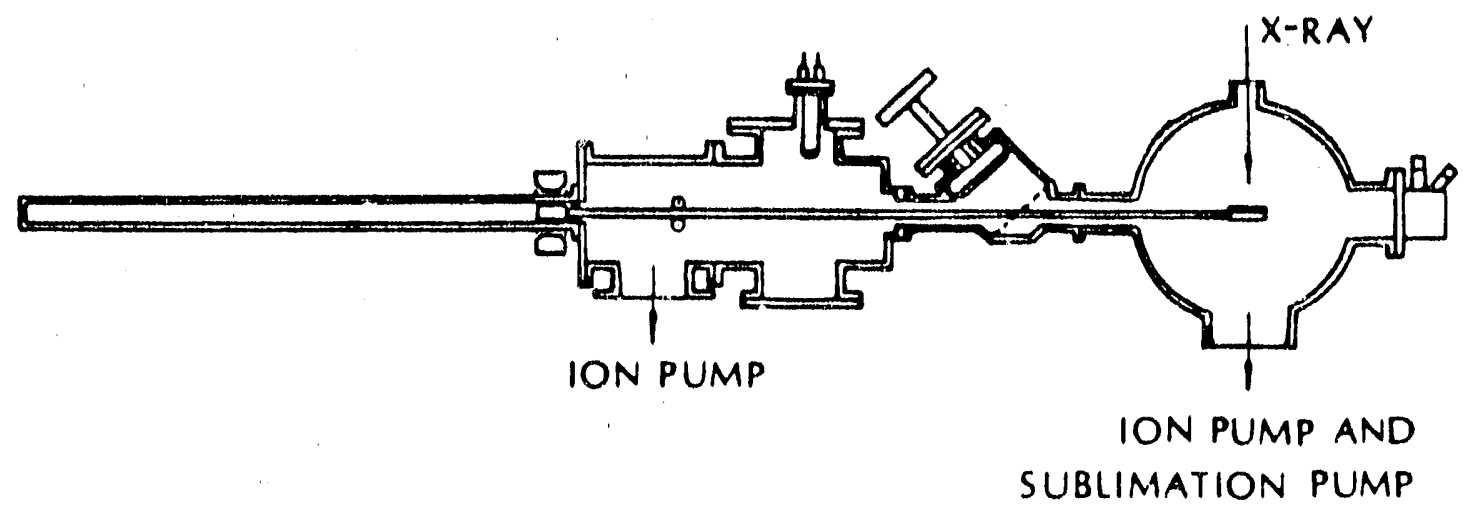

Figure 1. Dlagram showing the ESCA system and the metal deposition chamber. The sample can be moved from one chamber to the other through a metal-seal gate valve.

HEMISPHERICAL

ANALYZER

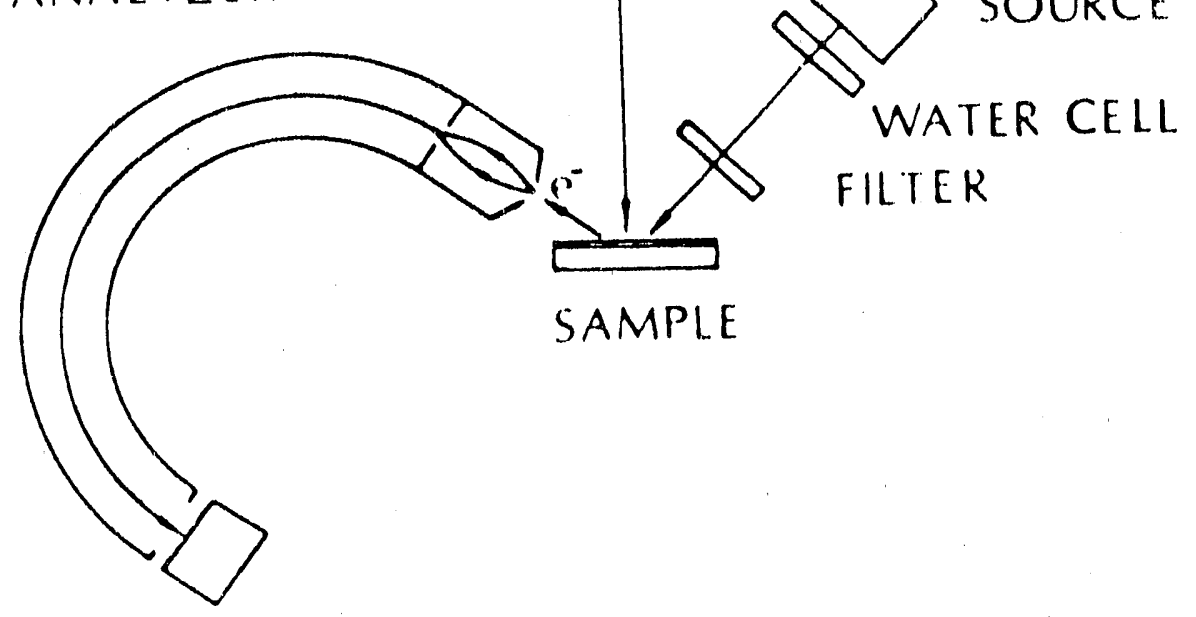

Figure 2. Diagram showing the experimental arrangement for measuring $X$-ray photoemission with light blas. 


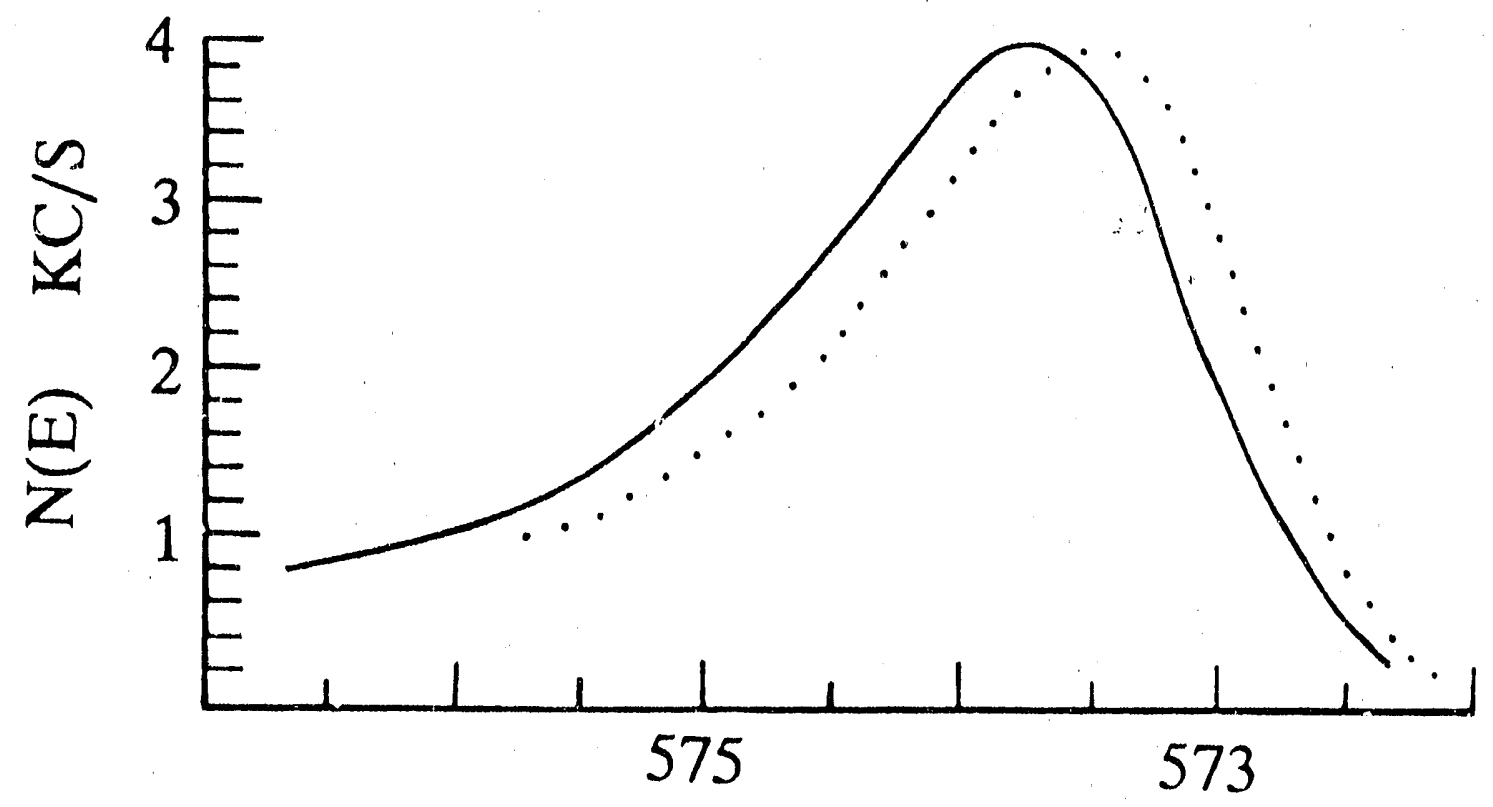

BINDING ENERGY (cV)

Figure 3. Photoelectron spectrum of $\mathrm{Cr}$ showing the $\mathrm{Cr} 2 \mathrm{P}-3 / 2$ peak. The solid line curve shows the peak when the xenon light is off. The dotted line shows the peak when the xenon light is on. 


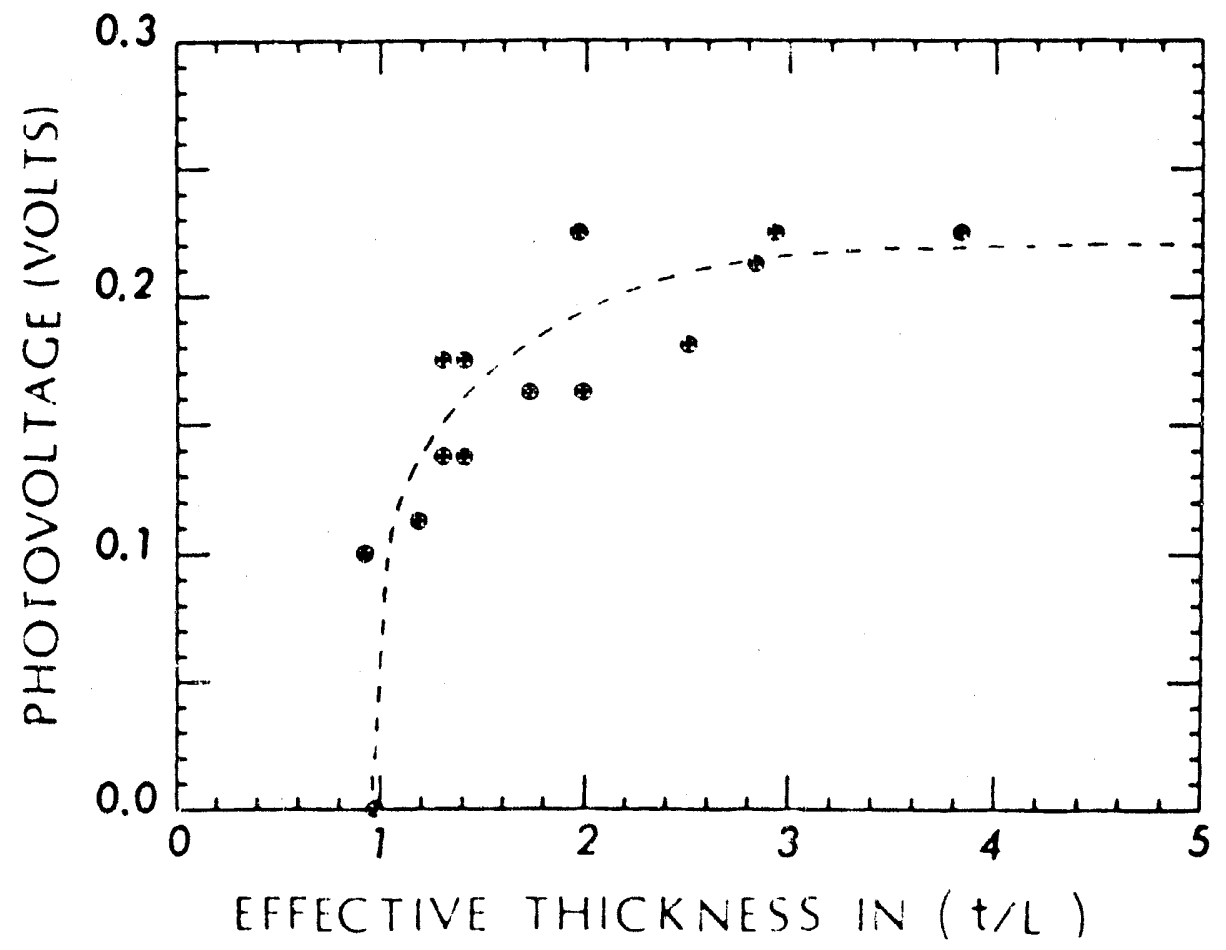

Figure 4. Photovoltage as seen in binding energy shift versus effective thickness of $\mathrm{Cr}$ deposited on oxidized p-type Si.

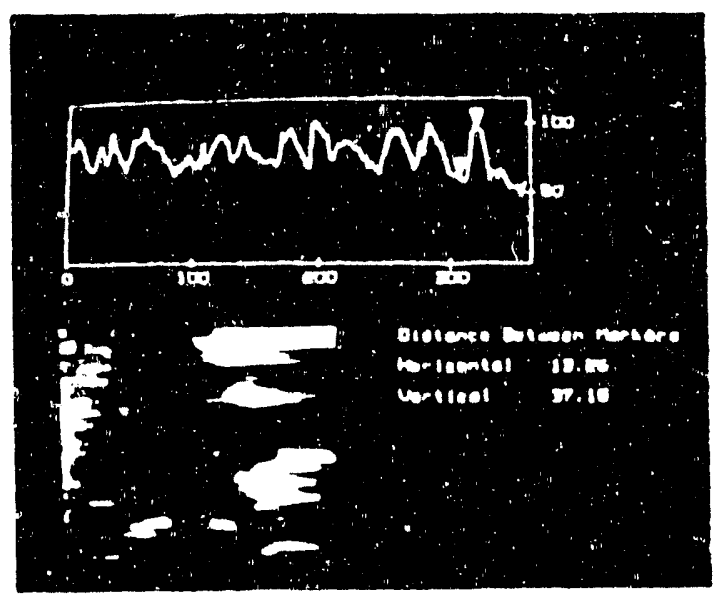

Figure 5. Structural features of discontinuous $\mathrm{Cr}$ layer as seen by scanning tunneling microscopy (STM). 


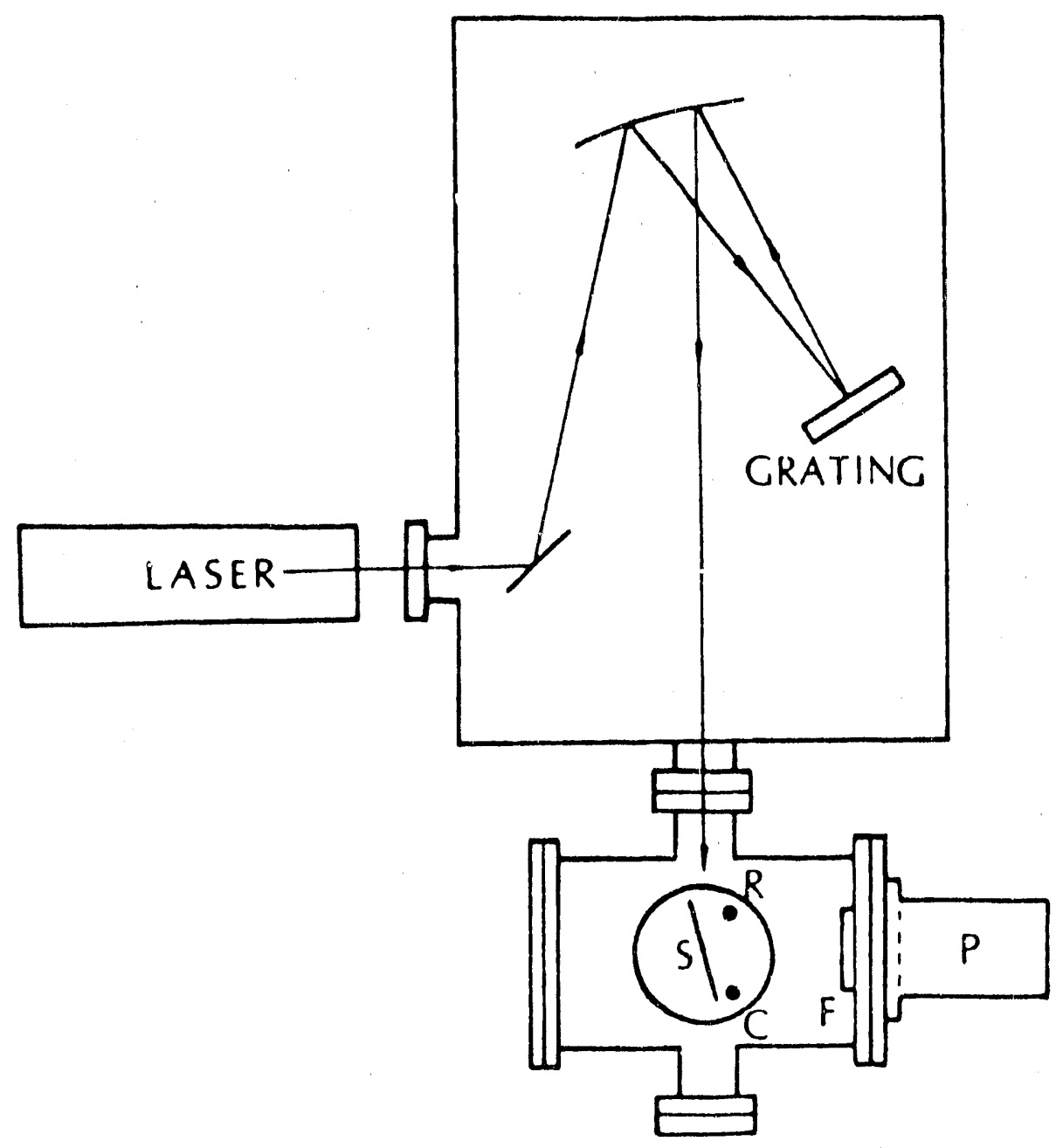

Figure 6. Diagram showing the experimental arrangement for photoluminescence measurements. S: InP sample;

R: reference electrode; C: counter electrode; F: filter;

P: photomultiplier tube. 


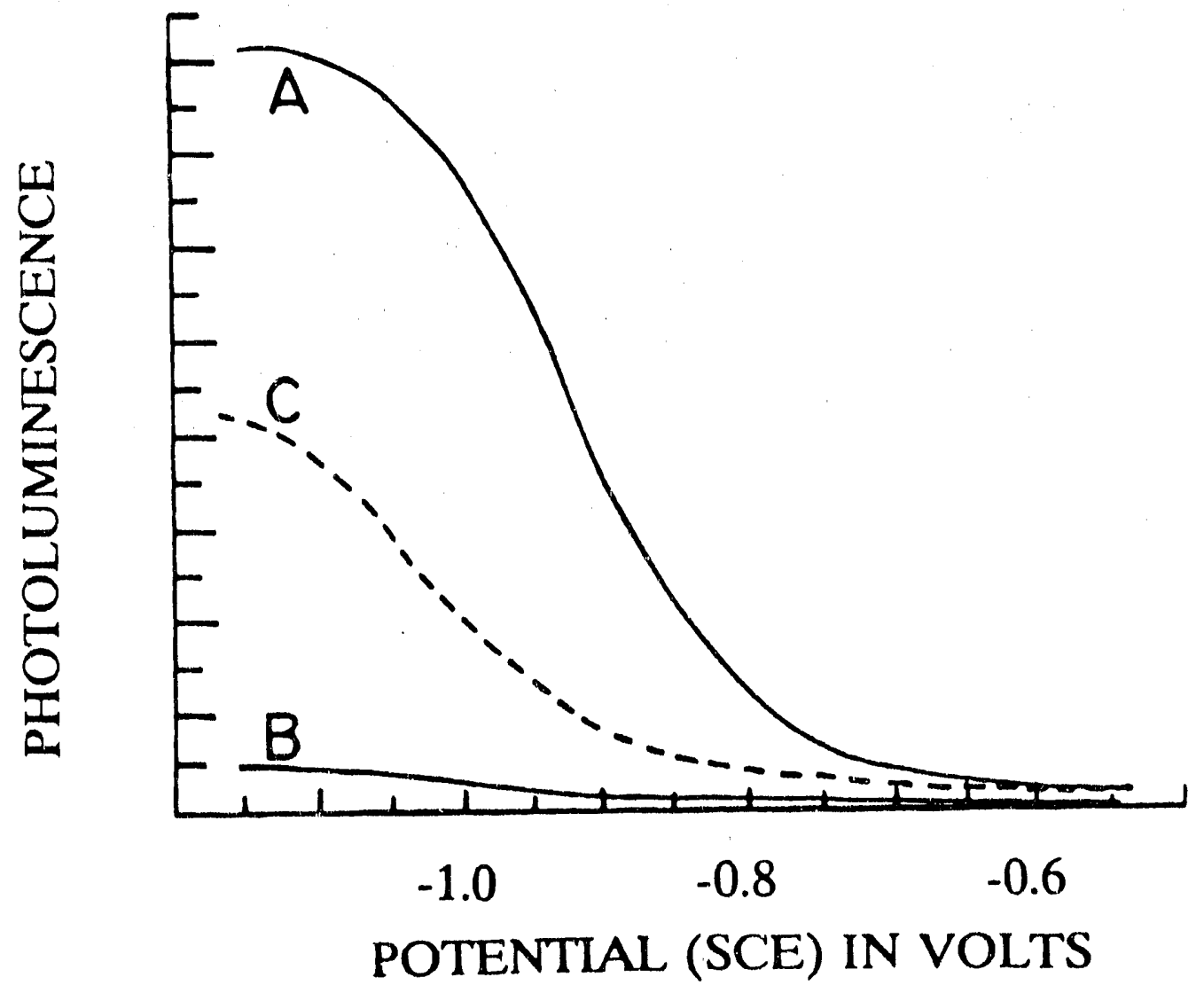

Figure 7. Photoluminescence of n-type $\ln P$ versus bias voltage (SCE) in $1 \mathrm{M} \mathrm{KCl}$ electrolyte. A) no Co on InP; B) $20 \%$ coverage by Co deposits; C) $90 \%$ coverage by Co. 
Task 2

PHOTOELECTROCHEMICAL PRODUCTION OF HYDROGEN

\author{
Subtasks 2.2 and 2.4 \\ SOLAR ENERGY CHEMICAL CONVERSION BY MEANS OF PEC \\ METHODS USING COATED SI ELECTRODES
}

\author{
Subtask Co-Leaders: Richard Rocheleau and Shiv K. Sharma \\ Qing-Hua Gao, Visiting Researcher
}

\title{
INTRODUCTION
}

Semiconductor photoelectrochemical (PEC) cells are being studied as a low cost method for the production of hydrogen from water using sunlight as the energy source. One of the main advantages of these systems is the direct conversion of solar energy into chemical energy in the form of $\mathrm{H}_{2}$.

There have been numerous articles on $\mathrm{H}_{2}$ production from semiconductor PEC cells using a variety of cell designs and semiconductor materials. With the exception of a few systems utilizing high cost, single crystal III-V semiconductors such as GaAs or InP, these PEC cells are typically low efficiency or unstable in aqueous solution or both. For example, stable photoanodes utilizing n-type $\mathrm{TiO}_{2}$ have been reported. However, the very wide bandgap limits the solar absorption and hence the conversion efficiencies. Semiconductors with lower bandgaps capable of higher efficiency are generally corroded in aqueous electrolyte solutions $[1,2]$. Electrode efficiency and stability (photocorrosion) continue to be the important issues.

Under this subtask we are carrying out an applied program directed toward the development of stable, high efficiency photoelectrodes for aqueous electrolytes. An integrated program including electrode fabrication, basic materials and interface characterization, and PEC cell performance has been started to optimize cell efficiency and stability. Only semiconductor materials with a potentially low cost such as $\mathrm{Si}, \mathrm{a}-\mathrm{Si}, \mathrm{CdSe}$, and $\mathrm{CdTe}$ will be considered.

Initial experiments have been carried out using p-type Si photocathodes. This system has been selected based on the recent promising results with $\mathrm{p}$ type silicon $[3,4]$ and the well-characterized nature of the semiconductor. The well-characterized semiconductor is useful for detailed study of the rate controlling processes at the semiconductor-electrolyte interface. The hydrogen evolution reaction under illumination is a complex multistep reaction which is still not well understood. The effect of various coatings on stability and efficiency will be studied. These treatments will include metallic and semiconductor coating. 
We have made progress in establishing our experimental equipment and procedures and the current-voltage behavior of photocathodes fabricated from ptype $\mathrm{Si}$ with various metal coatings for enhanced charge transfer.

\section{SCIENTIFIC BACKGROUND}

Figure 1 is the schematic energy level diagram for a photoelectrolytic cell using a p-type Si photocathode and Pt counterelectrode. The energy, band diagram is based on a Schottky-type model. The effect of the Helnfholtz layer is not shown. Examination of Figure 1 shows that the minimum voltage required to drive the electrolysis reaction is [5]

$$
V_{\min }=\frac{\Delta G}{n F}+\eta_{a}+\eta_{c}
$$

Where: $\frac{\Delta G}{n F}$ is the net free energy of the reaction in the electrolyte:

$$
\mathrm{H}_{2} \mathrm{O} \rightarrow \mathrm{H}_{2}+\frac{1}{2} \mathrm{O}_{2}
$$

The other voltages, $\eta_{\mathrm{a}}$ and $\eta_{\mathrm{c}}$, are the intrinsic overpotentials of the semiconductor cathode and anode respectively. This intrinsic overpotential is determined by the bandgap of the semiconductor, the flatband potential, and the redox potential of the electrolyte acceptor state; thus it is current independent. The intrinsic overpotential is not the same as the conventional electrochemical overpotential due to $\mathrm{iR}$ losses in the electrode and Helmholtz layer. This minimum voltage must be supplied from the voltage of the semiconductorelectrolyte junction and the external bias such that

$$
E_{B}+E_{g}-V_{B}-\Delta E_{F}=\frac{\Delta G}{n F}+\eta_{a}+\eta_{c}+i R
$$

Where: $\mathrm{E}_{\mathrm{g}}$ is the bandgap of the semiconductor,

$\Delta \mathrm{E}_{\mathrm{F}}$ is the difference between the valence band edge in the bulk and the Fermi level,

$V_{B}$ is the band bending, and

$\mathrm{E}_{\mathrm{B}}$ is the bias voltage.

An iR term has been included to show the additional voltage required to overcome current dependent losses through the semiconductor, electrolyte, and interfaces. The grouping $\mathrm{E}_{\mathrm{g}}-\mathrm{V}_{\mathrm{B}}-\Delta \mathrm{E}_{\mathrm{F}}$ represents the potential loss terms in the semiconductor resulting from the movement of electrons and holes from their point of creation to the respective electrolyte interface. In the electrolyte a portion of this potential energy is recovered as the free energy $\left(\frac{\Delta G}{n F}\right)$ of the net 
endocrgic reaction in the electrolyte. The remaining potential is lost through the irreversible, entropy-producing terms $\eta_{\mathrm{a}}, \eta_{\mathrm{c}}$, and $\mathrm{iR}$ (ohmic heating).

Gerischer [6] used a statistical approach and invoked the quasi-Fermi level concept for electrons and holes to describe the photogenerated potential for driving the cell reactions. A free energy balance based on this model (or the whole driving force of a photoclectrolytic cell in this sense) would be

$$
\begin{aligned}
& \Delta \mathrm{E}_{\mathrm{F}}{ }^{*}=\left(\mathrm{nE}_{\mathrm{F}}{ }^{*}-\mathrm{pE}_{\mathrm{F}}{ }^{*}\right)=\frac{\Delta \mathrm{G}}{\mathrm{nF}}+\eta_{\mathrm{c}^{\prime}}+\eta_{\mathrm{a}}{ }^{\prime}+\mathrm{iR} \\
& \text { Where: } \mathrm{nE}_{\mathrm{F}}{ }^{*} \text { and } \mathrm{pE}_{\mathrm{F}}{ }^{*} \text { are the quasi-Fermi levels at the interface } \\
& \text { for electrons and holes respectively; } \\
& \eta_{\mathrm{a}}{ }^{\prime} \text { is the difference between } \mathrm{pE}_{\mathrm{F}}{ }^{*} \text { and the } \frac{\mathrm{O}_{2}}{\mathrm{H}_{2} \mathrm{O}} \text { redox potential; } \\
& \quad \text { and } \\
& \eta_{\mathrm{c}}{ }^{\prime} \text { is the difference between } \mathrm{nE}_{\mathrm{F}}{ }^{*} \text { and the } \frac{\mathrm{H}^{+}}{\mathrm{H}_{2}} \text { redox potential. }
\end{aligned}
$$

Redox levels and quasi-Fermi levels are both electrochemical potentials for electrons. Net electron flow is thermodynamically forbidden except from a higher to a lower electrochemical potential. There is usually a misconception that photoelectrolysis is possible if the band edges straddle the hydrogen and oxygen redox levels. However, according to Gerischer, the electron and hole quasi-Fermi levels must straddle these redox levels and with sufficient extra separation to allow for band bending, overpotential, and interfacial recombination. In other words, the open circuit potential must be larger than $1.23 \mathrm{~V}$. The open circuit potential of either a good single crystal Si $p-n$ junction or Schottky barrier is typically 0.6 to $0.8 \mathrm{~V}$, so that a significant bias is required for single crystal silicon photoclectrodes.

In addition to correct bandedges, semiconductor photoelectrodes must efficiently transfer charge at the electrolyte interface to function effectively. In practice, the semiconductor surfaces are given a special treatment to raise the clectrocatalytic activity for the $\mathrm{H}_{2}$ generation reaction. This treatment frequently consists of the deposition of a catalytic metal such as Pt, often as a thin semitransparent or discontinuous coating. Such a treatment of the photocathode increases the current at a given bias. A shift in the onset potential to a bias more positive than the theoretical value $(-0.24 \mathrm{~V}$ relative to $S \mathrm{CE})$ or even more positive than a good Pt electrode can be considered as a result of light energy doing work on the system.

Improvements in the efficiency of the photoclectrochemical cells require the optimization of the photogeneration of carriers, efficient charge separation in the bulk, and efficient charge transfer with minimum surface recombination. The first of these depends primarily on the bandgap of the semiconductor and optical losses. Charge separation in the bulk is also dependent on the semiconductor 
quality and on the electrode configuration. The latter process (surface recombination) is effected by the defect state near the interface and the intrinsic charge transfer rates (hydrogen evolution reaction) at the solid/electrolyte interface. Although the energy band diagram (Figure 1 ) indicares the theoretical limits on the potentials within the cells, dynamic models accounting for the above terms or accurate equivalent circuit models are required for optimization of actual devices.

\section{EXPERIMENTAL}

Experiments were carried out to establish a baseline for the performance of PEC cells using p-type silicon photocathodes and to study the effect of process variables on PEC cell performance. Variables studied during this phase of the research included the resistivity of the wafer used for photoelectrode fabrication $(<0.02$ to $33 \Omega-\mathrm{cm})$, type of metal $v$,ed to enhance electrocatalytic activity (Ni and $\mathrm{Pt}$ ), effective thickness of the metal coating, and the method of metals deposition. The photocathodes are fabricated using appropriate sized pieces of the Si wafers. These Si wafers were degreased with petroleum ether, acetone, and ethyl alcohol; etched with aqua regia and a mixture of $\mathrm{HNO}_{3}: \mathrm{HCl}: \mathrm{HF}=1: 3: 3$ for $15 \mathrm{~min}$ and then with $10 \% \mathrm{HF}$ for $1 \mathrm{~min}$. The etching solution and etching time were optinized previously. The Si wafers were then fabricated into photoelectrodes using $\mathrm{In}-\mathrm{Ga}(1: 1)$ alloy as ohmic contact material to the back. Cu lead wire was fixed to the contact using "E-Solder" Ag conductive adhesive and epoxy resin. An active surface area of 0.5 or $1 \mathrm{~cm}^{2}$ was obtained by using a well defined paper adhered on the surface of the wafer. The remaining exposed border was sprayed with an epoxy resin paint, and the paper was then removed after drying.

The fabricated photoelectrodes were then coated with platinum or nickel film. Pt was photoclectrodeposited on the $\mathrm{p}$-Si surface in $0.01 \mathrm{M} \mathrm{H}_{2} \mathrm{PtCl}_{6}$ solution at $\mathrm{pH}$ of 4.5 using a tungsten-halogen lamp with a light intensity of 20 to $50 \mathrm{~mW} / \mathrm{cm}^{2}$, the potential applied being swept at the same time cyclically between $+0.2 \sim-0.5 \mathrm{~V}$ versus SCE at a rate of $200 \mathrm{mV} / \mathrm{second}$. A threemonolayer film would be obtained when $3 \mathrm{mC} / \mathrm{cm}^{2}$ of current passed. Ni was photoelectrodeposited in a Ni plating bath $\left(\mathrm{NiSO}_{4} \cdot 6 \mathrm{H}_{2} \mathrm{O} 13.5 \mathrm{~g} / \mathrm{L}, \mathrm{NH}_{4} \mathrm{Cl} 25\right.$ $\mathrm{g} / \mathrm{L}$ and $\mathrm{H}_{3} \mathrm{BO}_{3} 30 \mathrm{~g} / \mathrm{L}$ at $\left.\mathrm{pH} 5.6 \sim 5.9\right)$ swept cyclically between $+0.2 \sim-0.5 \mathrm{~V}$ versus SCE.

Platinum was also $\mathrm{Ar}^{+}$ion-sputtered onto the $\mathrm{Si}$ at different currents, $\mathrm{Ar}$ pressure, and time intervals. Sputtering at $100 \mathrm{mT}$ Torr with a current of $13 \sim 17$ $\mathrm{mA}$ for 4 min resulted in a film thickness of $>500 \AA$. The sputtered Pt films were sometimes annealed in an $\mathrm{Ar}$ atmosphere at $550^{\circ} \mathrm{C}$ for 30 min prior to fabrication into photoelectrodes. The completed electrodes (including Pt or $\mathrm{Ni}$ photocleciodeposited) were sometimes subjected to alkaline etching for $1 \mathrm{~min}$. The alkaline itching solutions are $4 \mathrm{M} \mathrm{NaOH}$ and $0.25 \mathrm{M} \mathrm{NaOH}$ containing $0.6 \mathrm{M} 2$-propanol at $85^{\circ}$ to $90^{\circ} \mathrm{C}$ respectively. 
Current-voltage measurcments were made using $0.5 \mathrm{M} \mathrm{H}_{2} \mathrm{SO}_{4}$ as the clectrolyte, with SCE as the reference electrode and $\mathrm{Pt}$ as the counterelectrode. A PAR 362 Scanning Potcntiostat and an HP3421A Data Acquisition Unit with an HP Integral Personal Computer were used to measure the current-voltage characteristics. The saved current-voltage data are first read to an IBM computer and then translated to Macintosh data. The $\mathrm{i}-\mathrm{V}$ curves are drawn using Kaleidagraph software.

Multi-channel micro-Raman equipment was used to detect the presence of $\mathrm{Pt}$ or PtSi on the substrate, to determine relative thickness and homogeneity of Pt films, and to study the catalytic effect.

\section{RESULTS}

During this subcontract period (November 1, 1989 to July 31, 1990) procedures for fabrication of $\mathrm{p}$-Si photocathodes with well-defined active areas were improved, and the instrumentation for comparative voltametric measurements was upgraded. We have also evaluated the various methods described in the literature for the reporting of photoelectrode efficiency. We have established preliminary criteria for our reporting procedures including systems which require external bias for hydrogen production. The construction of the state-of-the-art glow discharge system initiated last report period has been completed. Comparative voltametry measurements and Raman analysis have been performed on PEC cells with a variety of photocathodes fabricated from $\mathrm{p}$ type crystalline silicon.

Current-voltage behavior of the PEC cells was a nalyzed to qualitatively identify the mechanisms responsible for efficiency losses. Quantitative loss minimization procedures have been used with great success for optimization of photovoltaic devices. Procedures for quantitative analysis are now under development for the PEC systems.

Details of these results are presented in the following sections.

\section{EFFICIENCY MEASUREMENTS}

A survey of the literature indicates some disagreement regarding the measurement and reporting of efficiency for PEC cells which require external bias for operation. Figure 2 shows an idealized current -voltage $(\mathrm{J}-\mathrm{V})$ curve for a PEC cell operating with an ideal metal anode and a semiconductor based photocathode with negligible dark current. All voltages shown are relative to a saturated calomel reference electrode. Any operating point on the photocathode curve at bias potentials less than that shown for the "ideal cathode" represents an operation with an energy savings due to work performed by the light absorbed in the photocathode [7]. At potentials more negative than the "ideal cathode" there are no energy savings due to the light. Although the current may be limited by the generation of carriers (i.e., by the absorption of light), the kinetic energy 
for separation of the generated carriers is provided by the electrical bias. Under these conditions no net work can be ascribed to the light. Operation under these conditions is exactly analogous to the operation of a solar cell in reverse bias.

The point of maximum solar efficiency for any individual cell occurs at that operating point on the photocathode curve which maximizes the encrgy savings relative to the "ideal cathode." This formulation is consistent with that described by Heller [7], Ueda et al. [3] and by Ghosh and Maruska [8] but disagrees with the formulations discussed by Bockris and Murphy [9].

In addition to the general formulation for the calculation of efficiency, it is necessary to make the measurements under appropriate conditions. These include careful definition of the illuminated area and use of an appropriate illumination source. In this regard we have established procedures such that the illuminated area and that exposed to the clectrolyte are identical. Illumination should be based on the standards established by SERI for the testing of photovoltaic cells and modules. Any deviation from these conditions must be clearly identified if meaningful comparisons are to be made.

\section{ELECTRODE PREPARATION/MEASUREMENTS}

The procedures presently used for fabrication of the photocathodes were described in the experimental section. The larger area $\left(0.5\right.$ to $\left.1.0 \mathrm{~cm}^{2}\right)$ relative to previous samples has resulted in greater reproducibility in the measurement of the current density.

Considerable effort has gone into control of the metals deposition for improved reproducibility using both sputtering and cyclic photoelectrodeposition. Pattern masks have been designed and will be ordered to allow independent control of area coverage and film thickness. Optical measurements to determine absorption and reflection losses have been initiated. A Tencor Alpha 200 profilometer has been ordered, using university funds, for measurement of film thicknesses.

The equipment for voltametry measurements was also upgraded during this contract period. A Princeton Applicd Rescarch scanning potentiostat (model 362) was purchased with university funds for use in this project. The data acquisition equipment was also upgraded using borrowed equipment. Data are now recorded via an HP3421A Data Acquisition. Unit with an HP Integral Personal Computer. The data are downloaded to a Macintosh for analysis.

Voltametry measurements in the ligl:t are still being performed with a halogen bulb with an intensity of approximately $36 \mathrm{~mW} / \mathrm{cm}^{2}$. A new light source has been designed for greater area uniformity and operation at an intensity of $100 \mathrm{~mW} / \mathrm{cm}^{2}$. Due to funding limitations this new source will utilize ELH-tungsten halogen bulbs rather than the preferred filtered Xenon source. 
The construction of the state-of-the-art glow discharge system initiated last period has been completed. Start-up experiments including temperature and pressure control, plasma generation, and substrate transfer have been completed. Experiments to deposit amorphous and microcrystalline silicon and silicon-carbide are being initiated.

\section{VOLTAMETRY MEASUREMEN'TS}

Voltametry measurements in the dark and in the light were carried out using photocathodes fabricated using p-type silicon wafers. Different wafer resistivities, etching, and metallizations were used to establish baseline J-V behavior curves. These baseline studies are heing used to initiate the studies aimed at efficiency improvements. All J-V measurements reported were obtained using the conditions described in the experimental section, including Pt anodes, a light intensity of $36 \mathrm{~mW} / \mathrm{cm}^{2}$, and $0.5 \mathrm{M} \mathrm{H}_{2} \mathrm{SO}_{4}$ as the electrolyte.

Experiments to evaluate the effect of wafer resistivity on the J-V behavior of the photocathodes were performed. The $<111>$ p-type silicon wafers from Wafer Net, Inc. were obtained in threc resistivity ranges: 0.005 to $0.02 \mathrm{ohm}-\mathrm{cm}(255$ to 305 microns), 3 to $6 \mathrm{ohm}-\mathrm{cm}$ (355 to 405 microns), and 17 to $33 \mathrm{ohm}-\mathrm{cm}$ (500 to 550 microns). Platinized and unplatinized wafers were tested. Platinization was by the cyclic photoclectrochemical method. Thickness of the $\mathrm{Pt}$ was varied by controlling the number of cycles and post-ctching treatments. Figure 3 displays typical current voltage behavior of photocathodes for each of the resistivity ranges.

The J-V curves of the low resistivity electrodes (Fizure 3a) exhibit very large current densities in both the dark and the light with little difference between the two. As expected from the electrocatalytic activity of $\mathrm{Pt}$, the current density increases for the samples which were platinized compared to the bare $\mathrm{Si}$ samples. The high currents and absence of diode behavior indicate that these electrodes are operating as poor quality metal electrodes with some current modulation by the light. "The semiconductor/electrolyte contact is essentially ohmic in nature.

The J-V curves of the high resistivity samples (Figure $3 \mathrm{c}$ ) showed saturation currents within the range expected for photogenerated currents and exhibit significant diode behavior in the power region. The onset potential is significantly more positive than $-0.3 \mathrm{~V}$, indicating a power savings compared to a platinum cathode. However, efficiency is still very low. The short circuit and light generated currents are low for the light intensity used, indicative of optical losses. The voltage gain [compared to Pt or the ideal $-0.24 \mathrm{~V}(\mathrm{SCE})]$ is less than expected for a good silicon electrode, and the effective fill factor is also low. These results are indicative of possible problems with the interface (high reverse currents) and series and shunt losses. Additional samples and measurements are planned to identify and minimize the various losses. 
The J-V curves of the medium resistivity sample (Figure $3 \mathrm{~b}$ ) fall between the low and high resistivity values. Although the photogenerated currents are higher than those of the high resistivity sample, the absence of a shift in the onset potential to below $-0.3 \mathrm{~V}(\mathrm{SCE})$ and the lack of diode behavior in the power sector is indicative of very poor interfaces and possible high reverse saturation currents. Additional tests with wafers in this resistivity range are planned to improve the diode behavior.

Figure 4 displays a comparison of the J-V behavior of photocathodes fabricated on the high resistivity wafer using photoclectrochemically deposited nickel and platinum. The Pt curve is the same as seen in Figure 3. While the light generated currents (current density at negative bias) are similar in the two samples, the $\mathrm{Ni}$ coated cathode does not reduce the bias nor exhibit diode behavior in the power sector.

Figure 5 compares the J-V behavior of Si photocathodes with different thicknesses of photoclectrochemically deposited $\mathrm{Pt}$. The total amount of deposited $\mathrm{Pt}$ is in proportion to the number of cycles used. For comparison, the performance of a bare Si electrode is also shown. Again high resistivity silicon was used. The diode improves with the increased it, but the light generated current is reduced consistent with greater optical losses. The voltage shife observed in samples with the thicker $\mathrm{Pt}$ films is larger than expected for a $\mathrm{p}-\mathrm{Si} / \mathrm{Pt}$ Schottky diode, indicating the junction is likely with the electrolyte. The reduced voltage with low Pt coverage may be explained by increased surface recombination due to the poor charge transfer caused by insufficient Pt coverage.

Raman analysis of the photoelectrochemically deposited Pt shows that even the thicker deposited films are non-uniform or even discontinuous. Ueda et al.[3] reported that the best results are obtained when the Si surface is coated with a discontinuous metal coating to preserve the photovoltaic nature of the semiconductor/electrolyte junction but is sufficiently coated to give it the electrocatalytic effect of the metal. Detailed characterization of the Pt surface coverage, morphology, and optical losses will be necessary to separate the physical and electronic effects.

Figure 6 shows the performance of the best photocathode fabricated to date using sputter deposited Pt. This sample was fabricated by deposition of a thick sputtered film which was subsequently etched in alkaline solution for partial $\mathrm{Pt}$ removal. Line 2 in this figure shows an extremely small light generated current consistent with the high optical losses expected for the nearly opaque film. Following the alkaline etch, the behavior was similar to that of the photocathode with a very thin photoelectrochemically deposited Pt film (Figure 5, Curve 4). The Raman analysis of this sample was inconclusive. 


\section{REFERENCES}

1. Gerischer, H. 1977. J. Electroanal. Chem. 82:133.

2. Bard, A. J. and M. S. Wrighton. 1977. J. Electrochem. Soc. 124:1706.

3. Ueda, K., Y. Nakato, N. Suzuki, and H. Tsubomura. 1989. J. Electrochem. Soc. 136(8):2280.

4. Specht, M., H. -M. Kühne, and J. Schefold. 1990. In Proceedings of the Eighth World Hydrogen Energy Conference, Honolulu, Hawaii. Pergamon Press.

5. Nozik, A. J. 1978. Ann. Rev. Phys. Chem. 29:189.

6. Gerischer, H. 1979. Solar Energy Conversion - Solid State Physics Aspects. Topics in Applied Physics Vol. 31. B. O. Seraphin (ed).

7. Heller, A. 1982. Solar Energy 29(2):153.

8. Ghosh, A. K. and H. P. Maruska. 1977. J. Electrochem. Soc. 124:1516.

9. Bockris, J. O'M. and O. J. Murphy. 1982. Appl. Phys. Comm. 2(3):203. 


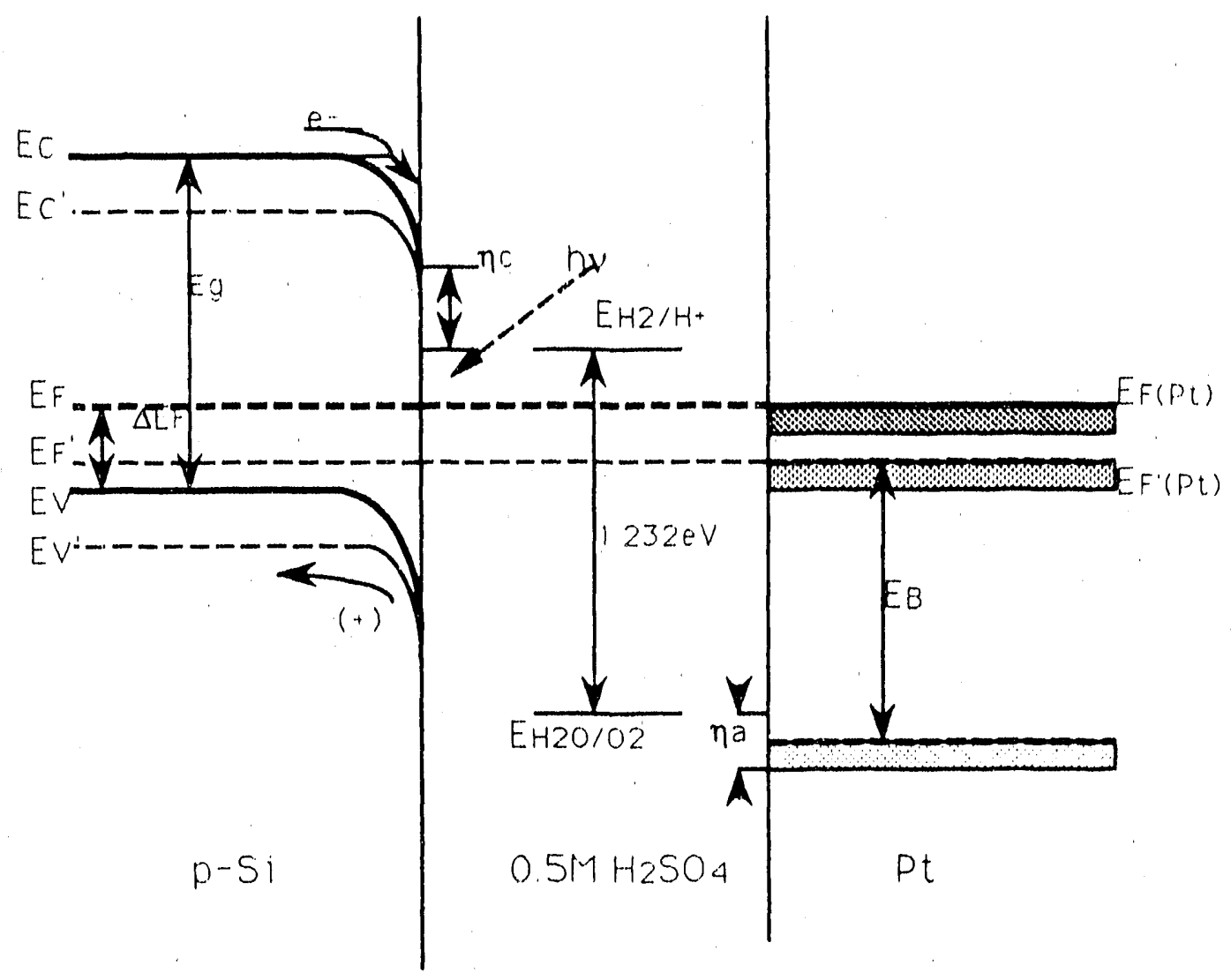

Figure 1. Schematic energy level diagram for Schottky-type photoelectrolysis cell using p-Si photocathode. $E_{C}, E_{V}$ and $E_{F}$ represent the energy levels of conductance band, valence band, and Ferml level of $p$-Si, while $E_{C}$, $E_{V^{\prime}}$, and $E_{F}$ show those levels under illumination, respectively. 


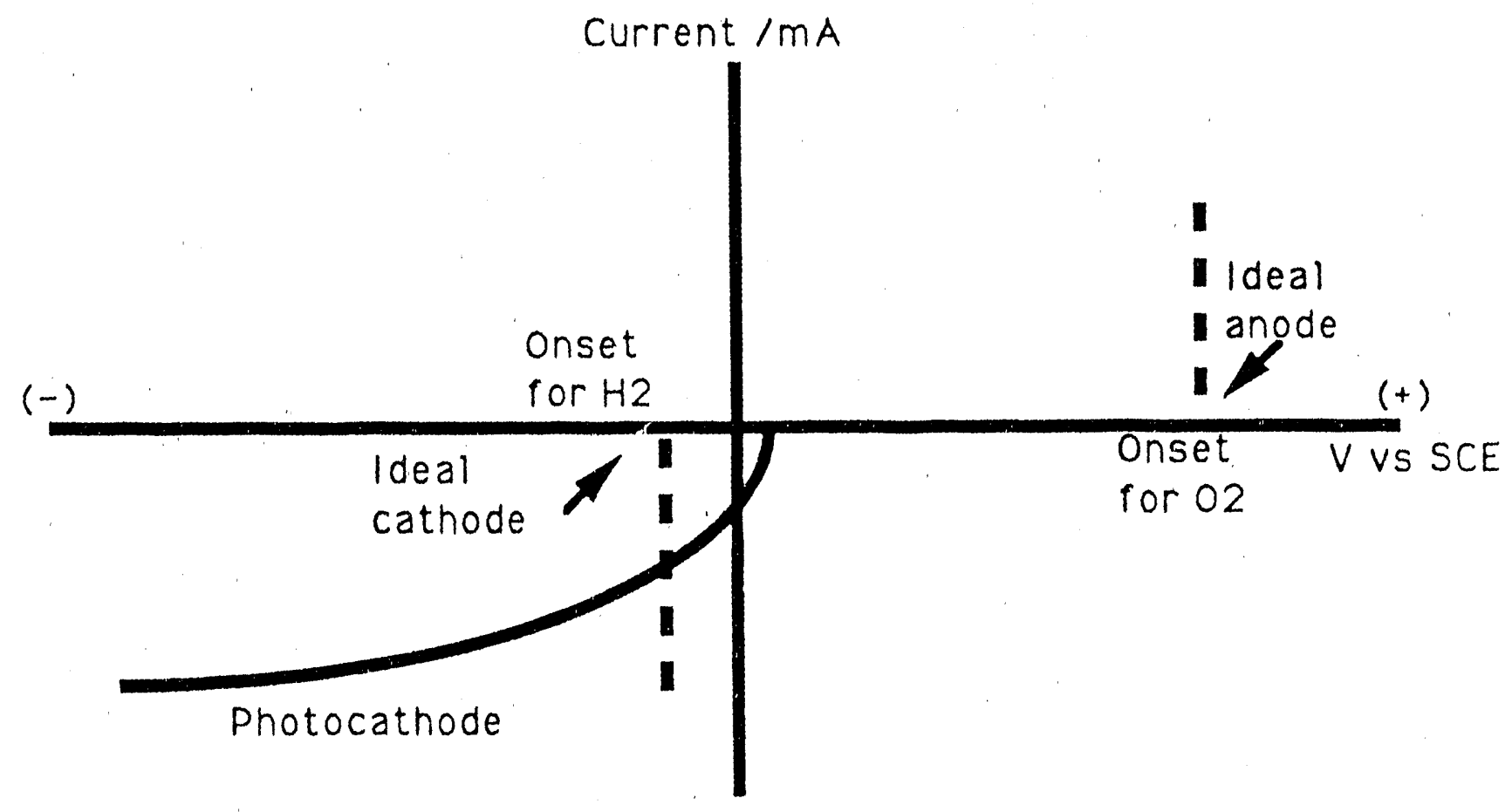

Figure 2. Current-voltage diagram for PEC cell operating with metal anode and photocathode 

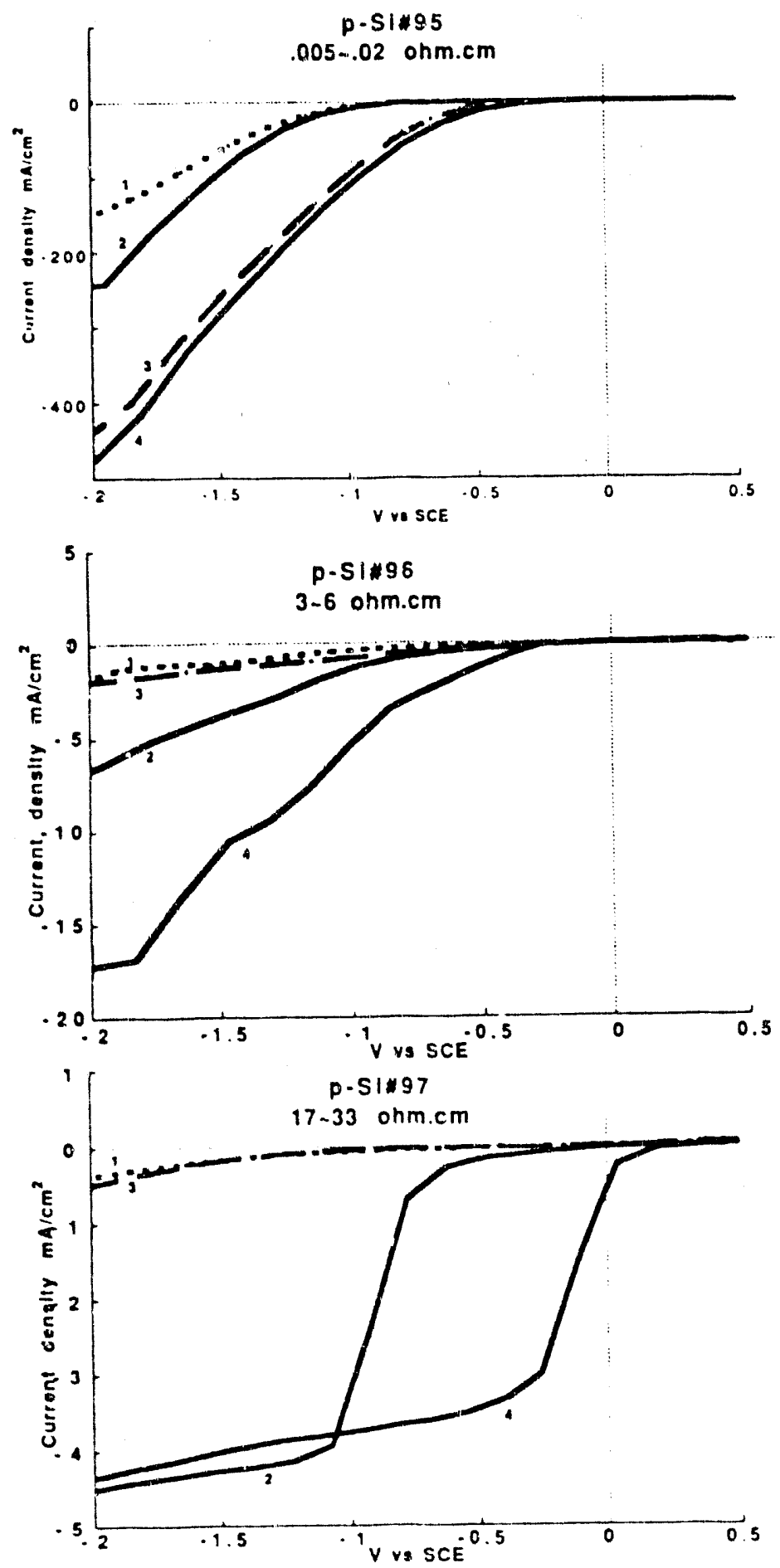

Figure 3. Current-voltage behavior for $\mathrm{p}$-Si photocathodes with different resistivities

(Curve 1: bare p-Si in dark,

Curve 2: bare $\mathrm{p}-\mathrm{SI}$ under $36 \mathrm{~mW} / \mathrm{cm}^{2}$ illum.,

Curve 3: platinized $\mathrm{p}$-Si in dark,

Curve 4: platinized p-Si under $36 \mathrm{~mW} / \mathrm{cm}^{2}$ illum.) 


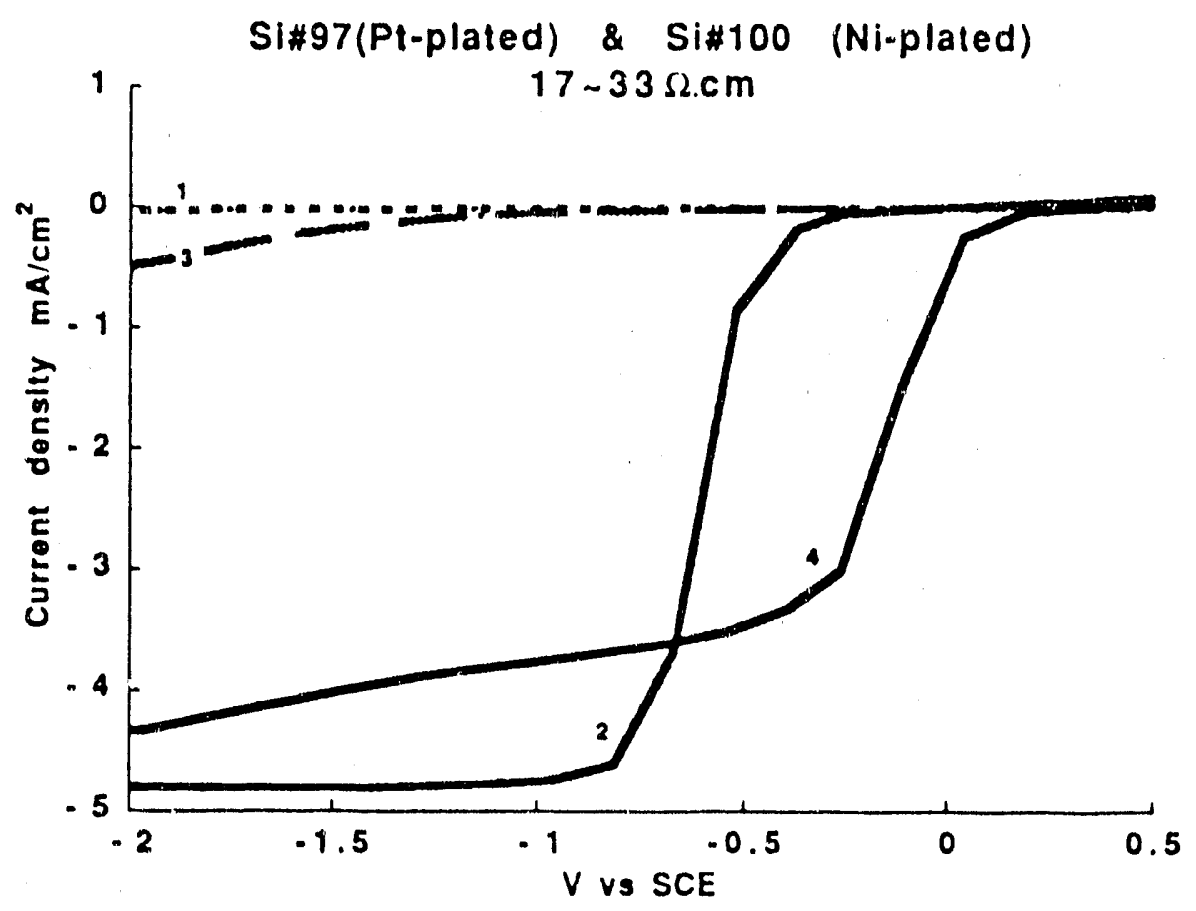

Figure 4. Comparison of current-voltage behavior for nickel and platinum coated photocathodes

(Curve 1: Ni-plated p-Si in dark,

Curve 2: Ni-plated $\mathrm{p}$-SI under $36 \mathrm{~mW} / \mathrm{cm}^{2}$ illum.,

Curve 3: Pt-plated p-Si in dark,

Curve 4: Pt-plated $\mathrm{p}$-Si under $36 \mathrm{~mW} / \mathrm{cm}^{2}$ illum.) 


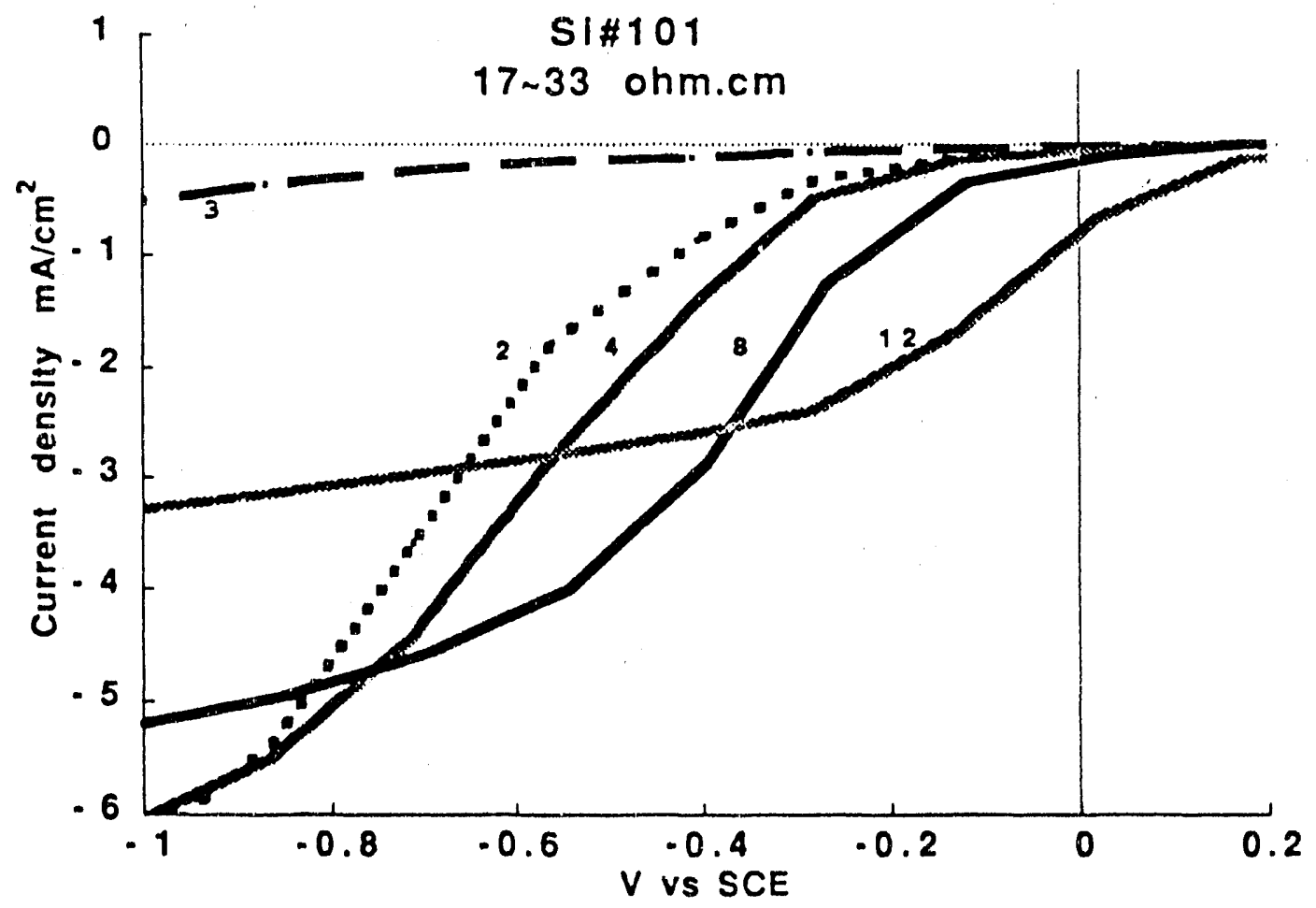

Figure 5. Effect of Pt thickness on current-voltage behavior of pSi photocathodes

(Curve 2: bare $\mathrm{p}-\mathrm{Si}$ under $36 \mathrm{~mW} / \mathrm{cm}^{2}$ illum.,

Curve 3: 1-cycle Pt/p-Si in dark,

Curve 4: 1-cycle $\mathrm{Pt} / \mathrm{p}$-Si under $36 \mathrm{~mW} / \mathrm{cm}^{2}$ illum.,

Curve 8: 5-cycle Pt/p-Si under $36 \mathrm{~mW} / \mathrm{cm}^{2}$ illum.,

Curve 12: 20-cycle Pt/p-Si under $36 \mathrm{~mW} / \mathrm{cm}^{2}$ illum.) 
p-SI \#113

$17 \sim 33$ ohm.cm

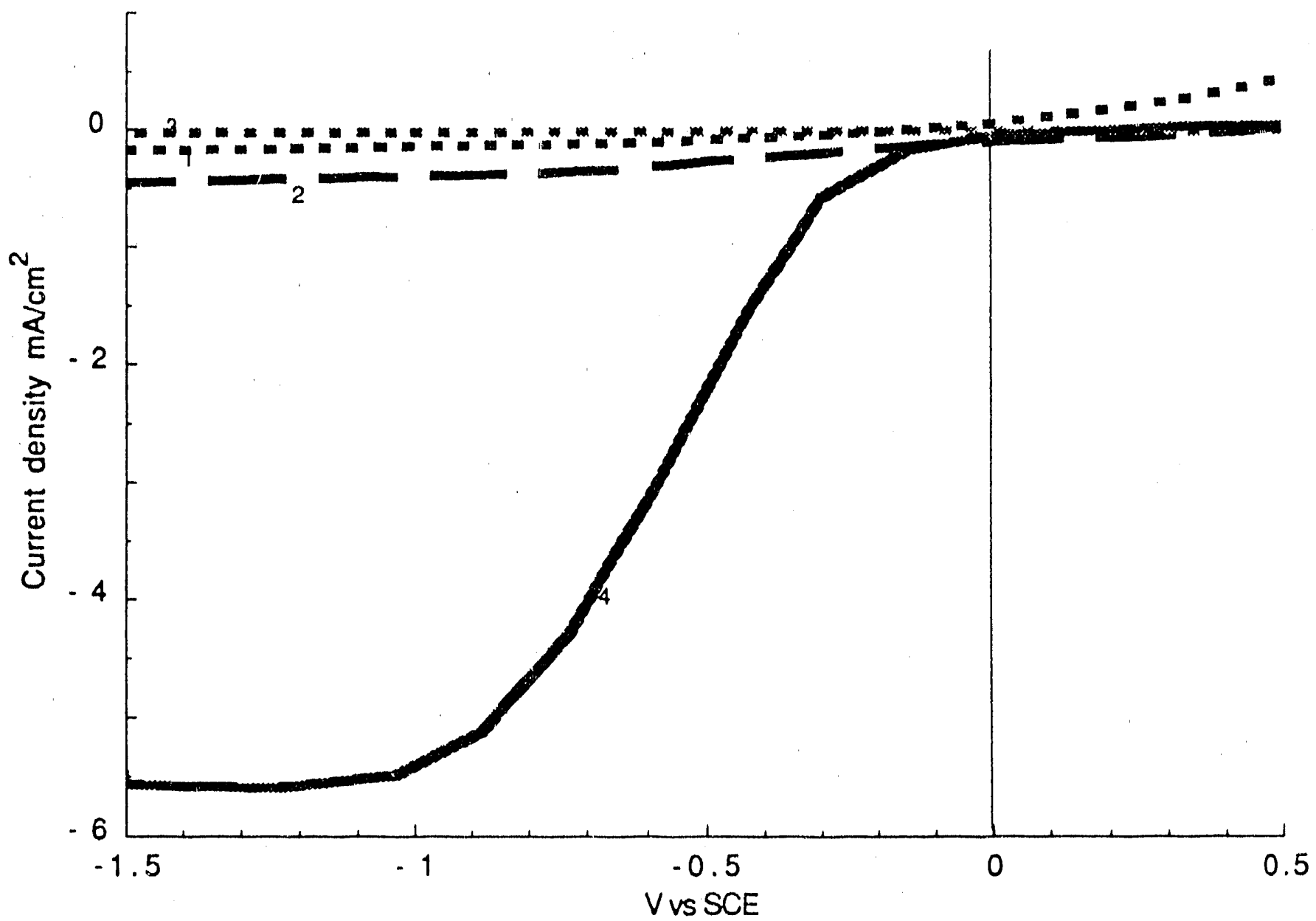

Figure 6. Current-Voltage behavior of $\mathrm{p}$-Si photocathode with sputtered Pt coating

(Curve 1: platinized $\mathrm{p}-\mathrm{Si}$ in dark,

Curve 2: platinized p-Si under $36 \mathrm{~mW} / \mathrm{cm}^{2}$ illum.,

Curve 3: platinized/alk-etched $\mathrm{p}$-Si in dark,

Curve 4: platinized/alk-etched $\mathrm{p}$-Si under $36 \mathrm{~mW} / \mathrm{cm}^{2}$ illum.) 


\title{
Task 2
}

PHOTOELECTROCHEMICAL PRODUCTION OF HYDROGEN

\author{
Subtask 2.3 \\ ASSESSMENT OF IMPEDANCE SPECTROSCOPY METHODS FOR \\ EVALUATION OF SEMICONDUCTOR-ELECTROLYTE INTERFACES
}

\author{
Subtask Leader: Bruce E. Liebert
}

\section{INTRODUCTION}

Impedance measurements have been proposed for characterization of III-V compound semiconductors to assess their performance in photoelectrochemical cells for the photoproduction of hydrogen. The impetus for this study was the difficulty in obtaining unambiguous flatband potentials on such advanced compound semiconductors as $\mathrm{Ga}_{\mathbf{x}} \mathrm{Al}_{1-\mathrm{x}} \mathrm{As}$ using traditional Mott-Schottky plots.

The first year of this task was devoted to the assessment of impedance methods used in the past, the subsequent analysis of the data, development of the necessary software to control the instrumentation, and the initiation of experimental work on p-type InP.

The second year of the project, which this report covers, continued the experimental work on the impedance of InP, modeling the results to appropriate equivalent circuits and determining the flatband potential in different electrolytes. Photoelectrochemical characterization of $\mathrm{GaInP}_{2}$ and $\mathrm{Ga}_{\mathrm{x}} \mathrm{Al}_{1-\mathrm{x}} \mathrm{As}$ was begun by Shyam Kocha, working closely with John Turner while Kocha was at SERI, using capacitance measurements, photocurrent spectroscopy, and photoreflectance to determine the flatband potential, position of band edges, and the direct and indirect bandgaps. The results will be compared to those obtained from impedance measurements at the University of Hawaii during year three.

\section{EXPERIMENTAL PROCEDURES}

\section{ELECTROCHEMICAL IMPEDANCE SPECTROSCOPY MEASUREMENTS}

The objectives and experimental procedures for the impedance measurements have been presented in last year's technical report. In addition to the Solartron 1286 potentiostat, an EG\&G 273 potentiostat with vendorsupplied impedance software was used for later samples. 


\section{CAPACITANCE MEASUREMENTS}

Capacitance measurements were performed with a PAR 173 potentiostat, 5204 lock-in analyzer, TEK FG501 function generator, DC504A counter/timer, DM5024 voltmeter, and TEK plotter. The data acquisition software

"AQCAPD" also plots and analyzes the data to determine the flatband potential and (apparent) doping density, which can be compared to that obtained from Hall measurements.

Indifferent electrolytes from $\mathrm{pH} 2.0$ to 12.0 were used in the absence of illumination at $100 \mathrm{~Hz}, 1 \mathrm{kHz}, 5 \mathrm{kHz}$, and $10 \mathrm{kHz}$. The perturbing potential was $20 \mathrm{mVpp}$. Based on the open circuit voltage, the applied potential was chosen to be slightly below the rest potential (for p-type samples) to reduce the possibility of pitting the sample's surface. The voltage scans ranged from the rest potential to $-1.0 \mathrm{~V}$ in steps of 25 to $50 \mathrm{mV}$. Some studies were performed with the sample under illumination at $600 \mathrm{~nm}$, with and without a redox couple. Forward and reverse scans were used to check for hysteresis.

\section{PHOTOCURRENT SPECTROSCOPY}

Photocurrent spectroscopy has been used to determine band gaps. The instrumentation consists of a tungsten-halogen $250 \mathrm{~W}$ lamp, a monochromator, a chopper, and a lock-in amplifier. The data acquisition software "PCURRS" is written in Fortran on an IBM PC. Scans can be obtained from 300 to $950 \mathrm{~nm}$ in steps of 1 or $2 \mathrm{~nm}$. A plot of photocurrent versus energy is readily obtained. The software also performs an analysis to determine the direct and/or indirect bandgap (if any).

\section{PHOTTOREFLECTANCE SPECTROSCOPY}

Photoreflectance spectroscopy can also be uired to determine the band gap. It has been used on a sample of $\mathrm{GaInP}$.

\section{PHOTODEPOSITION OF PLATINUM}

Platinum clusters were deposited on GaInP $\mathrm{P}_{2}$ surfaces to increase the efficiency of hydrogen evolution using various techniques. The best platinum films were obtained at low bias voltages with very low concentrations of Pt in the electrolyte. The deposition of $\mathrm{RuO}_{2}$ on $\mathrm{GaInP}_{2}$ was attempted using thermal decomposition at $120^{\circ} \mathrm{C}$; however, no indication of Ru was found on the surface. Higher temperatures $\left(300^{\circ}\right.$ to $\left.350^{\circ} \mathrm{C}\right)$ and different times will be attempted in the future. 


\section{EXPERIMENTAL RESULTS AND DISCUSSION}

\section{INDIUM PHOSPHIDE}

Mott-Schottky plots obtained from impedance spectroscopy measurements were determined at four $\mathrm{pH}$ values: $2.0,4.5,9.2$, and 12.0 . Linear plots were obtained, as displayed in Figure 1 for $\mathrm{pH} 9.2$. The flatband potential was found to vary by $60 \mathrm{mV} / \mathrm{pH}$ unit.

In general, InP has been found to be a well-behaved material in terms of its capacitance measurements, as displayed in Figures 2 and 3.

\section{GALLIUM INDIUM PHOSPHIDE}

Mott-Schottky plots, obtained from capacitance measurements, were quite linear and did not vary much with frequency. The resulting flatband potentials, for certain levels of the carrier concentration, lead to the possibility that water splitting may be feasible for this material. Compensated samples (first doped ntype and then p-type) resulted in nonlinear, frequency-dependent Mott-

Schottky plots. Different flatband potentials and apparent doping densities were obtained at different frequencies; therefore, these samples could not be characterized with any degrce of accuracy. The use of impedance spectroscopy methods on these samples will be started.

Photocurrent spectroscopy was performed over 600 to $750 \mathrm{~nm}$ and 600 to $950 \mathrm{~nm}$. As displayed in Figure 4, GaInP 2 was found to have a direct bandgap at about $1.825 \mathrm{eV}$ and indirect bandgap at $1.794 \mathrm{eV}$.

\section{GALLIUM ALUMINUM ARSENIDE}

Capacitance measurements of $\mathrm{Ga}_{\mathbf{x}} \mathrm{Al}_{1-\mathrm{x}} \mathrm{As}$ showed that Mott-Schottky plots were linea: at higher biases but tended to be nonlinear at lower biases and at higher values of $\mathrm{pH}$. As dispiayed in Figure 5, at a $\mathrm{pH}$ of 12, the plots were nonlinear over most of the range from 0 to $-1.0 \mathrm{~V}$ and thus were hard to characterize with any degree of accuracy. Some frequency dependence was obscrved as well as hysteresis on reverse scanning. This behavior is attributed to aluminum behaving as an amphoteric ion and forming various oxides. This material should be a prime candidate for future application of impedance spectroscopy in order to obtain linear Mott-Schottky plots.

Photocurrent spectroscopy has just begun on $\mathrm{Ga}_{\mathbf{x}} \mathrm{Al} \mathrm{l}_{1-\mathrm{x}} \mathrm{As}$ and the results are now being interpreted. There seems to be a background current due to the GaAs substrate. 


\section{SINGLE-QUANTUM-WELL $\mathrm{Ga}_{\mathbf{x}} \mathrm{Al}_{1-\mathrm{x}} \mathrm{As}$}

Mott-Schottky plots were obtained that are linear over most of the voltage range at low $\mathrm{pH}$; however, as displayed in Figure 6, at higher $\mathrm{pH}$ values, there was a greater frequency dependence and some nonliner rity at biases very close to the o.c. potential.

\section{GALLIUM ARSENIDE}

The flatband potential of gallium arsenide samples, grown by MOCVD techniques, was determined in aqueous solutions from $\mathrm{pH} 2.0$ to 12.0. A potassium ferrocyanide/ferricyanide redox couple was used to improve the linearity of Mott-Schottky plots.

Hysteresis was found in some samples and, in general, GaAs electrodes were not very stable in the solution and were relatively hard to characterize.

\section{SUMMARY}

A wide variety of experimental techniques has been used to investigate the photoelectrochemical properties of a number of III-V compound semiconductors. Of particular importance to the project during year two was the opportunity for Shyam Kocha to work with Art Nozik's group at SERI to develop the necessary expertise in techniques other than electrochemical impedance spectroscopy. This information will be essential when impedance techniques are used to characterize those materials that show nonlinear Mott-Schottky plots.

Besides providing linear and frequency independent Mott-Schottky plots, impedance techniques may also provide useful information on the electrodeelectrolyte interface such as the presence of surface states. Thus impedance meth $\approx$ ds for photoelectrochemical characterization will be able to provide important feedback to researchers interested in III-V semiconductors for the photoproduction of hydrogen. 


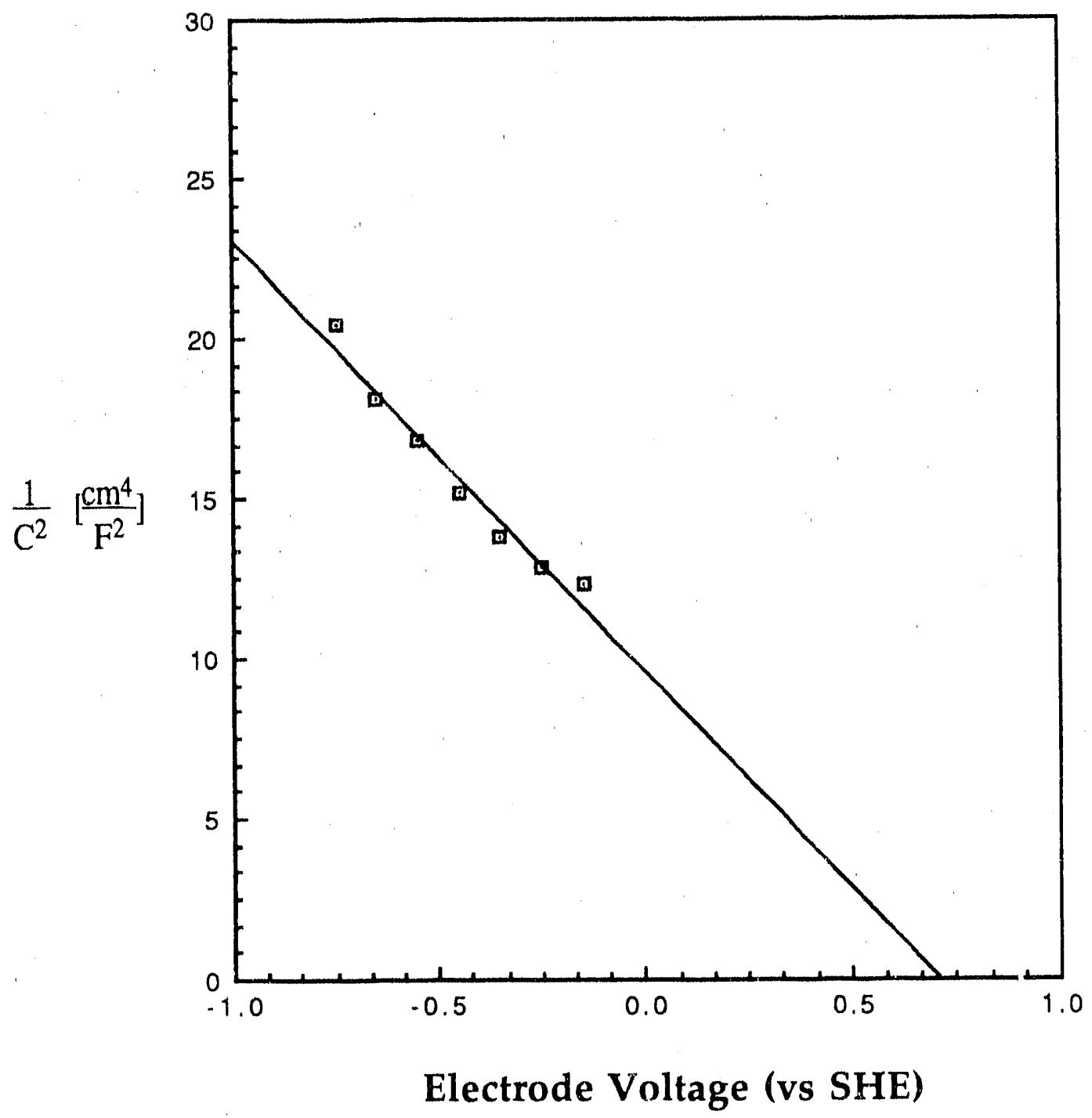

Figure 1. The Mott-Schottky plot for $\ln P[111]$ in $1 \mathrm{M} \mathrm{KCl}+0.1 \mathrm{M}$ $\mathrm{Na}_{2} \mathrm{~B}_{4} \mathrm{O}_{7}(\mathrm{pH}:=9.2$ ) obtained from impedance spectroscopy 


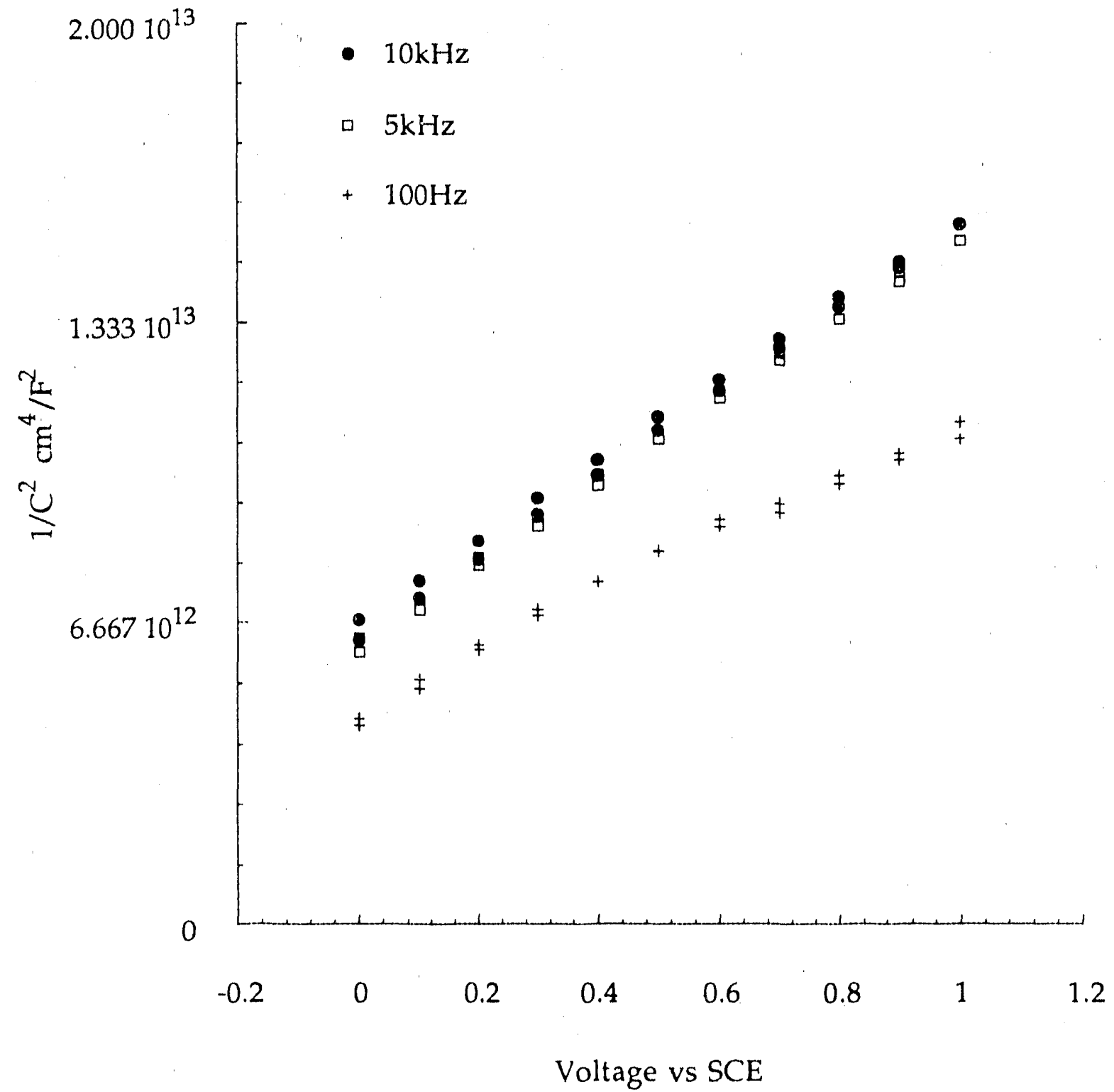

Figure 2. Mott-Schottky plots on $n$-InP obtained from capacitance measurements at 1,5 , and $10 \mathrm{kHz}$ at $\mathrm{pH}=2$ 


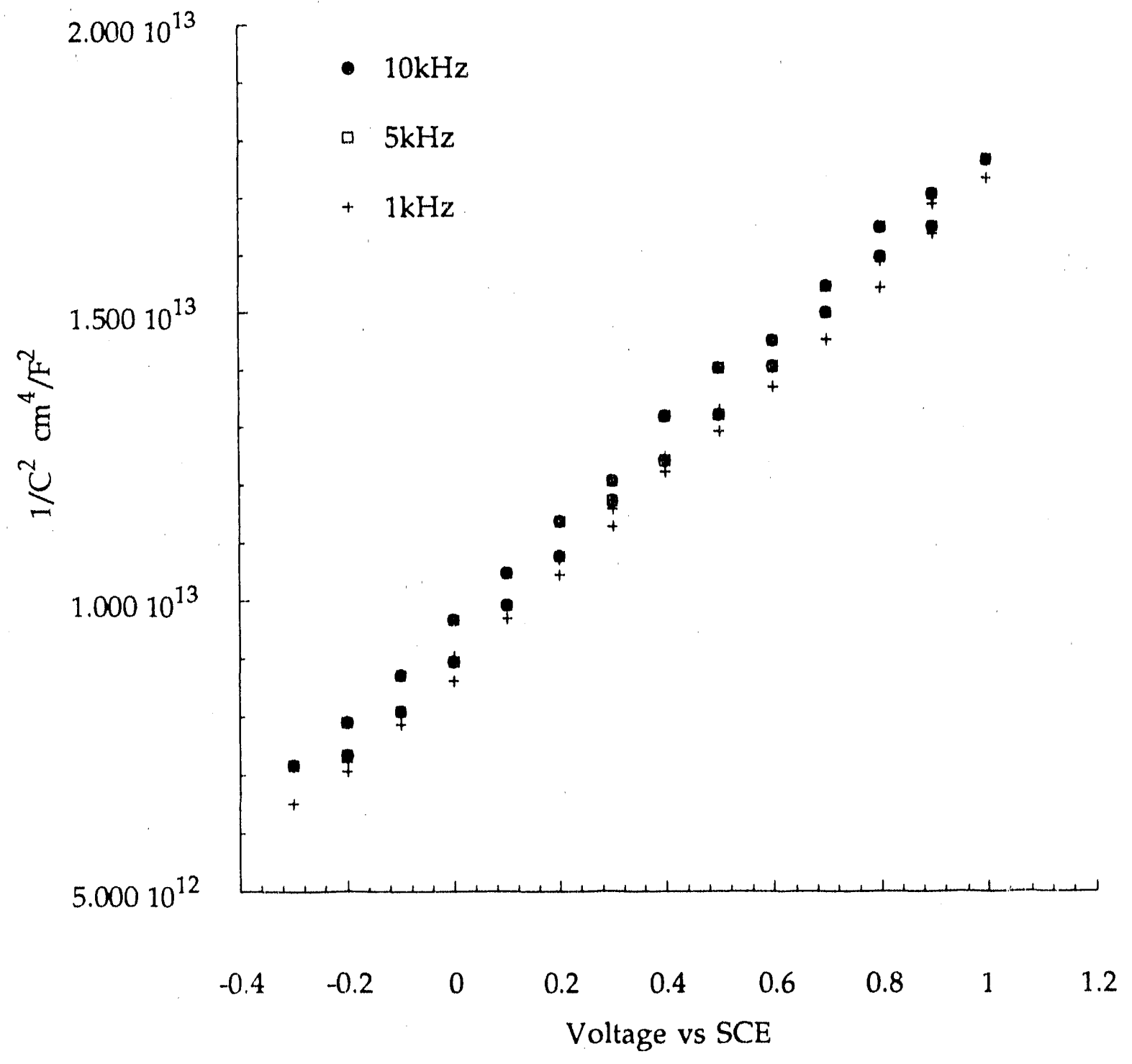

Figure 3. Mott-Schottky plots on $n$-InP obtained from capacitance measurements at 1,5 , and $10 \mathrm{kHz}$ at $\mathrm{pH}=12$ 
Photocurrent inalyedo

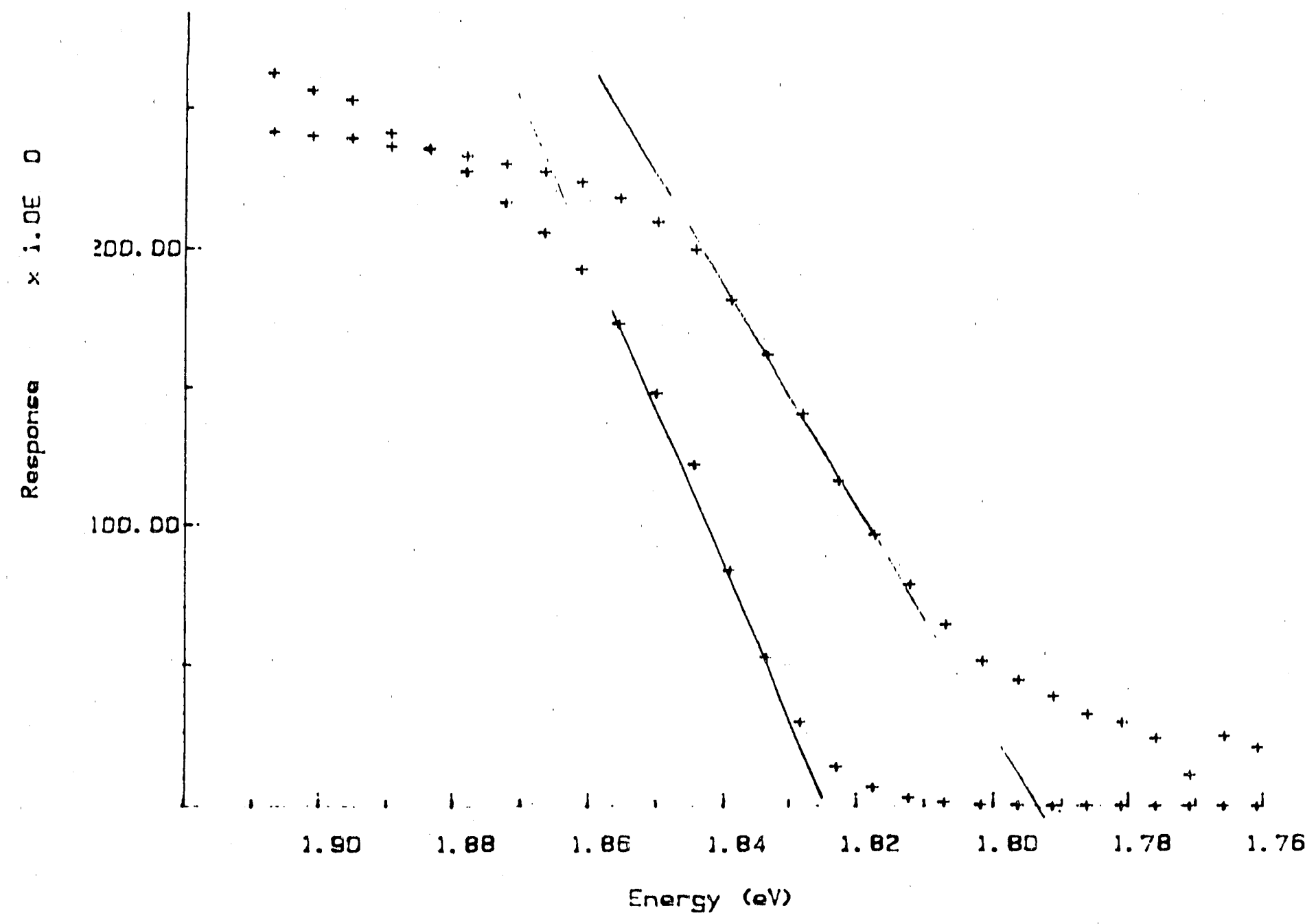

Figure 4. Photocurrent spectroscopy of Galn $\mathrm{P}_{2}$ showing both a direct bandgap at $1.825 \mathrm{eV}$ and an indirect bandgap at $1.794 \mathrm{eV}$ 


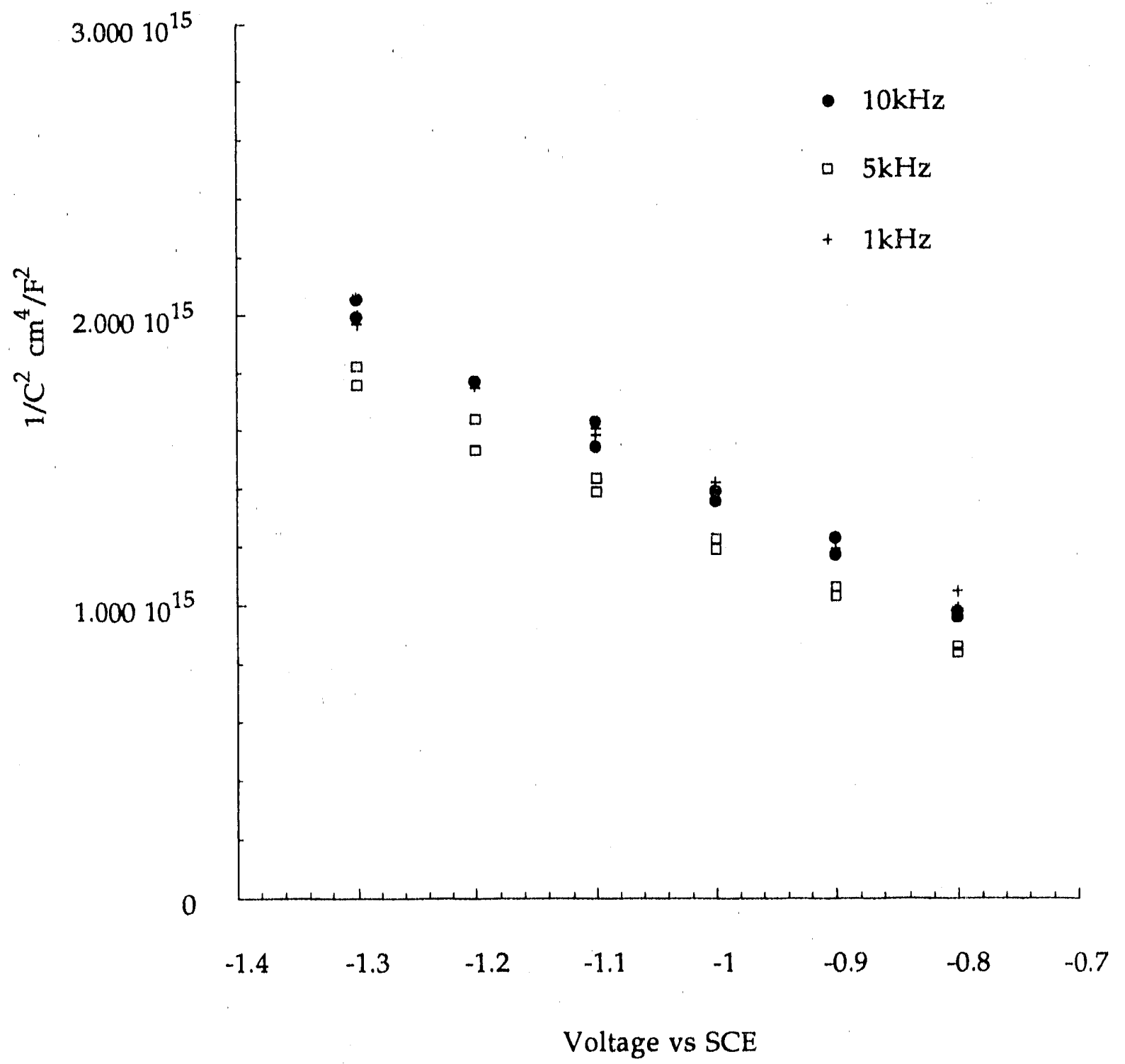

Figure 5. Mott-Schottky plots on $\mathrm{Ga}_{\mathrm{x}} \mathrm{A} \mathrm{I}_{1-\mathrm{x}} \mathrm{As}$ obtained from capacitance measurements at 1,5 , and $10 \mathrm{kHz}$ at $\mathrm{pH}=$ 12. The nonlinearity makes determination of the flatband potential difficult. 


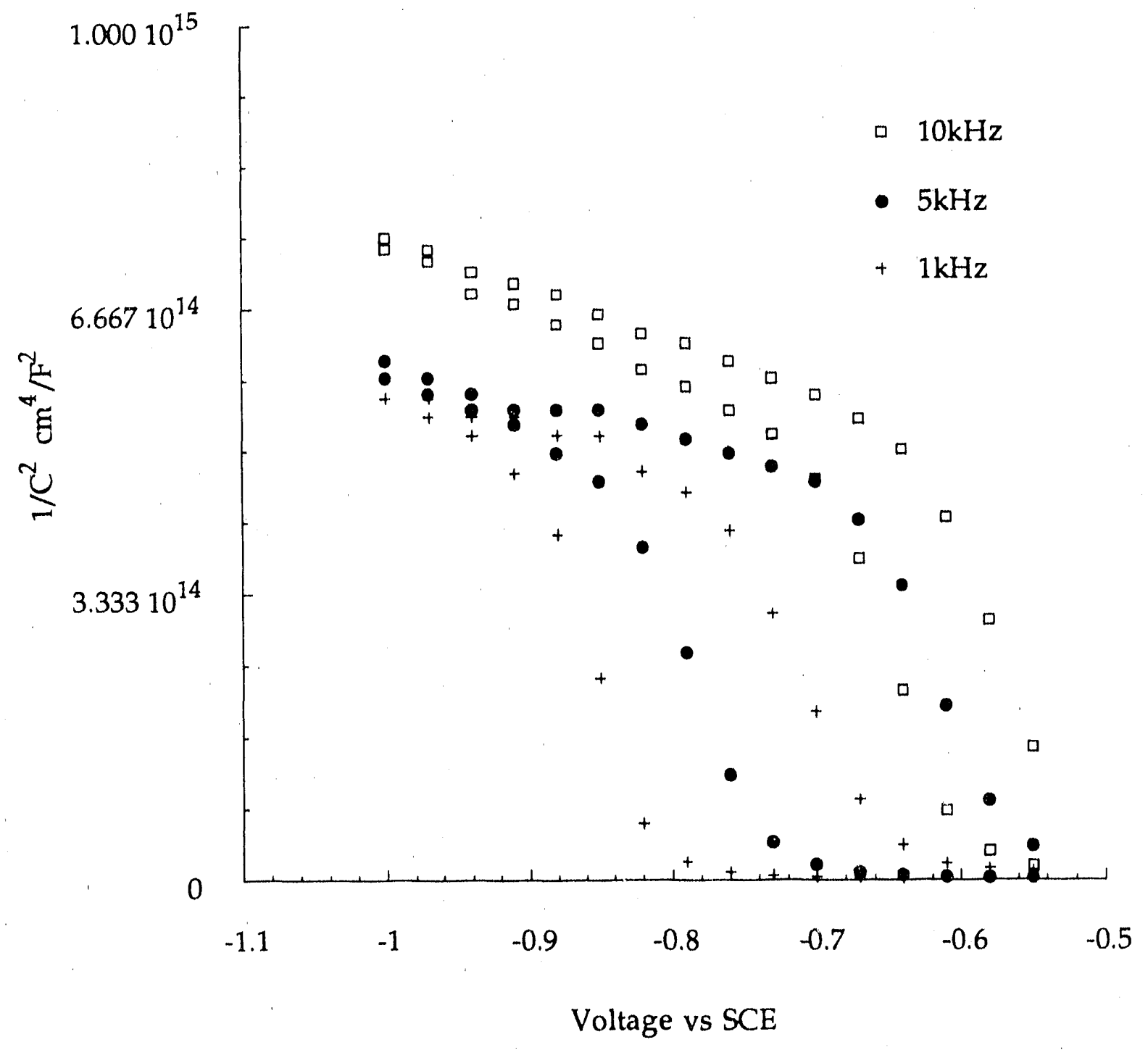

Figure 6. Mott-Schottky plots on single-quantum-well $\mathrm{Ga}_{x} \mathrm{Al} \mathbf{1}_{1-x} \mathrm{As}$ obtained from capacitance measurements at 1,5 , and 10 $\mathrm{kHz}$ at $\mathrm{pH}=12$. The nonlinearity makes determination of the flatband potential difficult. 


\section{Task 3 \\ SOLAR ENERGY CONVERSION WITH CYANOBACTERIA}

Task Co-Leaders: Edward J. By'ina and Suresh S. Patil

\section{INTRODUCTION}

Hydrogen production in cyanobacteria is particularly attractive because these organisms are able to generate their own source of organic substrates using light energy and use water as their ultimate source of reductant. Three basic enzyme systems are involved in hydrogen metabolism in cyanobacteria: nitrogenase, uptake nitrogenase, and reversible hydrogenase [1].

Nitrogenase, which is rapidly inactivated by oxygen, catalyzes the reduction of protons to hydrogen in both heterocystous and non-heterocystous organisms. Evolution of hydrogen by nitrogenase always accompanies nitrogen fixation. The formation of heterocysts allows organisms with these specialized cells to fix nitrogen under aerobic conditions, while most non-heterocystous organisms capable of nitrogen fixation can do so only under anaerobic conditions $[2,3]$. However, aerotic hydrogen fixation has apparently been observed in a limited number of non-heterocystous cyanobacteria $[3,4,5]$.

Uptake hydrogenase is found almost exclusively in heterocysts $[6,7]$, is typically membrane-bound in cyanobacteria [8], and functions to recapture hydrogen produced by nitrogenase. While the role of the reversible hydrogenase is presently unclear, it is probably also involved in hydrogen uptake. This enzyme is present in both non-heterocystous organisms and the vegetative cells of heterocystous cyanobacteria $[1,9]$. Immunochemical analysis [9] conflicts with earlier results which indicated that this enzyme is present in heterocysts. The reversible hydrogenase appears to be associated with the cytoplasmic membrane [10]. This soluble hydrogenase has been purified from Anabaena cylindrica [11] and consists of a $42 \mathrm{kDa}$ subunit and a $50 \mathrm{kDa}$ subunit. The gene encoding the $42 \mathrm{kDa}$ subunit has been cloned and sequenced [12].

Tu capitalize on this photosynthetic production of hydrogen, one must gain a better understanding of the mechanisms and regulation of the systems involved. This is especially important in riew of the fact that hydrogenase. mediated recapture of hydrogen appears to be one of the limiting factors on the evolution of hydrogen gas in cyanobacteria. While much attention has been directed at the nitregenase system in cyanobacteria, the hydrogenase systems have not been characterized as well. Hydrogenases have been purified to varying degrees of homogeneity and studied from a number of cyanobacteria $[8,10,1]$, 13], but molecular biological studies of cyanobacterial hydrogenase systems are only beginning. Hydrogenase genes have been isolated and sequenced from a number of other bacteria, including Bradyrhizobium ;aponicum [14], Desulforibrio gigas [15], Desulforibrio baculatus [16!, and Rbodobacter 
capsulatus [17]. These genes may be useful in the identification of the genes for the cyanobacterial uptake hydrogenases.

Anabaena sp. strain PCC 7120 (ATCC 27893) is a well-characterized heterocystous cyanobacteria which can serve as a model system for hydrogen metabolism. Both uptake and reversible hydrogenases have been partially purified from this organism $[6,8]$. A large number of genes from this organism have been cloned and sequenced, including many genes inyolved in nitrogen metabolism and heterocyst formation. Anabaena sp. PCC 7120 is amenable to genetic manipulation. DNA transfer via conjugation [18] into this organism has been developed. Shuttle vectors, capable of replication and selection in both $E$. coli and Anabaena, have been constructed [19]. Site-directed inactivation of genes in the Anabaena sp. PCC 7120 chromosome has been demonstrated [20]. A technique for positive selection of these double recombinants in the Anabaena chromosome has been developed [21]. These genetic tools facilitate the use of this Anabacna species as a model for the study of the molecular biology of cyanobacterial hydrogen production.

In our last report, heterologous hybridization experiments were described identifying DNA fragments from Anabaena sp. PCC 7120 which specifically hybridized to the structural genes of the $B$. japonicum uptake hydrogenase. In this report we describe the further characterization of these fragments, along with our other efforts to identify the uptake hydrogenase genes in Anabaena sp. PCC 7120 .

\section{RESULTS AND DISCUSSION}

While the overall protein sequence homology between the hydrogenases that have been characterized $[14-17]$ is rather low, conserved regions are observed in the small and large subunits of these hydrogenases. Th $\cdots$ sequence Gly-Cys-Lys-Gly-Pro is conserved among the small subunits. Among the large subunits, several sequences are conserved. These include: (1) His-Phe-TyrHis-Leu-(His/Ala)-Ala-Leu-Asp, (2) Arg-Ile-Cys-Gly-Val-Cys, and (3) GlyArg-Asp-Pro-Arg-Asp. Oligonucleotides were designed based on these protein sequences (Figure l). In an effort to confirm the results of the heterologous hybridization experiments, these: oligonucleotides were then used as hybridization probes against restriction digests of the Anabaena chromosome. Chromosomal DNA fragments were transferred to nylon membranes (GeneScreenPlus, NEN) by the method of Southern [22] after restriction endonuclease digestion and agarose gel electrophoretic separation of the Anabaena DNA. Polynucleotide kinase was used to radiolabel the oligonucleotides. The large subunit probe (OLIGO 2) hybridized to a $9-\mathrm{kb}$ HindIII fragment, similar to the results observed for the B. japonicum probe. The small subunit probe (OLIGO 1) hybridized to several Anabaena frayments (including a $2.1 \mathrm{~kb}$ HindIII fragment), however, no hybridization to DNA fragments in the size range observed with the B. japonicum probe was observed with this oligonucleotide. 


\begin{tabular}{|c|c|c|c|c|}
\hline $\begin{array}{r}\text { OLIGO } 1 \\
5^{\prime}-\text { GGG } \\
\text { A } \\
T \\
\mathrm{C}\end{array}$ & $\underset{T}{T G C} A A G$ & $\begin{array}{r}\text { GGG } \\
\mathrm{A} \\
\mathrm{T} \\
\mathrm{C}\end{array}$ & CC - - $3^{\prime}$ & $\begin{array}{l}\text { Sense oligonucleotide } \\
\text { corresponding to the conserved } \\
\text { small subunit sequence } \\
\text { Gly-Cys-Lys-Gly-Pro }\end{array}$ \\
\hline $\begin{array}{l}\text { OLIGO } 2 \\
5^{\prime}-\quad \text { GCA } \\
\text { A }\end{array}$ & $\begin{array}{ll}\text { GAC } & \text { GCC } \\
A & A \\
T & T \\
C & C\end{array}$ & $\begin{array}{l}\text { GCA } \\
A\end{array}$ & $\begin{array}{l}\text { GAT }-3^{\prime} \\
\mathrm{A} \\
\mathrm{T}\end{array}$ & $\begin{array}{l}\text { Antisense oligonucleotide } \\
\text { corresponding to the conserved } \\
\text { large subunit sequence } \\
\text { Arg-Ile-Cys-Gly-Val-Cys }\end{array}$ \\
\hline
\end{tabular}

Figure 1. Degenerate oligonucleotides based on conserved hydrogenase sequences

The oligonucleotide probe (OLIGO 2) was then used to probe the limited Anabaena chromosomal DNA library constructed to identify the DNA fragment hybridizing to the $B$. japonicum probe. This library contains Anabaena DNA HindIII fragments of approximately $9 \mathrm{~kb}$ in length contained in a palindromecontaining positive selection [23] cloning vector. One of these plasmids (PLASMID 1) hybridized strongly to the oligonucleotide, but hybridized only weakly to the B. japonicum probe. A second plasmid (PLASMID 2) hybridized much more strongly to the $B$. japonicum probe, but showed no hybridization with OLIGO 2. Both of these plasmids were purified on a CsCl-density gradient and characterized further.

After digesting DNA from PLASMID $\mathrm{l}$ with HindIII, the $9-\mathrm{kb}$ insert DNA fragment was recevered from a preparative agarose gel by electroclution [24]. This purified DNA fragment was used as the template in a primer-extension experiment, using OLIGO 2 as the oligonucleotide primer. This experiment indicated that the primer binds approximately $500 \mathrm{bp}$ from one of the HindIII sites of the 9-kb DNA fragment. A unique 3-kb HindIII-EcoRV fragment isolated from this insert hybridizes to OLIGO 2 and was cloned into Ml 3 for sequencing by the dideoxy-method [25]. The fragment was cloned into Ml3 in both orientations, in order to use OLIGO 2 as a sequencing primer in one direction and the Ml 3 universal sequencing primer from the end of the fragment in the other direction. The sequencing results are summarized as follows:

(1) Readable sequence could not be obtained using OLIGO 2 as primer. This is probably due to the short length (15 nucleotides) and degeneracy (192-fold) of the oligonucleotide.

(2) Using the Ml3 universal sequencing primer, the sequence of the $300 \mathrm{bp}$ at the end of the insert was determined. No open reading. frame of any considerable length was observed in any of the three 
reading frames. This suggests that the structural gene of the uptake hydrogenase is not present on PLASMID 1.

Analysis of PLASMID 2 indicated that a $3-\mathrm{kb}$ EcoRV fragment in the insert of this plasmid contains the DNA which specifically hybridizes to a probe consisting of the B. japonicum uptake hydrogenase structural genes. This fragment has been isolated from a preparative agarose gel and cloned into Ml 3 for sequence analysis. Single stranded phage DNA containing the 3-kb EcoRV fragment has been isolated. Characterization of this DNA fragment is currently in progress to determine whether the structural genes of the uptake hydrogenase are present on this fragment.

\section{REFERENCES}

1. Houchins, J. P. 1984. Biochim. Biophys. Acta. 768:227.

2. Rippka, R., J. Deruelles, J. B. Waterbury, M. Herdman, and R. Y. Stanier. 1979. J. Gen. Microbiol. 111:1.

3. Rippka, R. and J. B. Waterbury. 1977. FEMS Microbiol. Lett. 2:83.

4. Pearson, H. W., R. Howsley, C. K. Kjeldsen, and A. E. Wolsby. 1979. FEMS Microbiol. Lett. 5:163.

5. Carpenter, E. J. and C. C. Price. 1.976. Science 191:1278.

6. Houchins, J. P. and R. H. Burns. 1981. J. Bacteriol. 146:209.

7. Peterson, R. B. and C. P. Wolk. 1978. Plant Physiol. 61:688.

8. Houchins, J. P. and R. H. Burns. 1981. J. Bacteriol. 146:215.

9. Ewart, G. D. and G. D. Smith. 1989. Biochim. Biophys. Acta. 997:83.

10. Kentemich, T., M. Bahnweg, F. Mayer, and H. Bothe. 1989. Z. Naturforsch. 44c:384.

11. Ewart, G. D. and G. D. Smith. 1989. Arch. Biochem. Biophys. 268:327.

12. Ewart, G. D., K. C. Reed, and G. D. Smith. 1990. Eur. J. Biochem. $187: 215$.

13. Rao, K. K. and D. O. Hall. 1988. Methods Enzymol. 167:501.

14. Sayaredra-Soto, L. A., G. K. Powell, H. J. Evans, and R. O. Morris. 1988. Proc. Natl. Acad. Sci. USA 85:8395.

15. Li, C., H. D. Peck, J. LeGall, and A. E. Przybyla. 1987. DNA 6:539. 
16. Menon, N. K., H. D. Peck, J. LeGall, and A. E. Przybyla. 1987. J. Bacteriol. 169:5401.

17. Leclerc, M., A. Colbeau, B. Cauvin, and P. M. Vignais. 1988. Mol. Gen. Genet. 214:97.

18. Thicl, T. and C. P. Wolk. 1987. Methods Enzymol. 153:232.

19. Wolk, C. P., A. Vonshak, P. Kehoe, and J. Elhai. 1984. Proc. Natl. Acad. Sci. USA 81:1561.

20. Golden, J. W. and D. R. Wiest. 1988. Science 242:1421.

21. Cai, Y. and C. P. Wolk. 1990. J. Bacteriol. 172:3138.

22. Southern, E. 1975. J. Mol. Biol. 98:503.

23. Elhai, J. and C. P. Wolk. 1988. Gene. 68:119.

24. Maniatis, T., E. F. Fritsch, and J. Sambrook. 1982. Molecular Cloning: a Laboratory Manual. Cold Spring Harbor Laboratory. Cold Spring Harbor, New York.

25. Sanger, F., S. Nicklen, and A. R. Coulson. 1977. Proc. Natl. Acad. Sci. USA 74:5463. 


\title{
Task 4 \\ NONCLASSICAL POLYHYDRIDE METAL COMPLEXES AS HYDROGEN STORAGE MATERIALS
}

Task Leader: Craig Jensen

\begin{abstract}
Metal hydrides are a promising method of improved hydrogen storage. Application of elemental metals and alloys to hydrogen storage has been restricted by the low available hydrogen content and/or the dynamic behavior of these materials. An alternate class of metal hydrides, nonclassical polyhydride metal complexes, have potential as hydrogen materials. In our laboratory we have recently synthesized and characterized novel cobalt group nonclassical polyhydride complexes. These complexes have shown promising hydriding/dehydriding behavior. During the last year we have studied the reversible elimination of $\mathrm{H}_{2}$ from the iridium polyhydride complexes by ${ }^{31} \mathrm{P}$ NMR spectroscopy. In collaborative research efforts we have advanced our understanding of the metal- $\mathrm{H}_{2}$ interaction through inelastic neutron scattcring experiments and extended Hückel calculations. We have also initiated an effort to synthesize nonclassical polyhydride iron complexes stabilized by a single $\eta^{5}$. cyclopentadienyl ligand and have succeeded in isolating and characterizing an iron half sandwich hydride complex.
\end{abstract}

\section{INTRODUCTION}

A major concern in the development of hydrogen as a fuel is the problem of hydrogen storage. Hydrogen has traditionally been stored as a compressed gas or cryogenic liquid. The disadvantages of cylinder storage are the extreme pressure, weight, and volume requirements. Storage of hydrogen as a cryogenic liquid is unattractive due to the requirements of extremely low temperatures and high consumption of primary energy. Additionally, both traditional storage methods entail considerable safety risks. Storage of hydrogen as metal hydrides is safer and requires far less volume than its storage as a cryogenic liquid or a compressed gas. Unfortunately, metals and alloys of adequate hydriding/ dehydriding behaviors generally contain less than 1.0 weight per cent hydrogen, and, as a result, the weight of hydrogen systems based on traditional metal hydrides severely restricts their practical application [1]. Although alloys such as iron-titanium have shown acceptable kinetic behavior and can attain up to 2.00 weight per cent hydrogen, their utilization for hydrogen storage is extremely limitcd due to other problems such as high sensitivity to impurities [2]. Elemental metals and alloys may eventually find limited commercial hydrogen storage applications, but it would appear that a new class of materials must bc developed to allow utilization of hydrogen as an energy carrier. 
We have proposed the examination of an alternate class of metal hydrides, nonclassical polyhydride complexes, as hydrogen storage materials.

Polyhydride metal complexes can attain relatively high (5\%) weight per cent available hydrogen contents, however, classical polyhydride complexes gencrally undergo irreversible dihydrogen elimination. Recently, a new class of metal hydride complexes in which hydrogen bonds to the metal center while retaining a significant amount of $\mathrm{H}-\mathrm{H}$ bonding have been recognized [3].

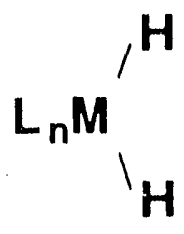

Classical Metal
Hydride Complex

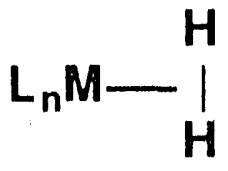

Nonclassical (Molecular Hydrogen) Complex

In most cases these nonclassical hydride or molecular hydrogen complexes have been found to undergo complete and reversible loss of $\mathrm{H}_{2}$ under mild conditions.

In our laboratory we have recently synthesized and characterized novel cobalt group nonclassical polyhydride complexes of the formula $\mathrm{MH}_{\mathrm{a}}\left(\mathrm{H}_{2}\right)_{\mathrm{b}}$ $\left(\mathrm{PR}_{3}\right)_{\mathrm{c}} \mathrm{Cl}_{\mathrm{d}}\left(\mathrm{M}=\mathrm{Co}, \mathrm{Ir}, \mathrm{Rh} ; \mathrm{R}=\mathrm{C}_{6} \mathrm{H}_{5}, \mathrm{C}_{6} \mathrm{H}_{11}, \mathrm{C}\left(\mathrm{CH}_{3}\right)_{3}, \mathrm{CH}\left(\mathrm{CH}_{3}\right)_{2} ; \mathrm{a}=1-2\right.$, $b=1-3, c=2-3, d=1-2)$. These complexes, which contain up to $1.6 \%$ available hydrogen, have shown promising hydriding/dehydriding behavior. The kinetics of the hydriding/dehydriding process of these materials in a given temperature range can be fine tuned by small changes in the ligands.

During the past year we have continued our studies of the reversible elimination of $\mathrm{H}_{2}$ from the prototypical iridium complexes. Additionally, we have participated in collaborative theoretical and neutron scattering studies to further elucidate the nature of the metal-dihydrogen interaction in these complexes. This year we have also initiated efforts to synthesize a novel class of iron polyhydride complexes which should have the same desirable hydriding/ dehydriding kinetic properties as the prototypical iridium complexes while containing greater weight per cent available hydrogen content.

\section{RESULTS}

\section{IRIDIUM NONCLASSICAL POLYHYDRIDE COMPLEXES}

We previously raported the results of our studies of the reversible elimination of $\mathrm{H}_{2}$ from the iridium dihydrogen complexes (Equation l) through 
both variable temperature ${ }^{1} \mathrm{H}$ NMR spectroscopy in solution and infrared spectroscopy of the complexes in the solid state [4]. In the past year we have investigated this phenomenon by variable temperature $31 \mathrm{P}$ NMR spectroscopy. Variable tempcrature ${ }^{31} \mathrm{P}\left({ }^{1} \mathrm{H}\right\}$ NMR spectra of a sample $\underline{2}$ under $0.5 \mathrm{~atm}$ of $\mathrm{H}_{2}$ in toluene- $\mathrm{d}_{8}$ are displayed in Figure 1 . At room temperature a broad $\left(\omega_{1 / 2}=30\right.$ $\mathrm{Hz}$ ) resonance is observed at $43 \mathrm{ppm}$. As the temperature is lowered, the resonance is seen to broaden due to the slowing of the exchange process until the coalescence temperature of $-25^{\circ} \mathrm{C}$ is reached. From this coalescence temperature, a $\Delta \mathrm{G} \dagger$ of $10,3 \mathrm{kcal} / \mathrm{mole}$ can be calculated, which is in good agreement with our earlier data from ${ }^{1} \mathrm{H}$ NMR spectroscopy. Below $-25^{\circ} \mathrm{C}$, separated resonances are clearly observed for the equilibrating species 1 and $\underline{2}$ at 53 and $37 \mathrm{ppm}$ respectively. Unlike the resonance observed for $\underline{2}$ by low temperature ${ }^{1} \mathrm{H}$ NMR spectroscopy, the resonance seen for $\underline{2}$ by $31 \mathrm{P}$ NMR spectroscopy continues to sharpen with decreasing temperature of $-95^{\circ} \mathrm{C}$ freezing limit of toluene- $\mathrm{d}_{8}$ since the chemical environmental of the phosphorous is unchanged by the exchanging $\mathrm{H}_{2}$ and hydride ligands.
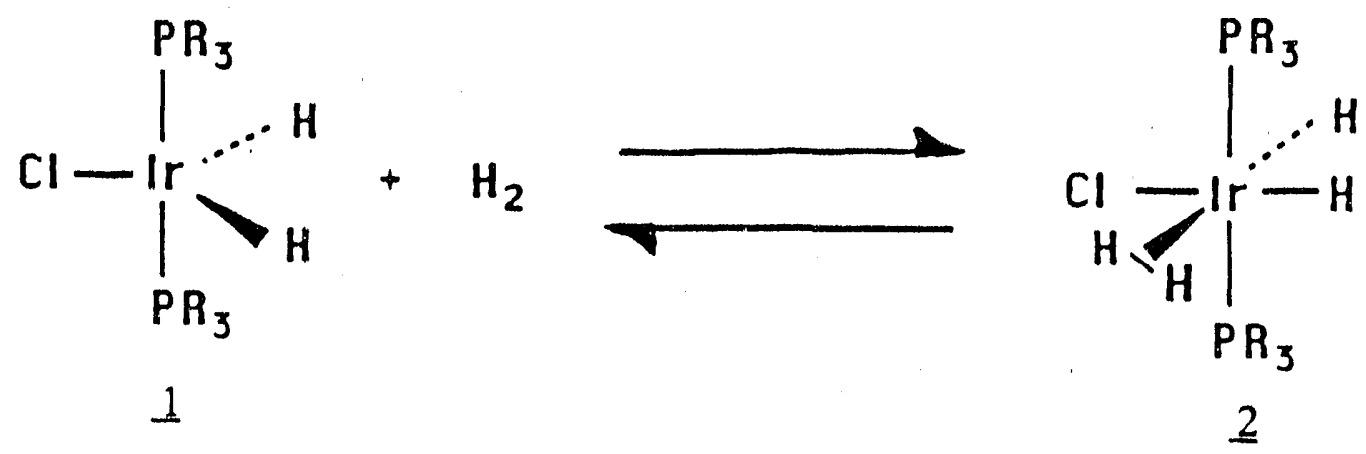

The nature of the metal-dihydrogen bond in the nonclassical hydride complexes has been a point of considerable interest and controversy $[3,5,6]$. Elucidation of these interactions has increased the fundamental understanding of the formation of metal hydrides as these compounds represent the early transition state along the reaction coordinate corresponding to the formation of a hydride complex. To further the understanding of the metal-dihydrogen interaction in these complexes, we have entered into collaborative research projects. In collaboration with Dr. Juergen Eckert of Los Alamos National Laboratory we have performed inelastic neutron scattering experiments on $\underline{2}$ which indicate that the rotation barrier of the $\mathrm{H}_{2}$ ligand in $\underline{2}$ is less than 2 $\mathrm{kcal} /$ mole. This very low barrier height is indicative of a weak interaction between the hydrogen and the metal center and thus preservation of a very significant degree of $\mathrm{H}-\mathrm{H}$ bonding. In a second collaborative effort Dr. Odile Eisenstein's group at the Universite de Paris-Sud, Orsay, France, has carried out extended Hückel calculations on $\underline{2}$. Their results indicate that, unlike other nonclassical polyhydride complexes [7], the $\mathrm{H}_{2}$ ligand in 2 is not stabilized by the cis hydride due to the presence of the chloride ligand in our complex. This result again underscores that the kinetics of the reversible loss of $\mathrm{H}_{2}$ by nonclassical polyhydride can be fine tuned through adjustment of the ancillary ligands in the complex. 


\section{NONCLASSICAL POLYHYRIDE IRON COMPLEXES CONTAINING $\pi$-ANCILLARY LIGANDS}

We have found that iron and cobalt nonclassical hydride complexes which are stabilized by relatively low molecular weight phosphines form tris- rather than bisphosphine complexes and are therefore eliminated as potential hydrogen storage materials due to their low percentage available hydrogen content. To circumvent this problem, we have begun synthetic efforts to prepare complexes stabilized by an $\eta^{5}$-cyclopentadienyl ligand. The low cost and relatively low molecular weight of iron make iron complexes especially attractive candidate storage materials.

Preparation of complexes of the type, $\left(\eta^{5}-\mathrm{C}_{5} \mathrm{H}_{5}\right) \mathrm{Fe}\left(\mathrm{H}_{2}\right)_{2} \mathrm{H}$, has been complicated by the general unavailability of iron hydride complexes containing one rather than two cyclopentadienyl ligands, so-called half sandwich complexes. Recent results in our laboratory and orhers indicate that half sandwich iron hydride complexes can be obtained employing $\mathrm{Fe}(\mathrm{II})(\mathrm{acac})_{2}$ as a starting material $[8]$. We are currently attempting to prepare the targeted iron polyhydride through the method seen below in scheme 1 . To date we successfully synthesize and purified $\mathrm{Fe}\left(\eta^{5}-\mathrm{C}_{5} \mathrm{Me}_{5}\right)\left(\mathrm{C}_{8} \mathrm{H}_{14}\right)(\mathrm{acac})$.

Additionally, we have prepared the novel iron hydride half-sandwich, $\mathrm{Fe}\left(\eta^{5}\right.$ $\left.\mathrm{C}_{5}\left(\mathrm{C}_{6} \mathrm{H}_{5}\right)_{4}\right\} \mathrm{H}\left(\mathrm{PMe}_{3}\right)_{2}$. This complex has been characterized by both ${ }^{1} \mathrm{H}$ and $31 \mathrm{P}$ NMR as well as through single crystal X-ray diffraction. An ORTEP projection of the complex is in Figure 2.

(Scheme 1)

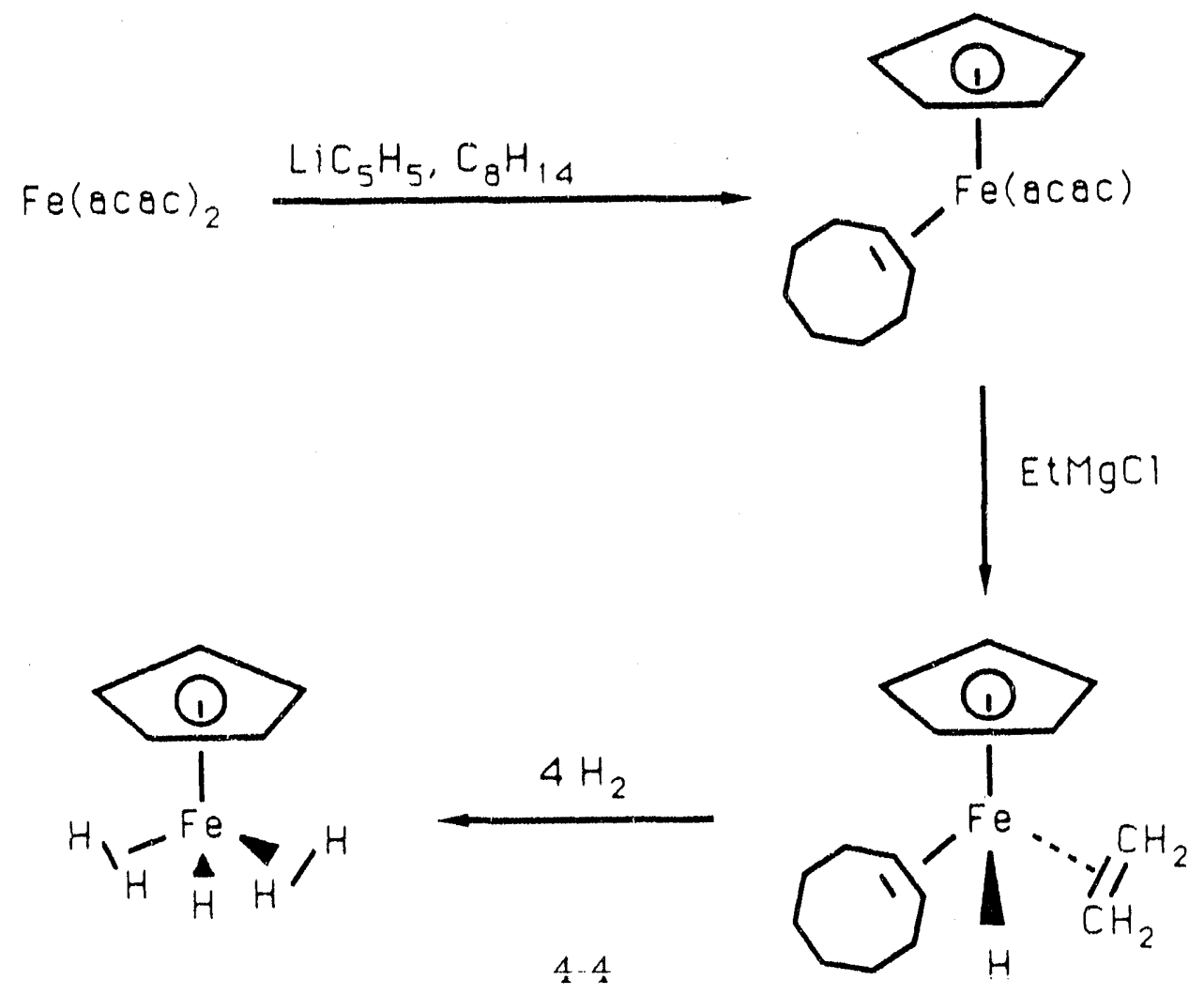




\section{FUTURE DIRECTIONS}

We plan to complete and then generalize our synthesis of nonclassical polyhydride iron complexes which are stabilized by cyclopentadienyl or indenyl ligands rather than trialkylphosphines. These complexes appear to offer increased potential as hydrogen storage materials due to their high potential weight per cent available hydrogen content. The indenyl ligands can "slip" to bonding modes of lower hapticity [9]. Thus complexes which are initially $\eta^{5-}$ can become $\eta^{3}$ and even $\eta^{1}$. Additionally, indenyl ligands are known to hydrogenate under mild conditions [10]. Occurrence of ring slippage in conjunction with hydrogenation of the indenyl ligand, as seen as Equation 2, would allow uptake of several additional equivalents of $\mathrm{H}_{2}$. A complex for which complete hydrogenation of the indenyl ligands can be achieved and reversed would contain greater than 7.8 per cent available hydrogen content. We also plan to determine the hydriding/dehydriding energetics of these materials in the solid state by infrared spectroscopy and tensometric titration. Finally, we have long planned to collaborate with Dr. Thomas Koetzle of Brookhaven National Laboratory on a single crystal neutron structure determination of $\underline{2}$. Unfortunately our studies have been delayed due to a temporary shut down of the Brookhaven reactor. We have now made arrangements with Dr. Koetzle and Dr. Arthur Schultz to carry out this experiment at Argonne National Laboratory this fall.
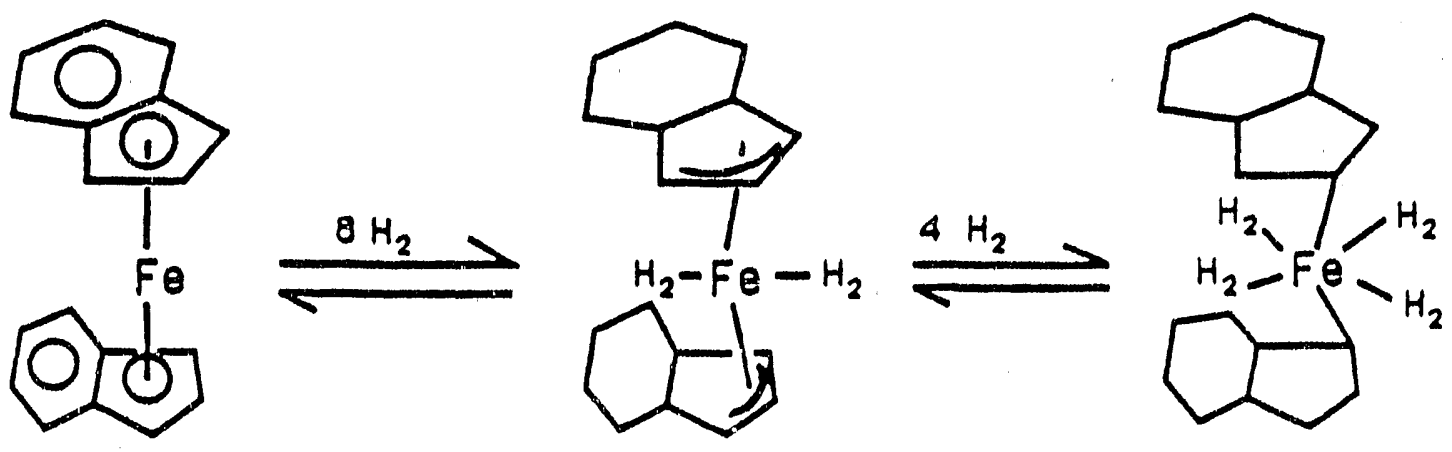


\section{REFERENCES}

1. (a) Selvam, P., B. Viswanathan, and C. S. Srinivassan. 1986. Int. J. Hydrogen Energy 11:169 and references thercin.

(b) Suda, S. 1987. Int. J. Hydrogen Energy 12:2323.

2. (a) Wallace, W. E., R. S. Craig, and O. V. S. Rao. 1980. Adp. Chem. Ser. 186:207.

(b) Pick, M.A. and M. Wenzel. 1977. Int. J. Hydrogen Energy 1:413.

3. Kubas, G. L. 1988. Acc. Chem. Res, 21:120 and references therein.

4. Mediati, M., G. N. Tachibana, and C. M. Jensen. 1990. Inorg. Chem. 29:3.

5. (a) Hay, P. J. 1987. J. Am. Chem. Soc. 109:705.

(b) Saillard, J. Y. and R Hoffmann. 1984. J. Am. Chem. Soc. 106:2006.

(c) Jean Y., O. Eisenstein, F. Volatron, B. Maouche, and F. Sefta. 1986. J. Am. Chem. Soc. 108:6587.

(d) Burdett, J. K., J. R. Phillips, M. R. Pourian, M. Poliakoff, J. J. Turner, and $\mathrm{R}$. Upmacis. 1987. Inorg. Chem. 26:3054.

6. (a) Cotton, F. A. and R. L. Luck. 1989. J. Am. Chem. Soc. 111:5757.

(b) Howard, J. A. K, S. A. Mason, O. Johnson, I. C. Diamond, C. Crennell, P. A. Kellar, and J. L. Spencer. 1988. J. Chem. Soc., Chem. Commun. 1502.

(c) Heinckey, D. M., N. G. Payne, and G. K. Schulte. 1988. J. Am. Chem. Soc. 110:2303.

(d) Zilm, K. W., D. M. Heinekey, J. M. Millar, N. G. Payne, and P. Demou. 1989. J. Am. Chem. Soc. 111:3088.

7. Van Der Sluys, L. S., J. Eckert, O. Eisenstein, J. H. Hall, J. C. Huffman, S. A. Jackson, T. F. Koetzle, G. J. Kubas, P. J. Vergamini, and K. G. Caulton. 1990. J. Am. Chem. Soc. 112:4831.

8. Paciello, R. A., J. M. Manriquez, J. E. Bercaw. 1990. Organometallics $9: 260$.

9. Casey, C. P. and J. M. O'Connor. 1985. Organometallics 4:384.

10. Osiechi, J. H., C. J. Hoffman, and D. P. Hollis. 1965. J. Organomet. Chem. 3:107. 


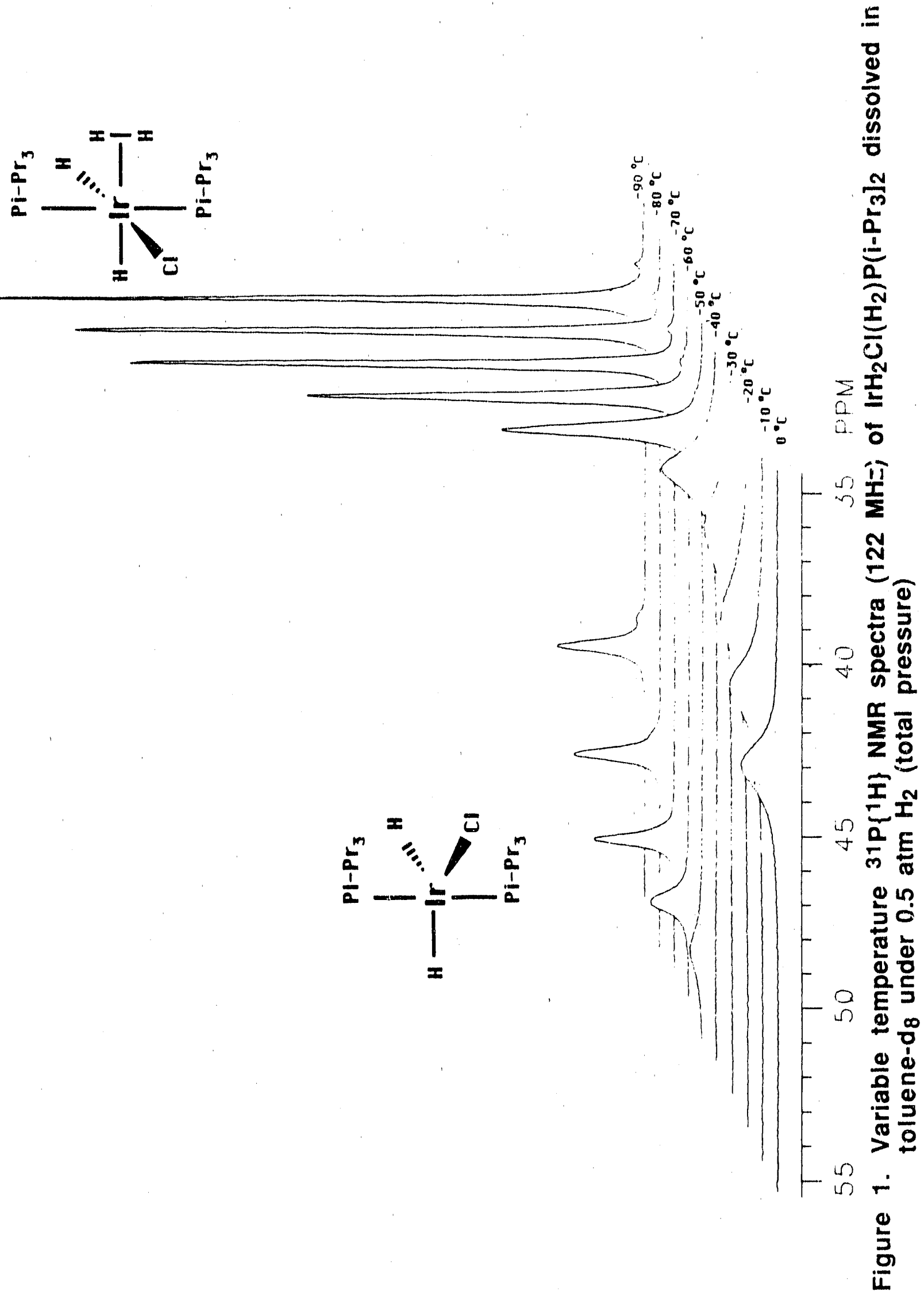




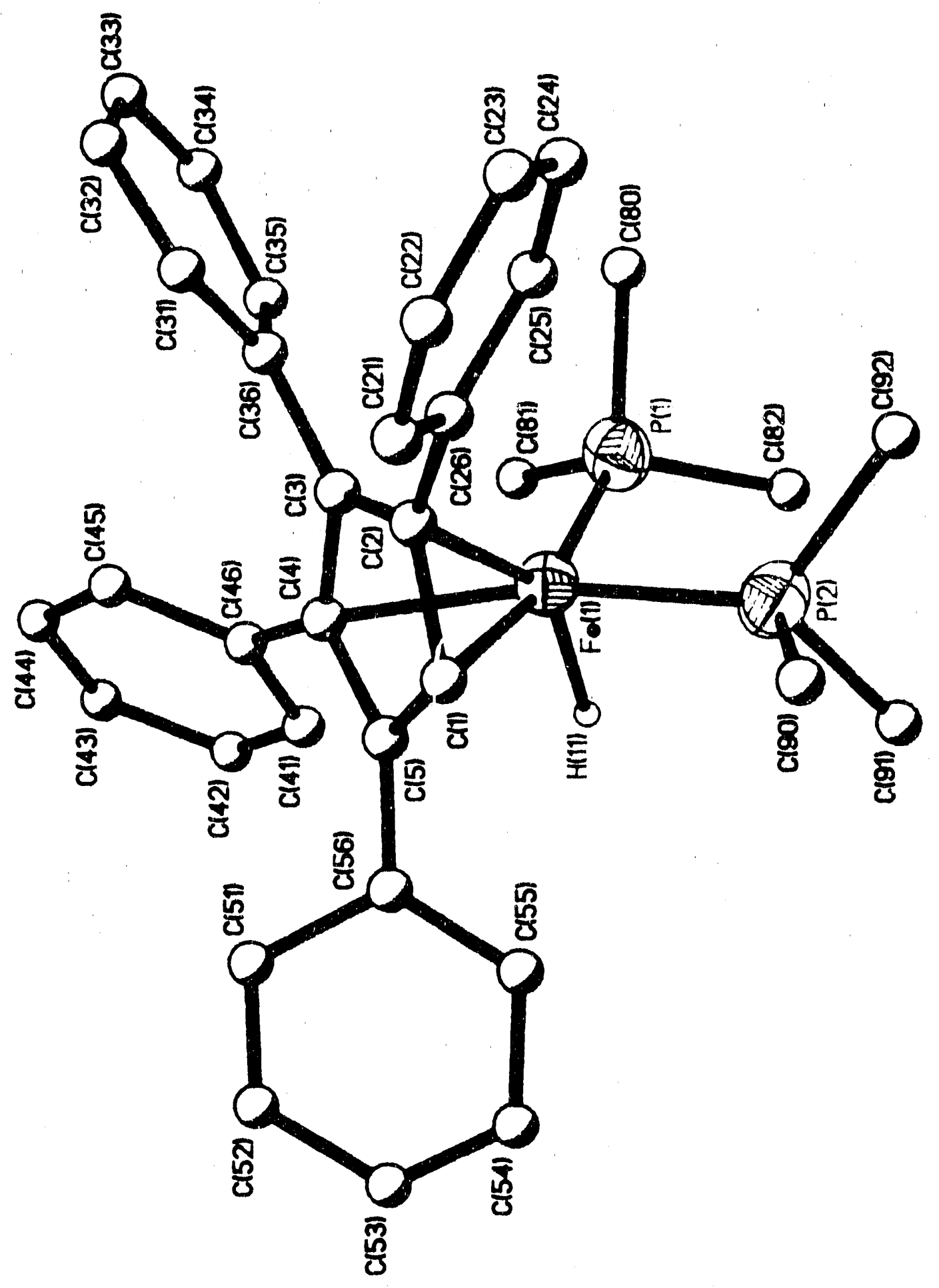

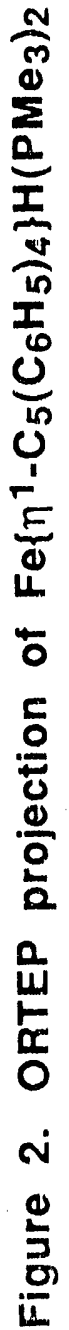




\title{
HYDROGEN FROM RENEWABLE RESOURCES RESEARCH
}

\author{
Appendix A
}

Statement of Work 
Revision 10/25/89

\author{
APPENIIIX $A-1$ \\ STATEMENT OF WORK \\ UNIVERSITY OF HIAWAII
}

\title{
IIYDROGEN FROM RENEWABLE RESOURCES RESEARCII
}

\section{INTRODUCTION}

The Solar Energy Research Institute (SERI) manages a Department of Energy (DOE) program of basic research in solar hydrogen production. In August 1985 a subcontract was awarded by SERI to the Hawaii Natural Encrgy Institute to complete a technology assessment of Hydrogen Production from Renewable Resources. A number of approaches were assessed within the context of the Hawaiian energy economy to identify specific applications which might be of interest to both the State of Hawaii and the Nation as a whole. In 1988, under contract to SFRI, the Hawaii Natural Energy Institutc and the Forida Solar Energy Center completed technolugy assessments of Hydrogen Production from Renewable Resources. While their particular focus was the State of Hawaii, they concluded that it is technically feasible to produce hydrogen from a variety of technologies, but the produced hydrogen is too expensive to compete as fuel in today's markets. The thrust of renewable hydrogen rescarch and development is to reduce the cost of hydrogen through process development, new processes and fundamental research.

In FY 1989 DOE funds were provided for the development of a program to produce hydrogen from renewable resources. This project is in support of that objective.

\section{SCOPE OF WORK}

Rescarch is organized into four tasks:

- Hydrogen via Pyrolytic Gasification of High Moisture Content Biomass in Supercritical Water

- Photoelectrochemical Hydrogen Production

- Solar Encrgy Conversion with Cyanobacteria

- Nonclassical Polyhydride Mctal Complexes as Hydrogen Storage Materials

Task 1 continues the investigation of the pyrolytic gasification of wet biomass to produce hydrogen using supercriticál watcr. Task 2 includes four photoelectrochemical subtasks: 1) photoclectrode 
preparation and matcrial characterization, 2) electronic charactcrization of photoclectrode interfaces, 3) clectrochemical characterization of phetociectrodes, and 4) photoelectrode optimization.

Under the general direction of Task Leader Dr. Suresh S. Patil (Director, Biolechnology Program, UH). Dr. Edward Bylina continues the work of Task 3, photobiological hydrogen production using cyanchacteria. Dr. Bylina is examining and characterizing cyanobacterial hydrogenase systems. A major University of Hawaii resource, i.e., a large algal culture collection under the direclion of Dr. R. Moore in Chemistry, continucs to scrve as a source of new organisms for this program in the molecular genetics of hydrogen cuolution.

Task 4 includes research on nonclassical polyhydride metal complexes for hydrogen storage. This project is a continuation of work iniliated in the previously cited 1987 hydrogen study.

In the pages following. proposed research is described as listed above. This is followed by brief discussions of HNEI project management, milestones, and deliverables.

\section{TASK 1: Ilydrogen via Pyrolytic Gasification of lligh Moisture Content Biomass}

\section{Background}

While hiomass per se has been recognized for some time as an alternative to fossil energy resources, in practice a large portion of the world's available stocks are unavailable for consideration because they cortain ton much moisturc. It is not economicaliy feasihle to dry wet biomass to a moisture content which can be used hy current thermochemical technologies. What is proposed here is the utilization of that biomass in its wet form. If successful, this work will open a new class of biomass for alternative encrgy programs. Herbaceous matcrials, grasses, and other high moisture content plant materials could, for the first time, be scriously considered. The focus of the research is the utilization of these wet materials for the production of hydrogen and other synthesis gas products.

The work for FY 1989 will build upon exploratory studies initiated during the 1988 funding cycle. During the past ten months research has yielded the following significant results:

o The presence of oxygen in supercritical water is detrimental to the production of a hydrogen-rich synthesis gas from biomass. Free oxygen preferentially attacks the hydrogen and carbon monoxide formed by pyrolysis; thereby reducing the yields of these valued gases. Free oxygen does not altack the hiomass substrate. Consequently, we have now abandoned partial oxidation in favor of high temperature pyrolysis.

o At 5000 psi (34.5 MPa) and temperatures excceding $500^{\circ} \mathrm{C}$ effectively complete pyrolytic gasification of algal cell slurrice and glucose can be achicved. The only major products are $\mathrm{H}_{2}, \mathrm{CO}_{2}$, and possibly some carton laid down on the reactor's walls. The chemistry observed secms to be:

$$
\mathrm{C}_{6} \mathrm{H}_{12} \mathrm{O}_{6}+6 \mathrm{H}_{2} \mathrm{O} \cdots 6 \mathrm{CO}_{2}+6 \mathrm{H}_{2}
$$


This is steam gasification of biomass.

o The stcam gasification reaction (1) above is associated with a strong exotherm, which can make the reaction difficult to control.

These results led us to identify the following objectives for our second year of research concerning the pyrolytic gasification of high moisture content biomass in supercritical water. Long term research goals remain the samc, i.c. the determination of the conditions best suited for producing hydrogen fiom "we! biomass" matcrials. NOTE: Task One research activitics will transfer to and continue under the SERI sponsored "Bicfucls" subcontract to HNEI in January of 1990.

\section{Objectives}

1. Establish the effect of feedstock composition on the pyrolytic gasification chemistry by studying several different whole biomass fecdstocks.

2. Refine carbon balance calculations using ultimate analyses of the biomass feedstock obtained from an outside laboratory.

3. Develop a global kinetic model for the pyrolytic gasification reaction.

4. Conduct an analysis of alternative high moisture content biomass feedstocks including, but not limited to availability, abundance, physical and chemical propertics, cost and global distribution. Preliminary economic analysis of the pyrolytic gasification process will also be initiated.

\section{Statement of Work}

Task 1.1 Obtain several alternative biomass fecdstocks.

Task 1.2 Obtain ullimate analyses of all feedstocks.

Task 1.3 Execule gasification experiments at temperatures in excess of $500{ }^{-} \mathrm{C}$ to obtain data characterizing the influence of fecdstock composition, temperature, and residence time or gas yicld and composition.

Task 1.4 Develop kinetic models to simulate and interprel the data.

Task 1.5 Conduct high moisture content feedstock analyses.

Task 1.6 Prepare the Final Report. 


\section{TASK 2: Photoclectrochemical Production of Ilydrogen}

\section{Background}

This task is concerned with improving hydrogen production using photoclectrode materials. Although widely studied in the last few years there have been relatively few developmental programs in which hasic materials and interface characterizations have been combined with an applied program directed toward fabrication of high efficiency, stable electrodes. Electrode efficiency and photocorrosion continue to be problematic. During last year a number of interface and electrode characterization techniques were developed, a photolysis cell built and, with funding from another source, construction of a state-of-the-art glow discharge deposition system started.

The efforts under this task will be coordinaled to maximize the use of basic scientific measurements and our amorphous silicon deposition capabilities toward a better understanding of the mechanisms limiting efficiency and stability, and for the optimization of hydrogen production by photoclectrochemical means. Special emphasis will be given to amorphous or microcrystalline materials either independently, or as coatings on more conventional electrodes, such as single crystal silicon.

Materials used in the fabrication of photoclectrodes will be characterized using standard optoelectronic methods. Optical and photocmission measurements will be used to determine the electronic structure of the interface for charge transfer between the semiconductor and electrolyte and to characterize the role of thin metals, metal clusters, and conductive amorphous, microcrystalline, rare earth, or polymeric coatings.

The efficiency and stability of completed electrodes will be measured to assess progress and to provide a means of interpreting basic measurements. The electrical characteristics of these electrodes will also be fully examined using a variely of electrochemical techniques including impedance spectroscopy.

Finally, changes in the chemical and structural composition of the electrodes after terting will be characterized using a varicly of malcrials and surface analysis techniques including Raman spectroscopy.

\section{Objectives}

The objectives for this research are: 1) develop high efficiency, stable, low-cost electrodes for the photoelectrolysis of water in a photoclectrochemical cell (PEC), 2) characterize and clarify the limitations on efficiency and stability imposed by electrode materials, 3) characterize and detail the chemical, structural, and electronic nature of the electrode/electrolyte interface and its effect on efficiency and stability, and 4) develop design criteria for high efficiency electrodes.

\section{Statement of Work}

In order to fulfill the objectives set forth above, the Hawaï Natural Energy Institule (IINEI) shall carry out an integrated research program for the development of high efficiency photoclectrodes. 
The program will consist of four subtasks which include:

o Photoclectrode preparation and matcrial characterization

- Electronic charactcrization of intcrlaccs

- Electrochemical characterization of photoclectrodes

o Photoclectrode optimization

The four subtasks will be fully integrated to identify the efficicncy limiting mechanisms and the causes of photoclectrode degradation under operating conditions. The characterization of materials and interfaces, and measurements of photoelectrode efficiency and stability will be used to develop new materials and electrode designs with improved performance. Each of these sublasks is described in greater detail below.

\section{Task 2.1 Materials preparation and photoelectrode fabrication}

Under this task; HNEI researchers shall deposit and characterize a variety of amorphous silicon and silicon alloys for use as electrodes in PEC cells. HNEI has obtained sufficient, independent funding and is presently building a state-of-the-art glow discharge system which will have the capability of depositing n-type, $n$-type, and intrinsic amorphous silicon-alloys with bandgaps ranging from as low as 1.1 (amorphous germanium) to greater than 2.5 (amorphous silicon-carbide). Microcrystalline films of these materials can be prepared by the proper selection of substrate temperature and hydrogen dilution. Hydrogen content and hydrogen bonding configuration can be varied widely by control of the substrate temperature and film growth rate (plasma power). The system is equipped for remote generation of the hydrogen radicals to study their effect on the electrode materials, allow post-deposition hydrogenation of the electrode materials, or modify surface characteristics in a clean environment.

Materials developed under this ask shall be deposited in various configurations including single layers of doped amorphous or microcrystalline materials, bilayers including a doped and intrinsic film for fabrication of Scholtky devices, and $\mathrm{p}$-i-n solar cells.

The materials fabricated under this task will be characterized using a wide range of chemical, structural and electronic characterization techniques. Chemical charactcrizations will be made to detcrmine the chemical composition, hydrogen bonding, impurity content, and the composition of the region near the interface. Where necessary samples will be sent to the appropriate outside laboratory for analysis. AUGER, Energy Dispersive X-Ray Analysis, Electron Microprobe and Secondary Ion Mass Spectroscopy will be used for bulk composition and impurity analysis, as appropriate. Fourier Transform Infrared Spectroscopy will be usct to characterize hydrogen content and the nature of the hydrogen bonding.

Photocorrosion continues to be a problem in many PEC cells. The effect of electrode configuration and materials on rates of photocorrosion will be studied. Micro-channel Raman spectroscopy will be the primary tool for detecting chemical changes in the surface and near surface layers. Chemically incrt films such as a-SiC will be explored for enhanced stability. Structural 
characterization of the clectrode materials will include Scanning Electron Microscopy for gross features and Raman to determine the extent of microcrystallinity.

The opto-electronic properties of the bulk doped and undoped materials will be continually assessed to provide a baseline of data to be related to PEC performance and for input to model calculations (Task 2.4). Characterization will include detcrmination of the bandgap from optical reflection and transmission measurement, photoconductivity, Fermi level position from the temperature dependence of the dark conductivity, and sub-bandgap absorption measurement to study the density of states near the valence band edge.

Additiona! processing, including coating the scmiconductor with thin layers of metals, metal-oxide conductors, conductive polymers, or particulate coatings will be carried out under this task. The effectiveness of thin-film coatings such as $\mathrm{Pt}, \mathrm{MnO} 2, \mathrm{RuO} 2$, and iridium silicide will be studied.

For comparison purposcs, photoelectrodes may be fabricated from single crystal silicon, or other semiconductor matcrials as directed by and provided by SERI.

\section{Task 2.2 Electronic characterization of interfaces}

Under this task, optical and photocmission measurements will be used to determine the electronic structure of the interface for charge transfer between the semiconductor and electrolyte. Of particular interest are: 1) the effect of thin metal layers on the band bending characteristic of $n$ and p-type photoelectrodes before and after exposure to hydrogen, and 2) the effect of recombination of pholocxcited carriers at the electrodes surface. Improving the understanding of these effects is important for designing more efficient photoelechemical systems to achieve photosplitting of water or, photoreduction of carbon dioxide.

Research shall be conducted on:

1. The charge transfer at the $\mathrm{n}$ - and $\mathrm{p}$-type semiconductor/metal/electrolyte interfaces before and after exposure to hydrogen,

2. the effect of recombination of photoexcited charge carriers at the semiconductor electrode surface, and

3. transfer of photoexcited electrons through thin doped and undoped SiC films (prepared as a part of Subtask 2.1 activities) on both p-type Si and n-type Si.

Studies shall be made on $n$ - and p-type semiconductor/thin oxide/metal phoioanodes in $0.1 \mathrm{M} \mathrm{KCl}$ solution with and without hydrogen treatment. For example, both dark ciurrent and photocurrent versus voltage (SCE) measurements shall be performed using $n$-and p-type Si/SiOx/Pd electrodes to investigate the effect of hydrogen in the solution on the current response and the onset potential. The goal of this study is to help resolve the issue of whether the semiconductor/metal or the metal/solution interface is morc important in controlling the photoelectrochemical current 
densily. The proposed work shall be done in collaboration with researchers under Task 2.3 and where appropriate using materials produced under Task 2.1. Photoluminescence measurements will be made to investigate the effect of recombination of photocxcited charge carricers at the semiconductor electrode surface for different materials such as InP and metal oxides.

The study of interface properties is being extended to include p-type semiconductor photoelectrodes which are of interest because they could be used for water splitting, or photoreduction of $\mathrm{CO}_{2}$, if the conduction band edge is located at a sufficiently high energy level without an external bias. This will include $\mathrm{p}$-type $\mathrm{SiC}$ which is expected to be more resistant to oxidation than unalloyed aSi:H. Multilayer structures utilizing this material will be fabricated under Task 2.1. The deposition and propertics of $n$-type SiC will also be explored.

\section{Task 2.3 Electrochemical characterization of photoelectrodes}

The opto-electronic nature of the electrode-electrolyte interface will be studicd using impedance spectroscopy techniques developed for the characterization of corrosion processes, but more recently applied to a number of semiconductor-electrolyte systems.

Information on the semiconductor-electrolyle interface can be obtained from capacitance measurements, but is frequently subject to dispersion in the capacitance. This increases the problem of interprctation and detcrmination of flatband potential. Work begun in the previous year will be continued with the assessment and refinement of impedance measurements utilizing a number of well-behaved semiconductor materials. This technique will also be used this year to study the not-so-well-bchaved amorphous materials.

Analysis of the data obtained from the experimental measurements will be performed using a powerful equivalent-circuit modeling tcchnique based on a nonlinear least-squares program developed at the University of Twente in the Netherlands. This program has been successfully used in the past to characterize solid-state ionic matcrials but has general applicability for impedance spectroscopy measurements on any system.

\section{Task 2.4 Photoelectrode Optimization}

Under this task, the efficiency and stability of electrodes consisting of various semiconductor configurations with, or without active, or protective coatings will be investigated. The dependence of efficiency on electrolytc composition, temperature, light intensity, and $\mathrm{pH}$ will be explored. Stability tests will be conducted by maintaining selected electrodes under normal operating conditions. Upon degradation (increased voltage, or decreased current density) the electrodes will be characterized using the methods described under Tasks 2.1 and 2.2 to determine the chemical and/or structural changes which have taken place. This information will be evaluated along with the electronic characterizations of the interfaces for optimization of the semiconductor and metallic components of the electrodes. This task will include model calculations to determine the lirritations of water splitling for various electrode configurations. 


\section{TASK 3: Solar Energy Conversion with Cyanobacteria}

\section{Background}

Larly work identified cyanobacteria as possessing great potential for hydrogen production. These organisms were viewed as particularly altractive because they are able to gencrate hydrogen from water and generate their own source of organic substrates using light energy.

Hydrogen production in cyanobacteria stems from three basic enzyme systems, the nitrogenase, the uplake hydrogenase, and the reversible hydrogenase systems. The first two systems are found almost exclusively in heterocysts, while the latter is found in both helerocysts and vegetative cells, as well as in non-nitrogen-fixing organisms. While the function of nitrogenase-generated hydrogen is unclear, the presence of the two hydrogenase systems is undoubtedly to reclaim the hydrogen-and the energy--Jost in gas production. This reclamation process appears to be the limiting factor on the evolution of hydrogen gas in cyanobacteria. Optimal growth in the form of oxygenic photosynthesis and nitrogen fixation is inversely related to hydrogen production in that they are inhibitory, or competitive.

In order to capitalize on this photosynthetic production of hydrogen, one must gain a better understanding of the mechanism and control of the systems involved. The nitrogenase systems has been under study by many groups for many years and a great deal of information has been gained in all aspects, including pilysiological, enzymatic and genelic control. Hydrogenase systems have not received as much attention, and research efforts for cyanobacteria in the field of molecular biology are virtually nonexistent. There have been several hydrogenase genes isolated from other bacteria, which may be of some use in the deteclion of cyanobacterial genes, however, due to the heterogeneous nature of these enzymes, an independent characterization may be necessary.

Within the cyanobacteria there are several strains that have been well established in recombinant DNA methodology. Although probably not the optimal hydrogen producers, these would serve as models for the ultimate genetic enhancement of an "ideal" strain. The hest-characterized cyanobacterium for recombinant techniques is Anocystis nidulans (or Synechococcus R2). This unicellular alga does not form hetercysts and may thus not be the appropriate model for this siudy, although its usefulness should not be underestimated.

Recently, techniques have been developed for the exchange of genctic material by conjugation in the filamentous cyanobacteria Anabaena sp. Several indigenous plasmids have been isolated from this species, only a few of which have been used to generate hybrid vectors. In addition, this organism demonstrates all of the characteristics necessary for a thorough study of the hydrogenproducing system. Using the established techniques for Anabaena, it is possible to isolate and characterize the hydrogenase genes and determine how they are regulated. Ultimately, one could envision the modification of the structural gene in a recombinant vector, so as to enhance the production of hydrogen in this, or any other receptive species.

The research goals in this task shall be accomplished by the Biotechnology program at the University of Hawaii. The Director of the Biotechnology Program, Dr. Suresh Patil, shall serve as Task Leader and shall report to the Project Director, Dr. Patrick K. Takahashi. Dr. Edward Bylina, Assistant Researcher with the Pacific Biomedical Rescarch Center, will serve as principal scientist, 
being responsible for all work involving genetic charactcrization and manipulation. Dr. Kelton $\mathbf{R}$. $\mathrm{McKinley,} \mathrm{HNEI,} \mathrm{will} \mathrm{be} \mathrm{participating} \mathrm{in} \mathrm{this} \mathrm{task} \mathrm{in} \mathrm{his} \mathrm{capacity} \mathrm{as} \mathrm{a} \mathrm{phycologist.}$

\section{Objective}

The objective of this Task is to investigate genctic enhancement methods for the development of improved strains of hydrogen producers.

\section{Statement of Work}

Continuing the work of the first year, the specific goals of this program are:

Task 3.1 Characlerization of Anabaena sp. (7120 and/or similar strains) hydrogenase gene sequences will be completed. Once tine DNA sequence has been determined, fragments containing hydrogenase genes will then be used as probes for further evaluation of transcriptional control of these gene products. In regard to the hydrogen uptake gene, it shall also be possible to determine its degree of association with the nif genome.

Task 3.2 Clones shall then be manipulated into various vectors to evaluate the effect on hydrogen production in response to:

a) in vivo expression on a conjugal vector,

b) modification of expression by fusion with different promoters with special emphasis placed on inducilile promoters where transcription can be turned on, or off at specific times with simple triggers,

c) site-directed mutagenesis of the chromosomal genome by homologous recombination (uptake hydrogenasc),

d) site-directed mutagenesis of the genome for enhancement of hydrogen generation (reversible hydrogenase).

Task 3.3 Genes which regulate hydrogen metabolism in other organisms will be surveyed for possible introduction into Anabaena. This activity will include:

8) identification of enzymes which may improve hydrogen production, for example hydrogenase from Clastridium,

b) obtaining genes for promising crzyme systems and modifying the promoter region of these materials to allow for use of cyanobacterial regulatory elcments,

c) actual introduction into appropriate shuttle ve tors and conjugated into Anabaena (hup-strain), and 
d) characterization of any so modified strains for hydrogen production.

Task 3.4 Concomitant to this work shall be the continued screening of available cyanobacteria for a super hydrogen-producing strain. The above experiments shall be either reproduced on this strain, or the "super" genes extracted from it and used in a more receptive strain.

\section{TASK 4: Nonclassical Polyhydride Metal Complexes as IIydrogen Storage Materials}

\section{Background}

Polyhydride metal complexes have the potential to store hydrogen. Transition metal complexes containing approximately 1.5 weight percent coordinated hydrogen have undergone complete and reversible dihydrogen dissociation under mild conditions. At the University of Hawaii, novel cobalt group polyhydride complexes of the formulas $\mathrm{IrH}_{2}\left(\mathrm{H}_{2}\right)\left(\mathrm{PR}_{3}\right)_{2} \mathrm{Cl}\left[\mathrm{R}=\mathrm{C}_{6} \mathrm{H}_{11}, \mathrm{C}\left(\mathrm{CH}_{3}\right)_{3}, \mathrm{CH}\left(\mathrm{CH}_{3}\right)_{2}\right]$; $\mathrm{RhH}_{x}\left(\mathrm{H}_{2}\right)_{y}\left(\mathrm{PR}_{3}\right)_{2} \mathrm{Cl}_{2}, \quad x=1-2, \quad y=0-1, \quad z=1-2, \quad\left[\mathrm{R}=\mathrm{C}_{6} \mathrm{H}_{11}, \quad \mathrm{C}\left(\mathrm{CH}_{3}\right)_{3}, \quad \mathrm{CH}\left(\mathrm{CH}_{3}\right)_{2}\right] ; \quad$ and $\mathrm{CoH}\left(\mathrm{H}_{2}\right)\left[\mathrm{P}\left(\mathrm{C}_{6} \mathrm{H}_{5}\right)_{3}\right]_{2}$ have been synthesized and characterized. These complexes have shown promising hydriding/dehydriding behavior. Additionally, this research has provided new insights into metal-molecular hydrogen bonding.

The proposed research involves both the continuation of our studies of the hydriding/dehydriding behaviors of the previously synthesized materials and an extension our synthetic efforts to the preparation of manganese, iron and cobalt polyhydride complexes containing if-aromatic ancillary ligands such as cyclopentadiene and indene. The newly targeted complexes are projected to retain $>5$ weight percent available hydrogen content and thus ofler attractive increased potential as hydrogen storage materials.

\section{Statement of Work}

In this task year we plan to continue our studies the hydriding/dehydriding behaviors of the nonclassical polyhydrides both in solution and in the solid state. Solution behavior will be monitored by high field, Fourier transform $1 \mathrm{H}$ nuclear magnelic resonance (FTNMR) spectroscopy and electrochemical measurements. The solid state studies shall involve monitoring the characteristic metal-hydride and hydrogen-hydrogen stretches by Fourier transform infrared (FTIR) spectroscopy. Our efforts to synthesize the targeted polyhydride complexes containing $\mathbb{T}$-aromatic ancillary ligands will involve characterization of obtained products by FTNMR and FTIR, as well as by single crystal $\mathrm{X}$-ray diffraction.

The proposed research should result in the detcrmination of the hydriding/dehydriding behaviors of our novel polyhydride complexes. This in turn should allow the evaluation of the potential of these complexes as hydrogen storage materials. We will also characterize novel polyhydride complexes containing $\mathbb{Z}$-aromatic ancillary ligands.

In addition to evaluating a new class of hydrogen storage materials, cur research has yiclded new 
information about the interaction of molecular hydrogen with metals. Our understanding of this phenomenon will be increased by kinetic studies, as well as through our synthesis and characterization of nonclassical polyhydrides.

\section{PROJECT MANAGEMENT}

The University of Hawaii at Manoa shall be the contractor for the "Hydrogen from Renewable Resources Research" program, with the Hawaii Natural Energy Institute (HNEI) as the lead organization. The principal investigator shall be Dr. Patrick $K$. Takahashi, Director of HNEI. The Program Manager will be Dr. Kelton R. McKinley, Associate Administrator for Energy and Ocean Resources Programs at HNEI. In gencral, project management shall follow the pattern set in the previous projects, "Hydrogen Energy from Rencwable Resources" and "Hydrogen for Synfuels (Hydrogen from Renewable Resources)."

The program shall be organized into five tasks as described in the previous sections, as follows:

Task 1: $\quad$ Hydrogen via Pyroiytic Gasification of High Moisture

Content Biomass in Supercritical Water

Task Leader: M. Antal, Coral Industries Professor, UHM.

Task 2: $\quad$ Photoclecuochemical Hydrogen Production

Task Leadcrs:

2.1) S. Sharma, Researcher in Materials and Energy Systems, and R. Rocheleau, Research Chemical Engineer, HNEI, UHM;

2.2) W. Pong, Professor, Physics and Astronomy, UHM;

2.3) B. Licbert, Associate Professor, Mechanical Engineering, UHM;

2.4) R. Rochelcau, Research Chemical Engineer, HNEI, UHM

Task 3: $\quad$ Solar Energy Conversion with Cyanobacteria

Task Leader: Suresh S. Patil, Director, Biotcchnology Program, UHM

Task 4: $\quad$ Nonclassical Polyhydride Metal Complexes as Hydrogen Storage Materials

Task Leader: Craig M. Jensen, Assistant Professor, Chemistry, UHM

Task 5: $\quad$ Project Management

New under program management for this year is a subtask associated with the up-coming World Hydrogen Energy Conlerence \#8, Hawaii Hydrogen 90, to be hosted by Hawaii Natural Energy Institute in conjunction with the International Association for Hydrogen Energy and co-sponsored by the U.S. Department of Energy and the Sular Energy Research Institute. 
Appearing under Task 5 is a no-overhead budget entry in support of planning for the conference. Monies are to be expended by conference coordinators in support of planning and exccution for one or more of the following categories: personnel, printing, office expenses, and/or conference expenses (e.g., audiovisual support). Additional FY ' 90 monies will be forthcoming in support of these same five categories as these monies become available to SERI. 

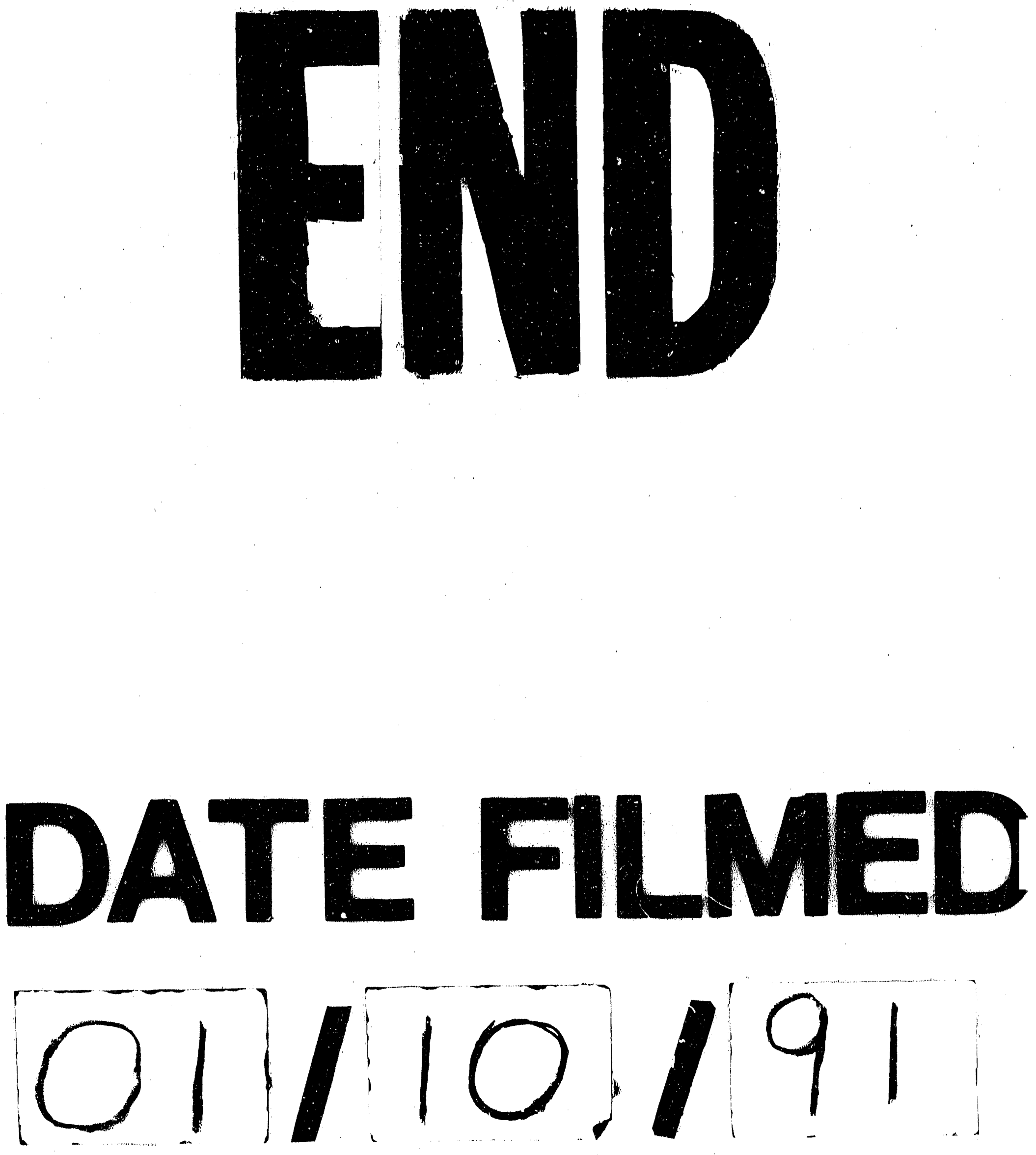
